\title{
Switching On and Off Interlayer Correlations and Porosity in 2D Covalent Organic Frameworks
}

Torben Sick, ${ }^{1,2}$ Julian M. Rotter, ${ }^{1}$ Stephan Reuter, ${ }^{1}$ Sharath Kandambeth, ${ }^{1}$ Nicolai N. Bach, ${ }^{1}$ Markus Döblinger, ${ }^{1}$ Julia Merz, ${ }^{3}$ Timothy Clark, ${ }^{4}$ Todd B. Marder, ${ }^{3}$ Thomas Bein ${ }^{1^{*}}$ and Dana D. Medina ${ }^{1^{*}}$

${ }^{1}$ Department of Chemistry and Center for NanoScience (CeNS), University of Munich (LMU), Butenandtstraße 5-13, 81377 Munich, Germany

${ }^{2}$ Micromeritics Instrument Corporation, 4356 Communications Drive, Norcross, Georgia 30093, United States

${ }^{3}$ Institut für Anorganische Chemie and Institute for Sustainable Chemistry \& Catalysis with Boron, Julius-Maximilians-Universität Würzburg, Am Hubland, 97074 Würzburg, Germany

4 Computer-Chemistry-Center, Department of Chemistry and Pharmacy, Friedrich-Alexander-University ErlangenNuremberg, Naegelsbachstr. 25, 91052 Erlangen, Germany.

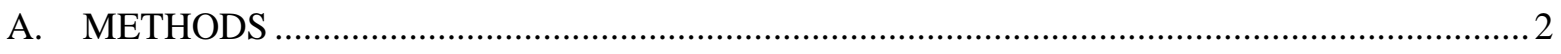

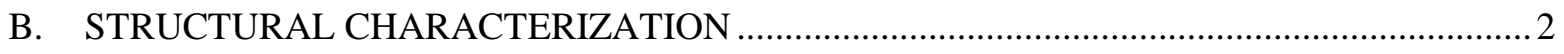

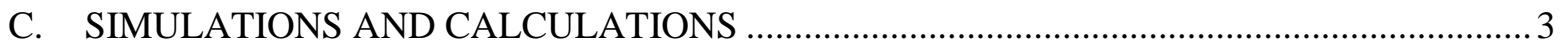

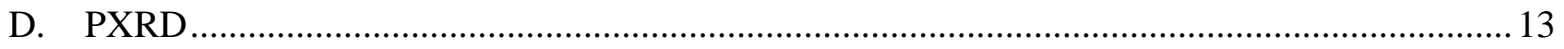

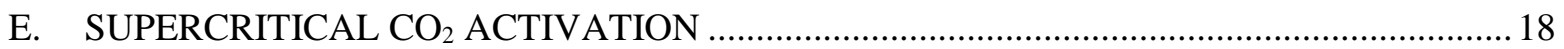
F. UNIT CELL PARAMETERS AND ATOMIC COORDINATES …......................................... 32

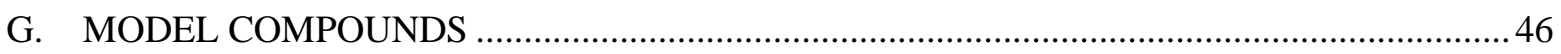

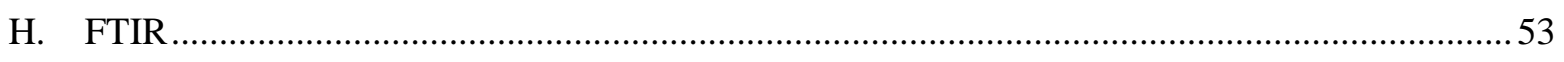

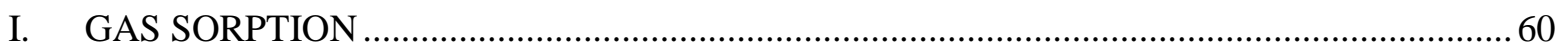

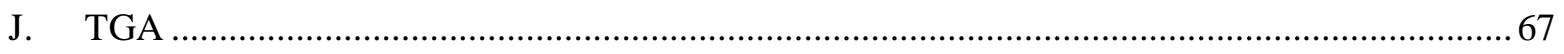

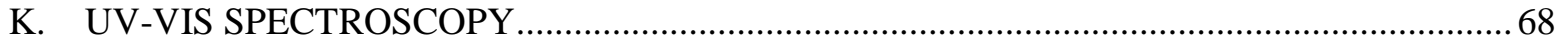

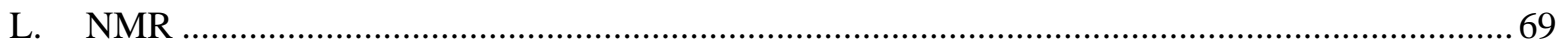

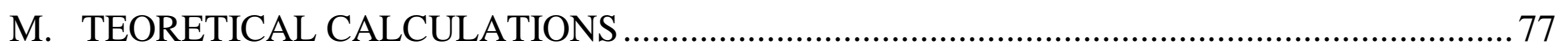

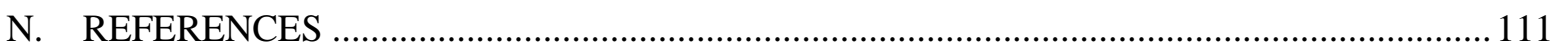




\section{A. METHODS}

All reagents and solvents were obtained from commercial suppliers and used as received unless otherwise stated. Acetone (extra dry, AcroSeal, 99.5\%, Acros), benzo[1,2- $b: 4,5-b$ ']dithiophene (BDT, >98\%, TCI), benzo[1,2-b:4,5-b']dithiophene-4,8-dione $\left(\mathrm{BDTO}_{2},>98 \%, \mathrm{TCI}\right), n$ butyllithium solution ( $n$-BuLi, $2.5 \mathrm{M}$ in $n$-hexane, Sigma-Aldrich), dichloromethane (DCM, in house supply), diethyl ether $\left(\mathrm{Et}_{2} \mathrm{O}\right.$, in house supply), 1,4-dioxane (anhydrous, 99.8\%, SigmaAldrich and in house supply), N,N-dimethylformamide (DMF, anhydrous, Sigma-Aldrich), ethanol (EtOH, extra dry, AcroSeal, 99.5\%, Acros and in house supply), ethyl $p$-toluenesulfonate (98\%, Sigma-Aldrich), glacial acetic acid (in house supply), mesitylene (Mes, anhydrous, SigmaAldrich), methanol (MeOH, anhydrous, 99.8\%, Sigma-Aldrich), methyl p-toluenesulfonate (98\%, Sigma-Aldrich), propyl $p$-toluenesulfonate (>98\%, TCI), sodium hydroxide (NaOH, 97\%; SigmaAldrich), terephthalaldehyde (TA, 99\%, Sigma-Aldrich), tetrahydrofuran (THF, extra dry, stabilized, Acros Organics and anhydrous, >99.9\%, inhibitor-free, Sigma-Aldrich), thieno[3,2b] thiophene-2,5-dicarboxaldehyde (TT, >93\%, TCI, recrystallized from DMF prior to use), 1,3,5tris(4-aminophenyl)benzene (TAPB, >93\%, TCI), zinc (dust, <10 $\mu \mathrm{m},>98 \%$, Sigma-Aldrich), 1,3-dioxane (97\%, Sigma-Aldrich), ethane (N35, air liquide) were obtained as noted.

\section{B. STRUCTURAL CHARACTERIZATION}

${ }^{1} \mathrm{H}$ NMR spectra were recorded on Bruker AV 400 and AV 400 TR spectrometers. Proton chemical shifts are expressed in parts per million ( $\delta$ scale) and are calibrated using residual undeuterated solvent peaks as an internal reference (e.g., DMSO- $\left.d_{6}: 2.50\right)$. Ultraviolet-Vis-infrared diffuse reflectance spectra (Kubelka-Munk spectra) were recorded on a Perkin-Elmer Lambda 1050 spectrometer equipped with a $150 \mathrm{~mm}$ integrating sphere. Diffuse reflectance measurements of COF powders were performed with a Harrick Praying Mantis accessory and referenced to $\mathrm{BaSO}_{4}$. Scanning electron microscopy (SEM) images were recorded with an FEI Helios NanoLab G3 UC scanning electron microscope equipped with a field emission gun operated at $3-5 \mathrm{kV}$. Transmission electron microscopy (TEM) was performed on an FEI Titan Themis equipped with a field emission gun operated at $300 \mathrm{kV}$. Powder X-ray diffraction (PXRD) measurements were performed using a Bruker D8 Discover with Ni-filtered $\mathrm{Cu} \mathrm{K} \alpha$ radiation and a LynxEye position-sensitive detector. 
Experimental XRD data were analyzed with Pawley refinement to optimize the hypothetical structure. The initial structure models of the COFs were built using the Forcite module of the Accelrys Materials Studio software package. We applied the space group with the highest possible symmetry, i.e., $P 6$, considering the propeller-like conformation of the central building blocks. Using this coarse model, we determined the unit cell parameters via Pawley refinement of our PXRD data. Nitrogen sorption isotherms were recorded on a Quantachrome Autosorb 1 at $77 \mathrm{~K}$ within a pressure range from $p / p^{0}=0.001$ to 0.98 . Prior to the measurement of the sorption isotherms, the samples were heated for $24 \mathrm{~h}$ at $120^{\circ} \mathrm{C}$ under turbo-pumped vacuum. For the evaluation of the surface area the BET model was applied between 0.05 and $0.2 p / p^{0}$. Pore size distributions were calculated using the QSDFT equilibrium model with a carbon kernel for cylindrical pores. Thermogravimetric analysis (TGA) measurements were performed on a Netzsch Jupiter ST 449 C instrument equipped with a Netzsch TASC 414/4 controller. The samples were heated from room temperature to $900{ }^{\circ} \mathrm{C}$ under a synthetic air flow $\left(20 \% \mathrm{O}_{2}, 80 \% \mathrm{~N}_{2}, 25 \mathrm{~mL} \mathrm{~min}^{-}\right.$ ${ }^{1}$ ) at a heating rate of $10 \mathrm{~K} / \mathrm{min}$. Fourier-transformed Infrared (FT-IR) spectra were recorded on a PerkinElmer spectrum BX spectrometer in a single reflection ATR mode using a $\mathrm{HeNe} 633 \mathrm{~nm}$ laser. The intensity data of the X-ray structure determinations were measured on a Bruker D8 Venture TXS system equipped with a multilayer mirror optics monochromator and a Mo Ka rotating-anode $\mathrm{X}$-ray tube $(\lambda=0.71073 \AA)$. The data collection was performed at $103 \mathrm{~K}$. The frames were integrated with the Bruker SAINT software package. ${ }^{1}$ Data were corrected for absorption effects using the Multi-Scan method (SADABS). ${ }^{2}$ The structures were solved and refined using the Bruker SHELXTL Software Package. ${ }^{3}$ All hydrogen atoms were calculated in positions having ideal geometry riding on their parent atoms. The data have been deposited with the Cambridge Crystallographic Data Centre (CCDC) and can be obtained free of charge from: https://www.ccdc.cam.ac.uk/structures/.

\section{SIMULATIONS AND CALCULATIONS}

All structures were fully optimized at the RMP2 $2^{4-6} / 6-31 \mathrm{G}(\mathrm{d})^{7,8}$ and B3LYP $/ 6-31+\mathrm{G}(\mathrm{d})$ Error! Bookmark not defined.,Error! Bookmark not defined., ${ }^{10}$ levels of theory and conformed as local minima by calculating their normal vibrations within the harmonic approximation at the same level of theory using the Gaussian09 suite of programs ${ }^{11}$ B3LYP calculations included Grimme's D3 correction for dispersion ${ }^{12}$ The energies reported are include the zero-point energy at the level 
of the geometry optimization. Molecular-electrostatic potentials were calculated based on the MP2/6-31G(d) electron density and are projected onto the 0.001 au isodensity surface ${ }^{13}$ and plotted with VMD. ${ }^{14}$

\section{Synthesis of linkers}

a) BDT monomers (adapted from Koßmehl et al. $)^{15}$

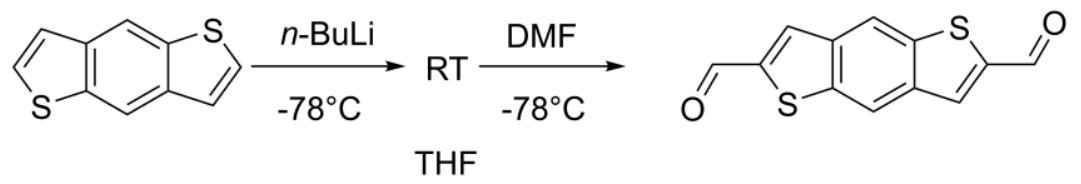

Benzo[1,2- $\left.b: 4,5-b^{\prime}\right]$ dithiophene $(1.0 \mathrm{~g}, 5.3 \mathrm{mmol})$ was dissolved in $100 \mathrm{~mL}$ of anhydrous, inhibitor-free THF in a degassed $250 \mathrm{~mL}$ flask under an argon atmosphere. The stirred solution was cooled to $-78{ }^{\circ} \mathrm{C}$ in a dry ice/acetone bath. A solution of $n$-butyl lithium $(5.0 \mathrm{~mL}, 2.5 \mathrm{M}$ in $n$ hexane, $12.5 \mathrm{mmol}$ ) was added dropwise within $10 \mathrm{~min}$. The solution was stirred for $30 \mathrm{~min}$ at $78{ }^{\circ} \mathrm{C}$ and, after removal of the cooling bath, for further $1 \mathrm{~h}$ at room temperature. The solution was then cooled again to $-78^{\circ} \mathrm{C}$ and DMF $(1.0 \mathrm{~mL}, 13.0 \mathrm{mmol})$ was added dropwise. After stirring and slow warming overnight, the solution was poured into ice water and filtered. The yellow precipitate was washed with water several times $(1000 \mathrm{~mL})$ and further treated with small amounts of $\mathrm{MeOH}$ and $\mathrm{Et}_{2} \mathrm{O}$. The solid was dried under reduced pressure, affording a yellow solid in $46 \%$ yield.

HRMS-EI: calculated (m/z): 245.9809, measured (m/z): 245.9806.

${ }^{1} \mathrm{H}$ NMR (400 MHz, DMSO- $\left.d_{6}\right) \delta(\mathrm{ppm}): 8.53(\mathrm{~s}, 2 \mathrm{H}), 8.89(\mathrm{~s}, 2 \mathrm{H}), 10.20(\mathrm{~s}, 2 \mathrm{H}) ;{ }^{13} \mathrm{C}\left\{{ }^{1} \mathrm{H}\right\} \mathrm{NMR}$ $\left(100 \mathrm{MHz}, \mathrm{DMSO}-d_{6}\right) \delta(\mathrm{ppm}): 186.6,144.9,138.9,138.4,135.3,121.6$.

b) BDT-OMe monomer (adapted from Koßmehl et al. $)^{15}$

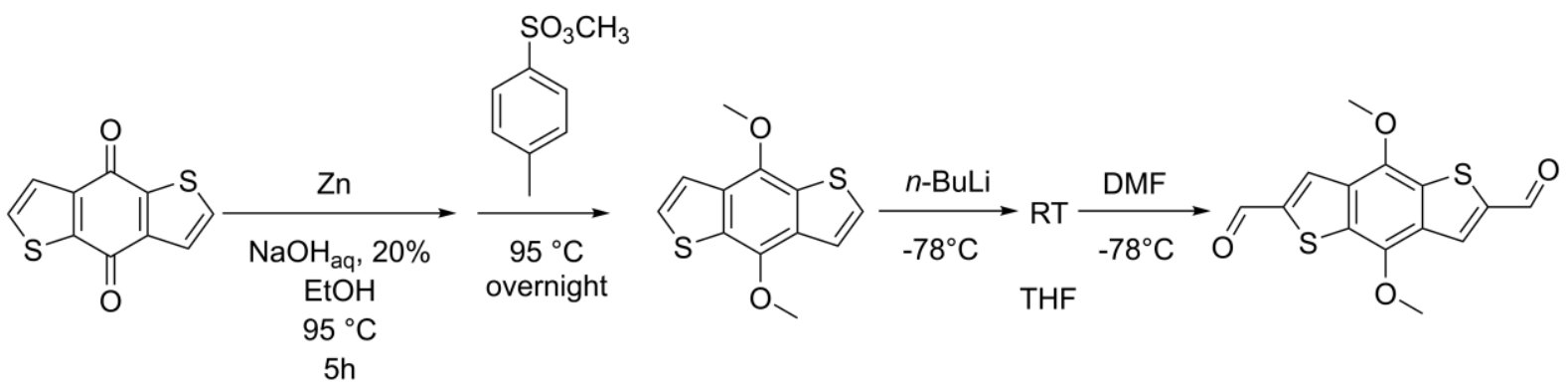


Under argon $1.55 \mathrm{~g}$ (7.04 mmol) of benzo[1,2-b:4,5-b']dithiophene-4,8-dione, $1.38 \mathrm{~g}$ (21.1 mmol) of zinc dust, $20 \mathrm{~mL}$ of an aqueous sodium hydroxide solution $(20 \%)$ and $20 \mathrm{~mL}$ of ethanol were heated at $95^{\circ} \mathrm{C}$ for $5 \mathrm{~h}$. To the hot solution, $4.0 \mathrm{~mL}$ ( $\left.26.5 \mathrm{mmol}\right)$ of methyl $p$-toluenesulfonate was slowly added and the reaction solution was kept at $95{ }^{\circ} \mathrm{C}$ overnight. After the reaction solution had cooled to room temperature, it was extracted with DCM $(3 \times 50 \mathrm{~mL})$ and the combined organic layers were washed with brine $(150 \mathrm{~mL})$ and dried over $\mathrm{MgSO}_{4}$. The obtained filtrate was evaporated under vacuum giving $608.5 \mathrm{mg}$ of a grey product ( $35 \%$ yield).

Without further purification, under argon, $500 \mathrm{mg}(2.0 \mathrm{mmol})$ of the product was dissolved in $25 \mathrm{~mL}$ of anhydrous inhibitor-free $\mathrm{THF}$ and cooled to $-78^{\circ} \mathrm{C}$ in a degassed $250 \mathrm{~mL}$ flask. Afterwards, $3.6 \mathrm{~mL}$ ( $9.0 \mathrm{mmol}, 2.5 \mathrm{M}$ in $n$-hexane, $4.5 \mathrm{eq})$ of $n$-BuLi was slowly added and the reaction solution was stirred for $20 \mathrm{~min}$ at $-78^{\circ} \mathrm{C}$. The solution was slowly warmed to $\mathrm{RT}$ and then stirred for $1 \mathrm{~h}$. After cooling again to $-78^{\circ} \mathrm{C}, 2 \mathrm{~mL}$ ( $26 \mathrm{mmol}$ ) of DMF was added and the reaction solution was stirred overnight. It was poured into ice water and the precipitate was collected by filtration and washed with an excess of water and small amounts of methanol. The highly insoluble solid was washed with hot ethanol, filtered and dried under vacuum before use. The final amount of isolated product was $475.0 \mathrm{mg}$ (77\% yield).

HRMS-EI: calculated (m/z): 306.0021, measured (m/z): 306.0015

${ }^{1} \mathrm{H}$ NMR (400 MHz, DMSO-d 6 ) $\delta$ (ppm): 10.20 (s, 2H), $8.71(\mathrm{~s}, 2 \mathrm{H}), 4.22(\mathrm{~s}, 6 \mathrm{H}) .{ }^{13} \mathrm{C}\left\{{ }^{1} \mathrm{H}\right\}$ NMR $\left(100 \mathrm{MHz}, \mathrm{DMSO}-d_{6}\right) \delta$ (ppm): 186.32, 147.11, 143.91, 132.60, 131.90, 99.49, 61.70.

\section{c) BDT-OET monomer (adapted from Koßmehl et al. $)^{15}$}

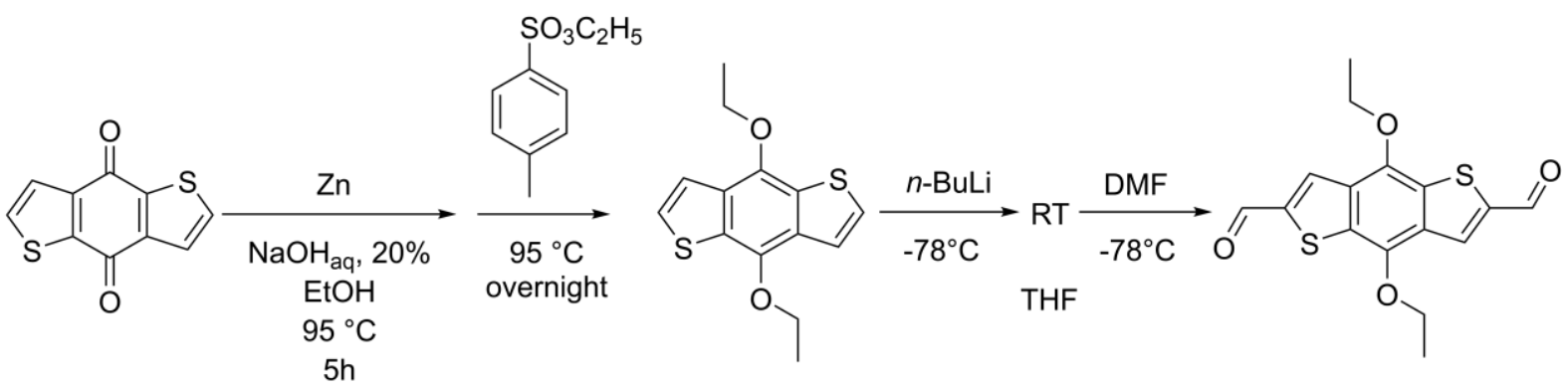

Under argon $1.10 \mathrm{~g}$ ( $4.99 \mathrm{mmol}, 1.0 \mathrm{eq})$ of benzo[1,2-b:4,5-b']dithiophene-4,8-dione, $0.981 \mathrm{~g}$ $(15.0 \mathrm{mmol}, 3.0 \mathrm{eq})$ of zinc dust, $10 \mathrm{~mL}$ of an aqueous sodium hydroxide solution (20\%) and 
$10 \mathrm{~mL}$ of ethanol were heated at $95^{\circ} \mathrm{C}$ for $5 \mathrm{~h}$. To the hot solution, $2.56 \mathrm{~mL}(3.00 \mathrm{~g}, 15.0 \mathrm{mmol}$, 3.0 eq) of ethyl $p$-toluenesulfonate was slowly added and the reaction solution was kept at $95{ }^{\circ} \mathrm{C}$ overnight. After the reaction solution had cooled to room temperature, it was extracted with DCM (3x $50 \mathrm{~mL})$ and the combined organic layers were washed with brine $(150 \mathrm{~mL})$ and dried over $\mathrm{Na}_{2} \mathrm{SO}_{4}$. The obtained filtrate was evaporated under vacuum. The crude product was purified by flash column chromatography ( (49\% yield).

${ }^{1} \mathrm{H}$ NMR (400 MHz, $\left.\mathrm{CDCl}_{3}\right) \delta(\mathrm{ppm}): 7.46(\mathrm{~d}, \mathrm{~J}=5.5 \mathrm{~Hz}, 2 \mathrm{H}), 7.35$ (d, J = $\left.5.5 \mathrm{~Hz}, 2 \mathrm{H}\right), 4.35$ (q, J $=7.0 \mathrm{~Hz}, 4 \mathrm{H}), 1.47(\mathrm{t}, \mathrm{J}=7.0 \mathrm{~Hz}, 6 \mathrm{H}) .{ }^{13} \mathrm{C}\left\{{ }^{1} \mathrm{H}\right\} \mathrm{NMR}\left(100 \mathrm{MHz}, \mathrm{CDCl}_{3}\right) \delta(\mathrm{ppm}): 144.3,131.8$, $130.4,126.0,120.3,69.4,16.1$.

Under argon, $500 \mathrm{mg}$ (1.80 mmol) of 4,8-diethoxybenzo[1,2- $b: 4,5-b^{\prime}$ ]dithiophene was dissolved in $25 \mathrm{~mL}$ of anhydrous inhibitor-free $\mathrm{THF}$ and cooled to $-78^{\circ} \mathrm{C}$. Afterwards, $3.6 \mathrm{~mL}(9.0 \mathrm{mmol}$, $2.5 \mathrm{M}$ in $n$-hexane, $4.5 \mathrm{eq}$ ) of $n$-BuLi was slowly added and the reaction solution was stirred for

$20 \mathrm{~min}$ at $-78{ }^{\circ} \mathrm{C}$. The solution was slowly warmed to RT and then stirred for $1 \mathrm{~h}$. After cooling again to $-78{ }^{\circ} \mathrm{C}, 2 \mathrm{~mL}(26 \mathrm{mmol})$ of $\mathrm{DMF}$ was added and the reaction solution was stirred overnight. It was poured into ice water and the precipitate was collected by filtration and washed with water $(1 \mathrm{~L})$. After drying under vacuum, $560 \mathrm{mg}(1.67 \mathrm{mmol})$ of an orange product was obtained (93\% yield).

HRMS-EI: calculated (m/z): 334.0334, Measured (m/z): 334.0336.

${ }^{1} \mathrm{H}$ NMR (400 MHz, DMSO-d $)_{6} \delta(\mathrm{ppm}): 10.18(\mathrm{~s}, 2 \mathrm{H}), 8.65(\mathrm{~s}, 2 \mathrm{H}), 4.45(\mathrm{q}, J=7.0 \mathrm{~Hz}, 4 \mathrm{H}), 1.45$ $(\mathrm{t}, J=7.0 \mathrm{~Hz}, 6 \mathrm{H}) ;{ }^{13} \mathrm{C}\left\{{ }^{1} \mathrm{H}\right\} \mathrm{NMR}\left(100 \mathrm{MHz}, \mathrm{DMSO}-d_{6}\right) \delta(\mathrm{ppm}): 186.38,146.16,143.89,132.77$, 132.70, 131.04, 70.27, 15.87 .

\section{d) BDT-OPr monomer (adapted from Koßmehl et al. $)^{15}$}




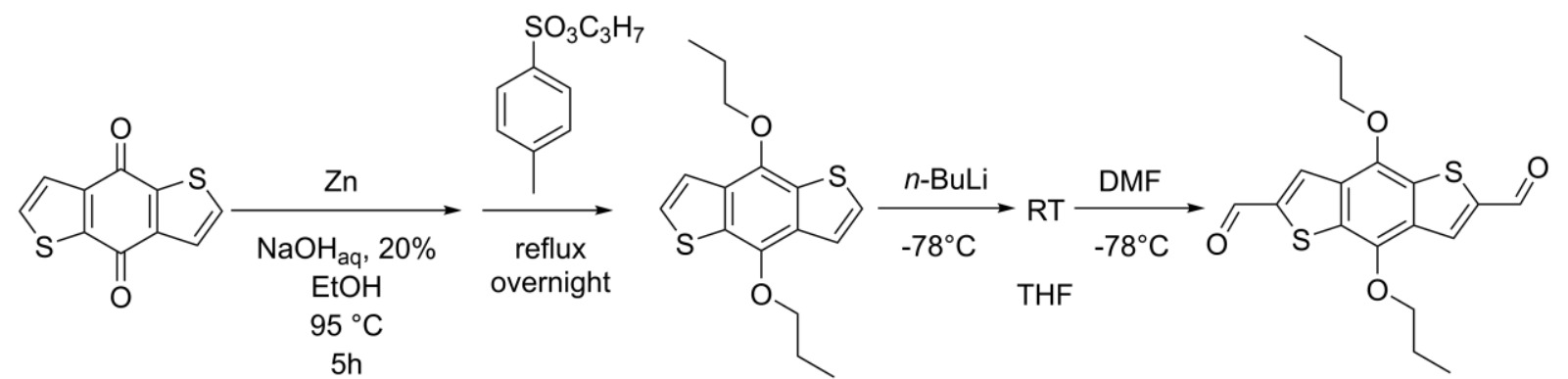

Under argon $1.1 \mathrm{~g}$ (5.0 mmol) of benzo[1,2-b:4,5- $\left.b^{\prime}\right]$ dithiophene-4,8-dione, $0.98 \mathrm{~g}$ (15 mmol) of zinc dust, $5.5 \mathrm{~mL}$ of an aqueous sodium hydroxide solution $(20 \%)$ and $4.4 \mathrm{~mL}$ of ethanol were refluxed for $5 \mathrm{~h}$. To the hot solution, $2.8 \mathrm{~mL}(15 \mathrm{mmol})$ of propyl $p$-toluenesulfonate was slowly added and the reaction solution was refluxed at $95{ }^{\circ} \mathrm{C}$ overnight. After the reaction solution had cooled to room temperature, it was filtered and the solid Soxhlet-extracted with toluene $(50 \mathrm{~mL})$. The obtained filtrate was concentrated under vacuum giving $920 \mathrm{mg}$ (60\% yield).

Without further purification, under argon $920 \mathrm{mg}(3.0 \mathrm{mmol})$ of the product was dissolved in $25 \mathrm{~mL}$ of anhydrous inhibitor-free $\mathrm{THF}$ and cooled to $-78{ }^{\circ} \mathrm{C}$. Afterwards, $3.6 \mathrm{~mL}(9.0 \mathrm{mmol}$, $2.5 \mathrm{M}$ in $n$-hexane, $3 \mathrm{eq}$ ) of $n$-BuLi was slowly added and the brownish reaction solution was stirred for $20 \mathrm{~min}$ at $-78{ }^{\circ} \mathrm{C}$. The solution was slowly warmed to RT to be stirred for $1 \mathrm{~h}$. After cooling again to $-78^{\circ} \mathrm{C}, 1.0 \mathrm{~mL}(13 \mathrm{mmol})$ of $\mathrm{DMF}$ was added and the reaction solution was stirred overnight. It was poured into ice water and the precipitate was collected by filtration and washed with water $(1 \mathrm{~L})$. After drying under vacuum, $883 \mathrm{mg}(2.43 \mathrm{mmol})$ of red product was obtained (81\% yield).

HRMS-EI: calculated (m/z): 362.0647 measured (m/z): 362.0659.

${ }^{1} \mathrm{H}$ NMR (400 MHz, DMSO-d6) $\delta$ (ppm): 10.19 (s, 2H), 8.65 (s, 2H), 4.36 (t, J=6.4 Hz, 4H), 1.82 $-1.91(\mathrm{~m}, 4 \mathrm{H}), 1.10(\mathrm{t}, J=7.4 \mathrm{~Hz}, 6 \mathrm{H}) .{ }^{13} \mathrm{C}\left\{{ }^{1} \mathrm{H}\right\}$ NMR (100 MHz, DMSO- $\left.d_{6}\right) \delta(\mathrm{ppm}): 186.42$, $146.35,143.86,132.59,132.45,130.78,76.01,23.28,10.39$.

e) Synthesis of pyrene-2,7-dicarboxaldehyde
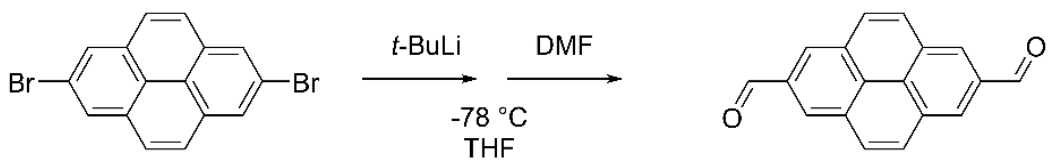
Under argon $1.00 \mathrm{~g}(2.78 \mathrm{mmol}, 1 \mathrm{eq})$ of 2,7-dibromopyrene (synthesis adapted from $\left.{ }^{16}\right)$ was suspended in $200 \mathrm{~mL}$ of anhydrous THF in a flame-dried flask. The suspension was stirred for 30 min in a cooling bath (acetone/ dry ice, $\left.-78^{\circ} \mathrm{C}\right)$. After slow addition of $3.68 \mathrm{~mL}(6.25 \mathrm{mmol}$, $2.3 \mathrm{eq}$ ) of $t$ - $\mathrm{BuLi}\left(1.7 \mathrm{M}\right.$ in $n$-pentane), the mixture was stirred for $2 \mathrm{~h}$ at $-78^{\circ} \mathrm{C}$. Anhydrous DMF (1.95 mL, $25.3 \mathrm{mmol}, 9 \mathrm{eq})$ was slowly added. The cooling bath was removed, and the reaction mixture was stirred overnight. The mixture was quenched with $20 \mathrm{~mL}$ of aqueous hydrochloric acid $(1.2 \mathrm{M})$. The solid was collected by filtration, washed with $\mathrm{H}_{2} \mathrm{O}, \mathrm{Et}_{2} \mathrm{O}$, and THF and then dried under vacuum. The filtrate was extracted with DCM $(3 \times 50 \mathrm{~mL})$, and the organic phases were combined and washed with water $(3 \times 50 \mathrm{~mL})$ and brine (one time $50 \mathrm{~mL}$ ). The organic phase was dried over $\mathrm{Na}_{2} \mathrm{SO}_{4}$, filtered and DCM was removed under vacuum. The crude product was purified by column chromatography $(8 / 2 \mathrm{v} / \mathrm{v}$ cyclohexane/EtOAc), combined with the washed solid and recrystallized from toluene to result in $0.50 \mathrm{~g}$ (1.94 mmol, 70\% yield) of pyrene-2,7dicarbaldehyde.

HRMS-EI: calculated (m/z): 258.0681, measured (m/z): 258.0660.

${ }^{1} \mathrm{H}$ NMR (400 MHz, DMSO-d 6 ) $\delta(\mathrm{ppm}): 10.48$ (s, 2H), 8.89 (s, 4H), 8.47 (s, 4H).

${ }^{13} \mathrm{C}\left\{{ }^{1} \mathrm{H}\right\}$ NMR (100 MHz, DMSO- $\left.d_{6}\right) \delta(\mathrm{ppm}): 193.63,134.42,131.69,128.96,126.32,126.08$. 


\section{COF syntheses}

a) TA TAPB-COF:

Under argon, a $6 \mathrm{~mL}$ glass tube was charged with TA (12.07 mg, $0.09 \mathrm{mmol}, 1.5 \mathrm{eq})$ and TAPB (21.09 mg, $0.06 \mathrm{mmol}, 1 \mathrm{eq})$. The reactants were suspended in $1 \mathrm{~mL}$ of an 8:1 (v/v) mixture of 1,4dioxane/mesitylene. Aqueous acetic acid (6 M, $100 \mu \mathrm{l})$ was added, the tube was sealed, and the reaction mixture was kept at $100{ }^{\circ} \mathrm{C}$ for $72 \mathrm{~h}$. A yellow precipitate was isolated by filtration under vacuum and extracted with $\mathrm{CO}_{2}$ under supercritical conditions for $2 \mathrm{~h}$ to yield $26.3 \mathrm{mg}(88 \%)$ of product. Details of the extractions are given below under section C. Anal. calc. for $\mathrm{N}_{6} \mathrm{C}_{72} \mathrm{H}_{48}$ : $\mathrm{N}$, 8.43; C, 86.72; H, 4.85. Found: N, 8.29; C, 85.15; H, 4.92.

\section{b) TT TAPB-COF:}

Under argon, a $6 \mathrm{~mL}$ glass tube was charged with TT (11.77 mg, $0.06 \mathrm{mmol}, 1.5 \mathrm{eq})$ and TAPB (14.06 mg, $0.04 \mathrm{mmol}, 1 \mathrm{eq})$. The reactants were suspended in $1 \mathrm{~mL}$ of an 8:1 (v/v) mixture of 1,4dioxane/mesitylene. Aqueous acetic acid $(6 \mathrm{M}, 100 \mu \mathrm{l})$ was added, the tube was sealed, and the reaction mixture was kept at $100{ }^{\circ} \mathrm{C}$ for $72 \mathrm{~h}$. A brown precipitate was isolated by filtration under vacuum and extracted with $\mathrm{CO}_{2}$ under supercritical conditions for $2 \mathrm{~h}$ to yield $18.3 \mathrm{mg}(77 \%)$ of product. Anal. calc. for $\mathrm{N}_{6} \mathrm{~S}_{6} \mathrm{C}_{72} \mathrm{H}_{42}$ : N, 7.10; S, 16.26; C, 73.07; H, 3.58. Found: N, 6.97; S, 15.57; C, 72.12; H, 3.90.

\section{c) BDT TAPB-COF:}

Under argon, a $6 \mathrm{~mL}$ glass tube was charged with BDT (7.39 mg, $0.03 \mathrm{mmol}, 1.5 \mathrm{eq})$ and TAPB (7.03 mg, $0.02 \mathrm{mmol}, 1 \mathrm{eq})$. The reactants were suspended in $1 \mathrm{~mL}$ of an 8:1 (v/v) mixture of 1,4dioxane/mesitylene. Aqueous acetic acid $(6 \mathrm{M}, 100 \mu \mathrm{l})$ was added, the tube was sealed, and the reaction mixture was kept at $100{ }^{\circ} \mathrm{C}$ for $72 \mathrm{~h}$. A yellowish precipitate was isolated by filtration under vacuum, washed with 1,4-dioxane and extracted with $\mathrm{CO}_{2}$ under supercritical conditions for 2 h to yield $9.3 \mathrm{mg}(70 \%)$ of product. Anal. calc. for $\mathrm{N}_{6} \mathrm{~S}_{6} \mathrm{C}_{84} \mathrm{H}_{48}$ : N, 6.28; S, 14.38; C, 75.42; H, 3.92. Found: N, 6.07; S, 14,87; C, 73.82; H, 3.91. 


\section{d) BDT-OMe TAPB-COF:}

Under argon, a $6 \mathrm{~mL}$ glass tube was charged with BDT-OMe $(9.19 \mathrm{mg}, 0.03 \mathrm{mmol}, 1.5 \mathrm{eq})$ and TAPB (7.03 mg, $0.02 \mathrm{mmol}, 1 \mathrm{eq})$. The reactants were suspended in $1 \mathrm{~mL}$ of an 8:1 (v/v) mixture of 1,4-dioxane/mesitylene. Aqueous acetic acid (6 M, $100 \mu \mathrm{l})$ was added, the tube was sealed, and the reaction mixture was kept at $100{ }^{\circ} \mathrm{C}$ for $72 \mathrm{~h}$. A red precipitate was isolated by filtration under vacuum, washed with 1,4-dioxane and extracted with $\mathrm{CO}_{2}$ under supercritical conditions for $2 \mathrm{~h}$ to yield $11.4 \mathrm{mg}(75 \%)$ of product. Anal. calc. for $\mathrm{N}_{6} \mathrm{O}_{6} \mathrm{~S}_{6} \mathrm{C}_{90} \mathrm{H}_{60}: \mathrm{N}, 5.55 ; \mathrm{S}, 12.71 ; \mathrm{C}, 71.40 ; \mathrm{H}$, 4.00. Found: N, 5.44; S, 12.23; C, 70.45; H, 4.22.

\section{e) BDT-OEt TAPB-COF:}

Under argon, a $6 \mathrm{~mL}$ glass tube was charged with BDT-OEt (10.03 mg, $0.03 \mathrm{mmol}, 1.5 \mathrm{eq})$ and TAPB (7.03 mg, $0.02 \mathrm{mmol}, 1 \mathrm{eq})$. The reactants were suspended in $1 \mathrm{~mL}$ of an 8:1 (v/v) mixture of 1,4-dioxane/mesitylene. Aqueous acetic acid (6 M, $100 \mu \mathrm{l})$ was added, the tube was sealed, and the reaction mixture was kept at $100{ }^{\circ} \mathrm{C}$ for $72 \mathrm{~h}$. A red precipitate was isolated by filtration under vacuum, washed with 1,4-dioxane and extracted with $\mathrm{CO}_{2}$ under supercritical conditions for $2 \mathrm{~h}$ to yield $9.3 \mathrm{mg}(58 \%)$ of product. Anal. calc. for $\mathrm{N}_{6} \mathrm{O}_{6} \mathrm{~S}_{6} \mathrm{C}_{96} \mathrm{H}_{72}: \mathrm{N}, 5.26 ; \mathrm{S}, 12.04 ; \mathrm{C}, 72.15 ; \mathrm{H}$, 4.54. Found: N, 5.32; S, 10.89; C, 71.61; H, 4.61.

\section{f) BDT-OPr TAPB-COF:}

Under argon, a $6 \mathrm{~mL}$ glass tube was charged with BDT-OPr (10.87 mg, $0.03 \mathrm{mmol}, 1.5 \mathrm{eq})$ and TAPB (7.03 mg, $0.02 \mathrm{mmol}, 1 \mathrm{eq})$. The reactants were suspended in $1 \mathrm{~mL}$ of an 8:1 (v/v) mixture of 1,4-dioxane/mesitylene. Aqueous acetic acid (6 M, $100 \mu \mathrm{l})$ was added, the tube was sealed, and the reaction mixture was kept at $100{ }^{\circ} \mathrm{C}$ for $72 \mathrm{~h}$. An orange precipitate was isolated by filtration under vacuum, washed with 1,4-dioxane and extracted with $\mathrm{CO}_{2}$ under supercritical conditions for $2 \mathrm{~h}$ to yield $12.8 \mathrm{mg}(76 \%)$ of product. Anal. calc. for $\mathrm{N}_{6} \mathrm{O}_{6} \mathrm{~S}_{6} \mathrm{C}_{102} \mathrm{H}_{84}$ : N, 5.00; S, 11.44; C, 72.83; H, 5.03. Found: N, 4.46; S, 10.36; C, 71.50; H, 5.57. 


\section{g) Pyrene-2,7 TAPB-COF:}

Under argon, a $6 \mathrm{~mL}$ glass tube was charged with pyrene-2,7-dicarbaldehyde (7.75 mg, $0.03 \mathrm{mmol}, 1.5 \mathrm{eq})$ and TAPB $(7.03 \mathrm{mg}, 0.02 \mathrm{mmol}, 1 \mathrm{eq})$. The reactants were suspended in $1 \mathrm{~mL}$ of a 9:1 (v/v) mixture of benzyl alcohol/mesitylene. Aqueous acetic acid (6 M, $100 \mu \mathrm{l})$ was added, the tube was sealed, and the reaction mixture was kept at $120{ }^{\circ} \mathrm{C}$ for $72 \mathrm{~h}$. A brownish precipitate was isolated by filtration, washed with 1,4-dioxane and extracted with $\mathrm{CO}_{2}$ under supercritical conditions for $2 \mathrm{~h}$ to yield $9.5 \mathrm{mg}(69 \%)$ of product. Anal. calc. for $\mathrm{N}_{2} \mathrm{C}_{102} \mathrm{H}_{60}$ : N, 6.14; C, 89.45; H, 4.42. Found: N, 5.27; C, 75.73; H, 4.06.

\section{h) Supercritical fluid extraction with carbon dioxide}

Approximately $10 \mathrm{mg}$ of the COF powder sample was suction filtered and rinsed with 1,4-dioxane $(10 \mathrm{~mL})$. The sample was transferred to a homemade $\mathrm{scCO}_{2}$ extraction metal holder with sample chambers, which were then blocked by a filter paper. The holder was closed and tightened with a screw and subsequently placed in a sodium chloride/ice cooled autoclave $\left(5^{\circ} \mathrm{C}\right.$, Figure S1) containing a temperature probe and a pressure gauge (Parr Instruments). The autoclave was tightly closed with screws and a circlip. Carbon dioxide (99.999\%) from a gas bottle was passed in the autoclave until the pressure reached the maximum (45 bar). Leaving this valve open, gas was released by another valve until a temperature of $5{ }^{\circ} \mathrm{C}$ was reached within the autoclave. This temperature was kept for $30 \mathrm{~s}$. Only the releasing valve was closed again. The temperature within the autoclave rose to approximately 10 to $12{ }^{\circ} \mathrm{C}$. After the temperature reached $6{ }^{\circ} \mathrm{C}$ again, the valve, connecting gas bottle and autoclave, was tightly closed and afterwards the carbon dioxide cylinder valve was also closed. The autoclave was slowly heated to $40{ }^{\circ} \mathrm{C}$ by a heating jacket. When the pressure exceeded 100 bar, pressure was slowly released by a valve to 85 bar. This procedure was repeated until $40{ }^{\circ} \mathrm{C}$ and 85 bar were reached. After $2 \mathrm{~h}$ the pressure was slowly, entirely released, and the powder was collected and dried under vacuum at $100{ }^{\circ} \mathrm{C}$. 


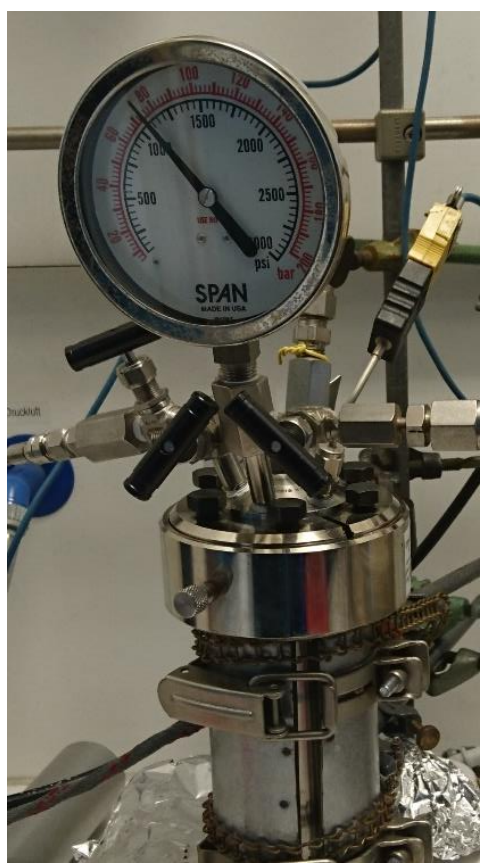

Figure $\mathrm{S} 1$. Autoclave used for $\mathrm{scCO}_{2}$ activation. 


\section{PXRD}

\section{Solvent treatment}

Rinsing freshly synthesized TAPB COFs with 1,4-dioxane, representing the main component of the reaction mixture, led to amorphization. The samples were vacuum-dried prior to PXRD measurements (Figure S2).

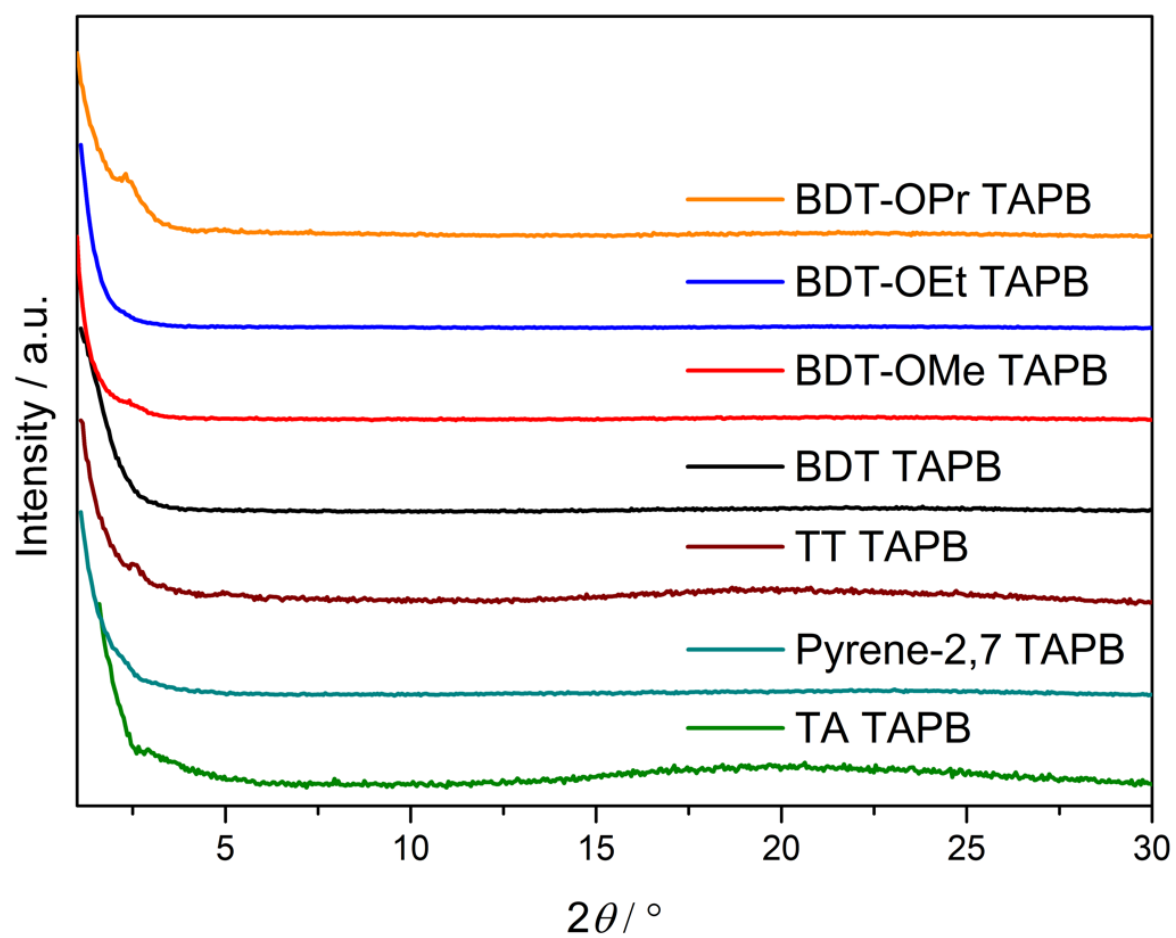

Figure S2. PXRDs of TAPB-COFs rinsed with an excess of 1,4-dioxane and eventually vacuumdried. Reflections indicating a high degree of order could not be detected.

In the following, we investigated freshly prepared COFs, which were rinsed with a solvent and finally solvent exchanged for $24 \mathrm{~h}$ prior to vacuum drying. 
Solvent stability of the different COFs.
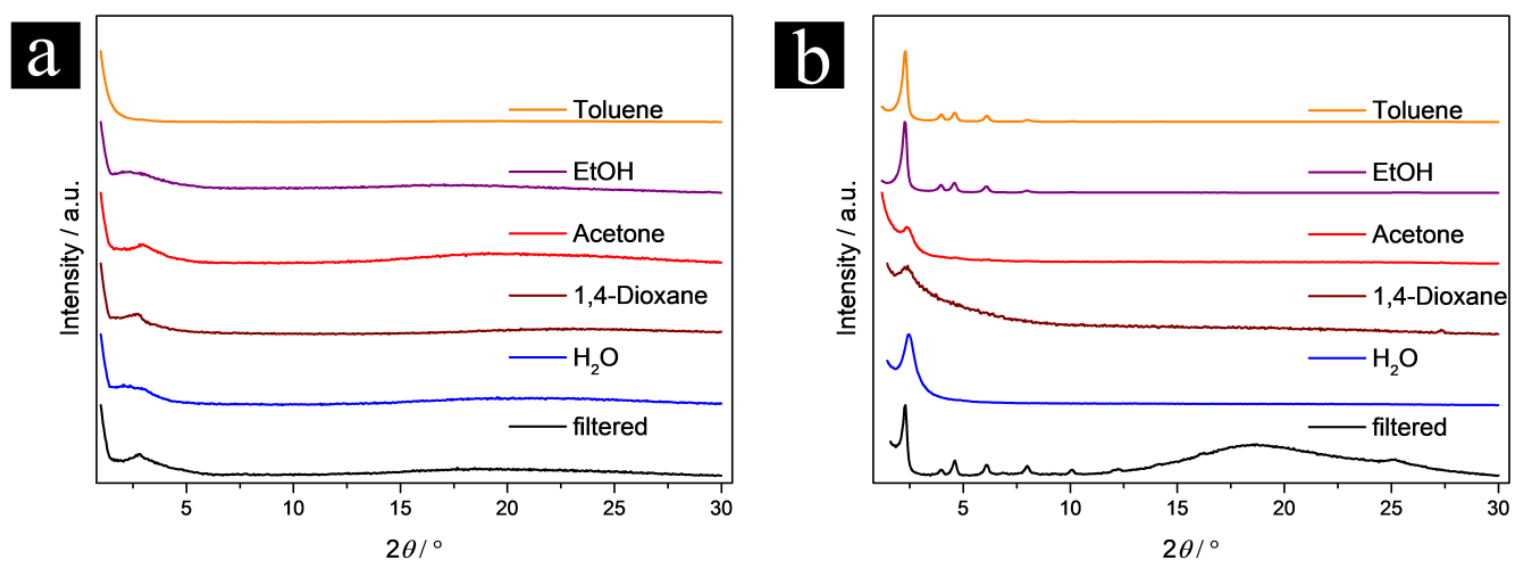

Figure S3. a) PXRDs of TA TAPB-COF exposed for $24 \mathrm{~h}$ to different solvents. b) PXRDs of Pyrene-2,7 TAPB-COFs exposed for $24 \mathrm{~h}$ to different solvents. The samples were vacuum-dried after solvent exposure. In comparison, as-synthesized filtered sample is shown in black.
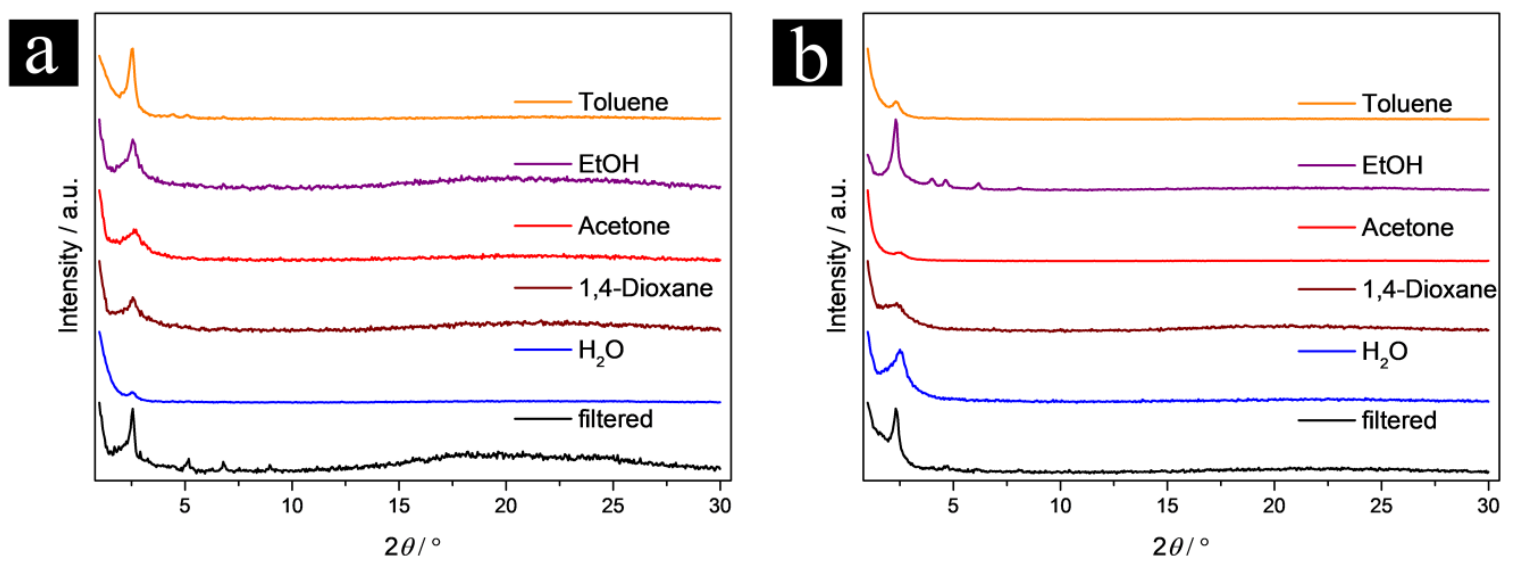

Figure S4. a) PXRDs of TT TAPB-COF exposed for $24 \mathrm{~h}$ to different solvents. b) PXRDs of BDT TAPB-COFs exposed for $24 \mathrm{~h}$ to different solvents. The samples were vacuum-dried after solvent exposure. In comparison, as-synthesized filtered sample is shown in black. 

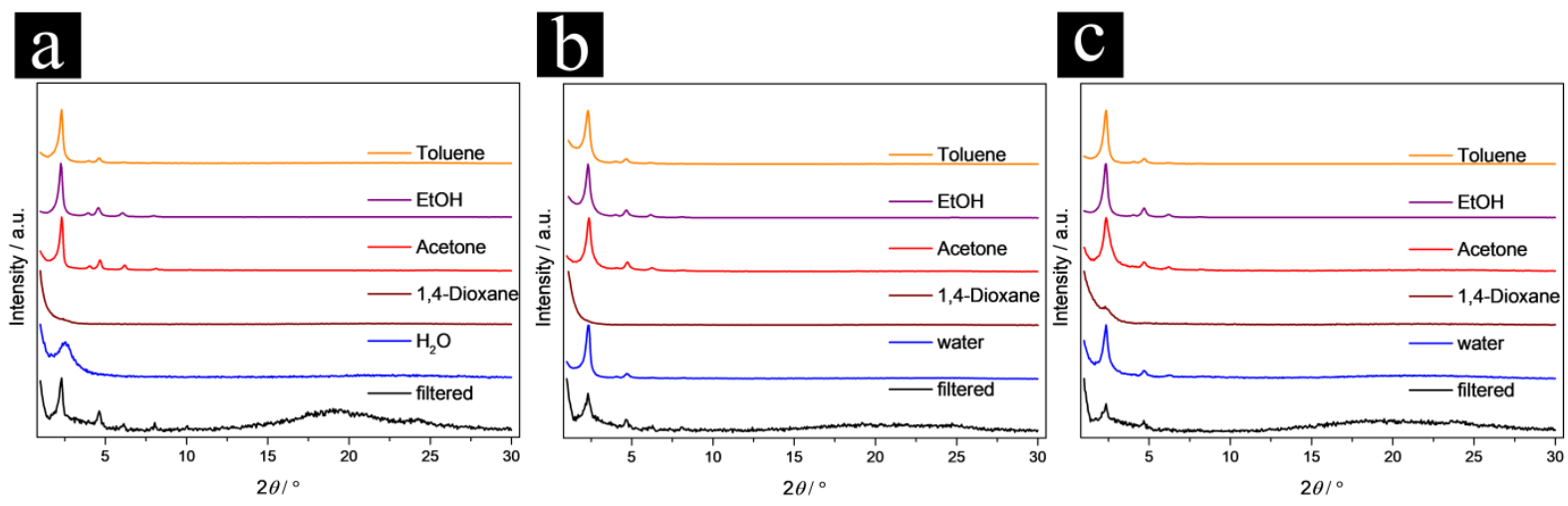

Figure S5. a) PXRDs of BDT-OMe TAPB-COF exposed for $24 \mathrm{~h}$ to different solvents. b) PXRDs of BDT-OEt TAPB-COFs exposed for $24 \mathrm{~h}$ to different solvents. c) PXRDs of BDT-OPr TAPB$\mathrm{COF}$ exposed for $24 \mathrm{~h}$ to different solvents. The samples were vacuum-dried after solvent exposure. In comparison, as-synthesized filtered sample is shown in black.

\section{Solvent treatment after $\mathrm{scCO}_{2}$ activation}

In the following section, we investigated the $\mathrm{scCO}_{2}$ activated $\mathrm{COF}$ samples regarding their stability towards solvent treatments. The $\mathrm{scCO}_{2}$ activated $\mathrm{COFs}$ were suspended for $24 \mathrm{~h}$ in the respective solvent $(5 \mathrm{mg} / \mathrm{mL})$ and finally dried under vacuum for $30 \mathrm{~min}$.
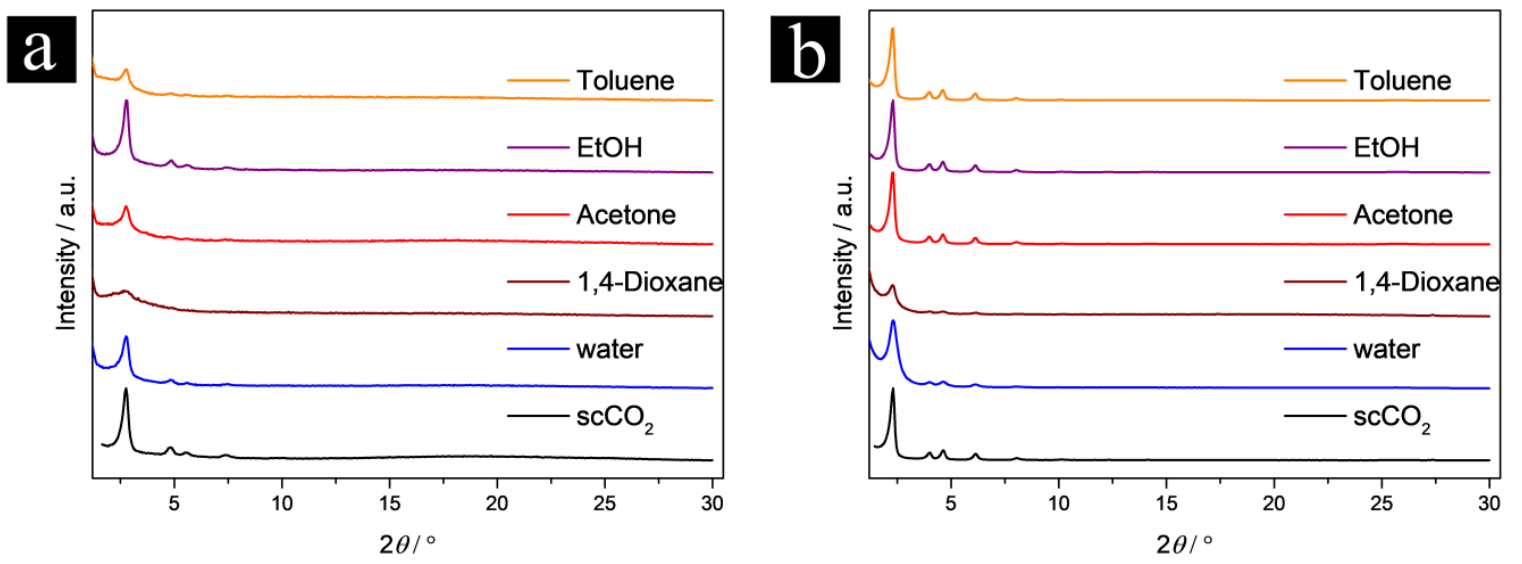

Figure S6. a) PXRDs of $\mathrm{scCO}_{2}$ activated TA TAPB-COF (black) exposed for $24 \mathrm{~h}$ to different solvents. b) PXRDs of $\mathrm{scCO}_{2}$ activated Pyrene-2,7 TAPB-COF (black) suspended for $24 \mathrm{~h}$ in different solvents. The samples were vacuum-dried after the solvent treatment prior to the analysis. 

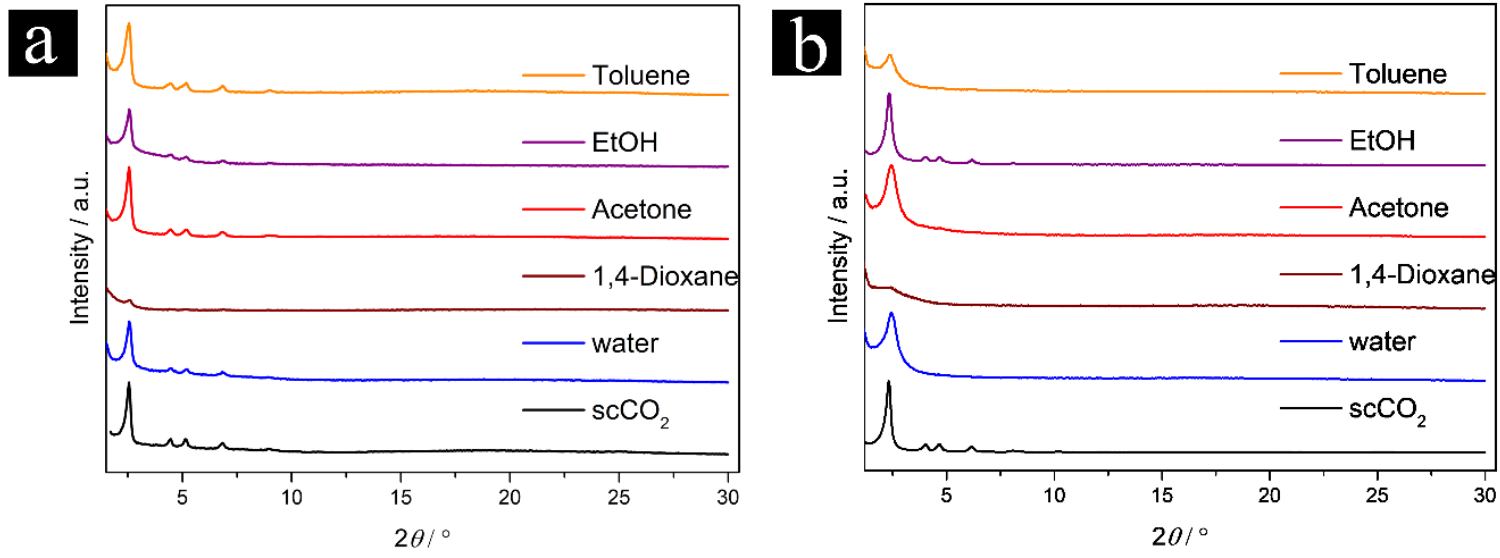

Figure S7. a) PXRDs of $\mathrm{scCO}_{2}$ activated TT TAPB-COF (black) suspended for $24 \mathrm{~h}$ in different solvents. b) PXRDs of $\mathrm{scCO}_{2}$ activated BDT TAPB-COF (black) suspended for $24 \mathrm{~h}$ in different solvents. The samples were vacuum-dried after the solvent treatment prior to the analysis.
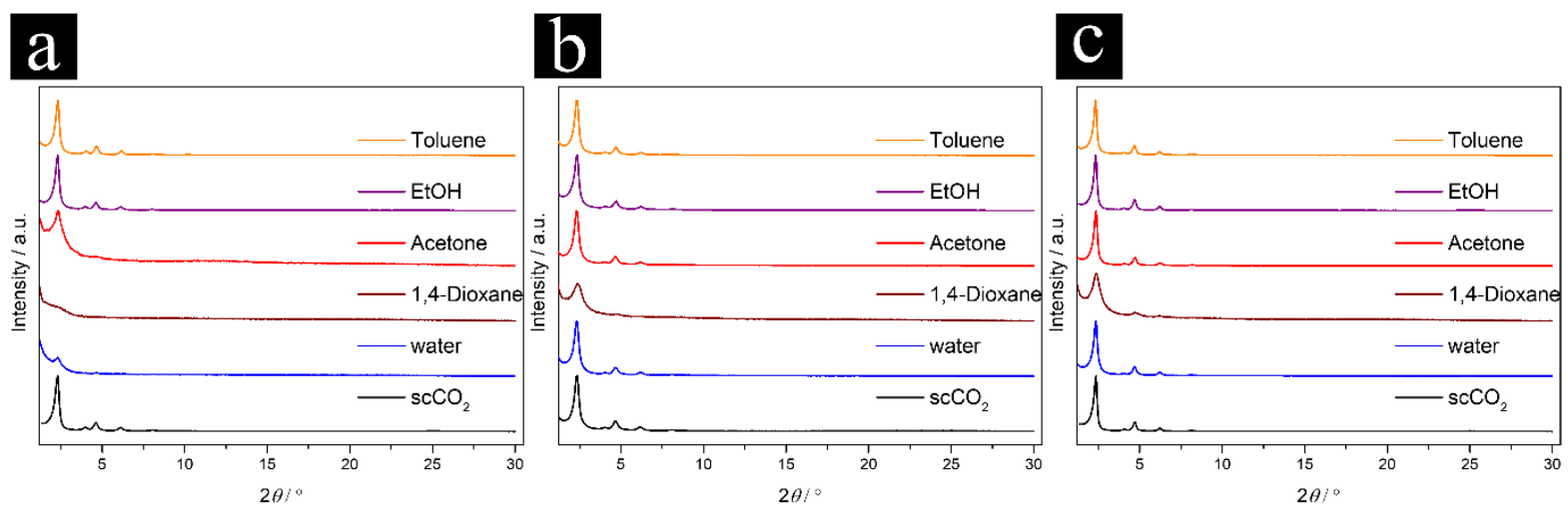

Figure S8. a) PXRDs of $\mathrm{scCO}_{2}$ activated BDT-OMe TAPB-COF (black) suspended for $24 \mathrm{~h}$ in different solvents. b) PXRDs of $\mathrm{scCO}_{2}$ activated BDT-OEt TAPB-COFs suspended for $24 \mathrm{~h}$ in different solvents. c) PXRDs of $\mathrm{scCO}_{2}$ activated BDT-OPr TAPB-COF (black) suspended for $24 \mathrm{~h}$ in different solvents. The samples were vacuum-dried after the solvent treatment, prior to the analysis.

\section{Vapor treatment after $\mathrm{ScCO}_{2}$ activation}

In the following section, we investigated the $\mathrm{scCO}_{2}$ activated $\mathrm{COF}$ samples regarding their stability towards vapor treatments. The $\mathrm{scCO}_{2}$ activated $\mathrm{COFs}$ were placed in a vial in a bigger vapor chamber without direct contact of solvent to $\mathrm{scCO}_{2}$ activated COF. After vapor exposure for $24 \mathrm{~h}$, the powders were dried under vacuum for $30 \mathrm{~min}$. 

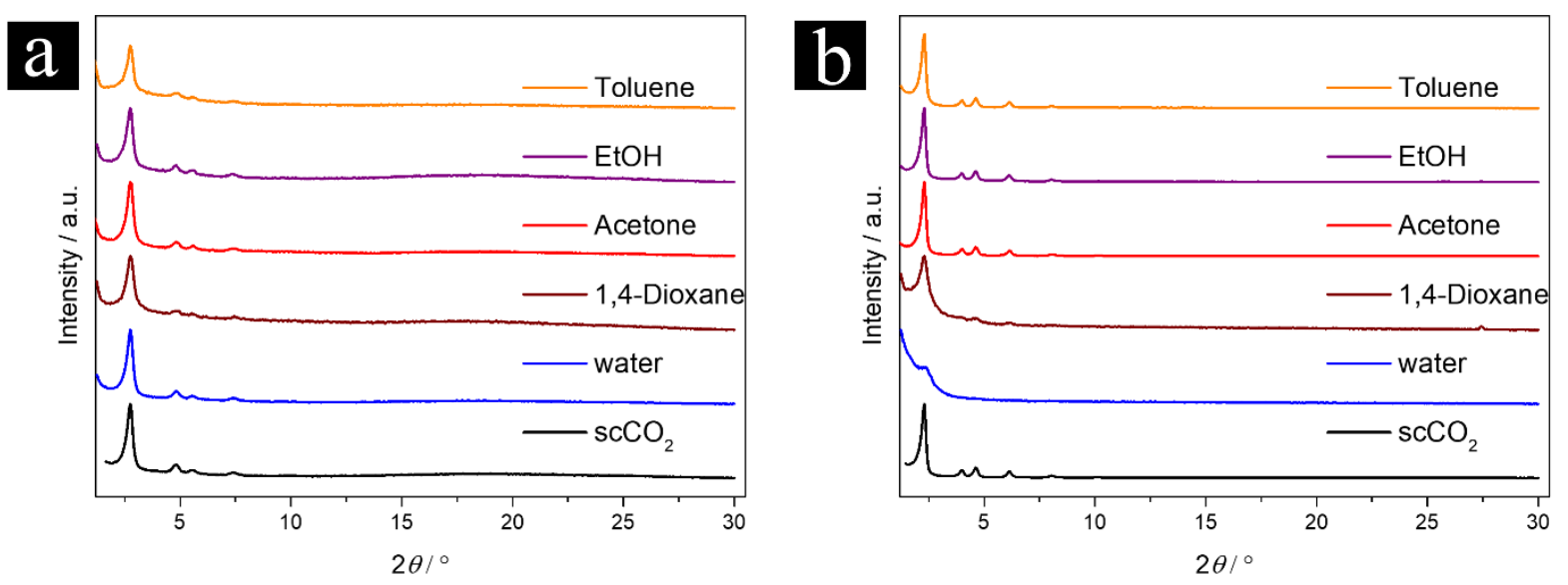

Figure S9. a) PXRDs of $\mathrm{scCO}_{2}$ activated TA TAPB-COF (black) exposed for $24 \mathrm{~h}$ to different solvent vapors. b) PXRDs of $\mathrm{scCO}_{2}$ activated Pyrene-2,7 TAPB-COF (black) exposed for $24 \mathrm{~h}$ to different solvent vapors. The samples were vacuum-dried after vapor exposure, prior to the analysis.
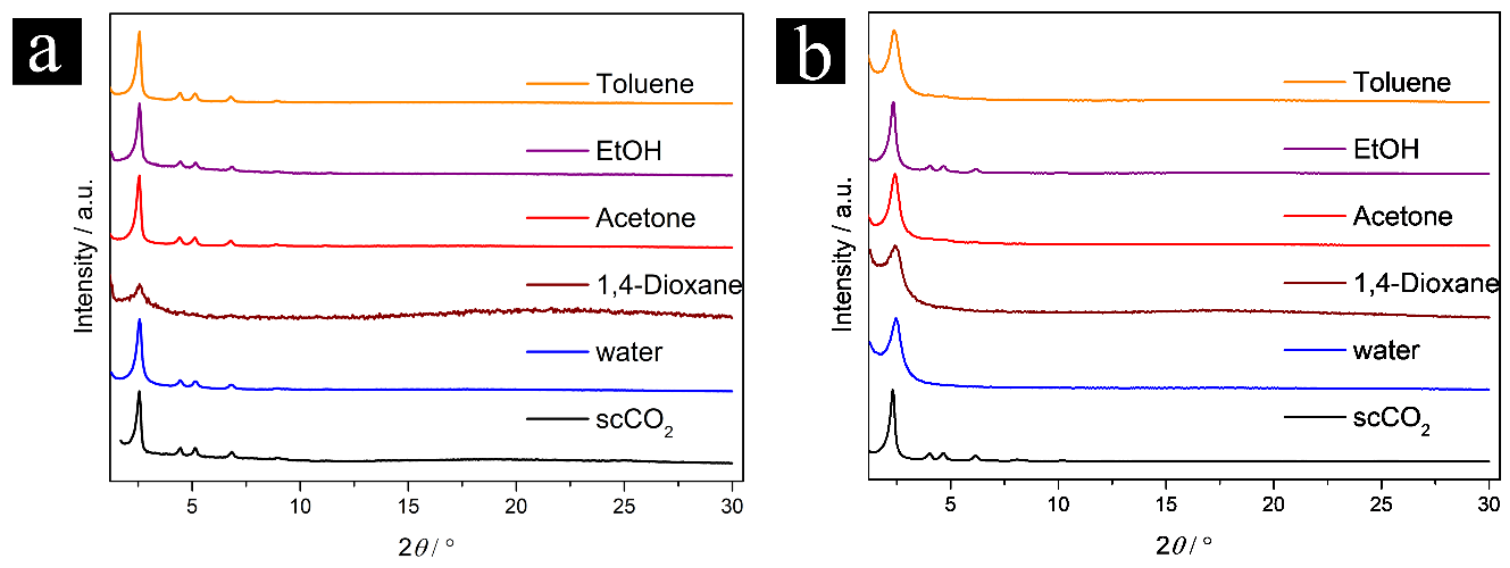

Figure S10. a) PXRDs of $\mathrm{scCO}_{2}$ activated TT TAPB-COF (black) exposed for $24 \mathrm{~h}$ to different solvent vapors. b) PXRDs of $\mathrm{scCO}_{2}$ activated BDT TAPB-COF (black) exposed for $24 \mathrm{~h}$ to different solvent vapors. The samples were vacuum-dried after vapor exposure prior to the analysis. 

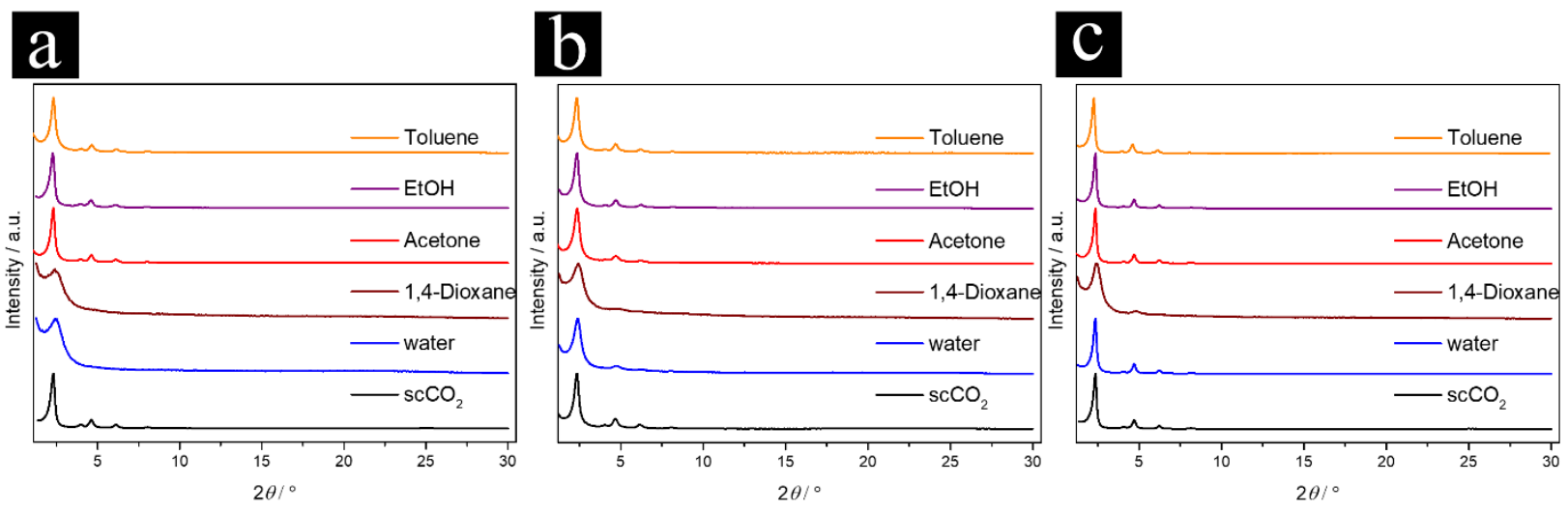

Figure S11. a) PXRDs of $\mathrm{scCO}_{2}$ activated BDT-OMe TAPB-COF (black) exposed for $24 \mathrm{~h}$ to different solvent vapors. b) PXRDs of $\mathrm{scCO}_{2}$ activated BDT-OEt TAPB-COFs exposed for $24 \mathrm{~h}$ to different solvent vapors. c) PXRDs of $\mathrm{scCO}_{2}$ activated BDT-OPr TAPB-COF (black) exposed for $24 \mathrm{~h}$ to different solvent vapors. The samples were vacuum-dried after solvent exposure prior to the analysis.

\section{E. SUPERCRITICAL $\mathrm{CO}_{2}$ ACTIVATION}

The supercritical $\mathrm{CO}_{2}$ activation (extraction) is well suited for achieving high structural definition and high specific surface areas, which is partially attributed to extracting side products. Using the $\mathrm{CO}_{2}$ activation protocol, a highly crystalline $\mathrm{COF}$ material was obtained even after a short reaction time of one day (Figure S12). 


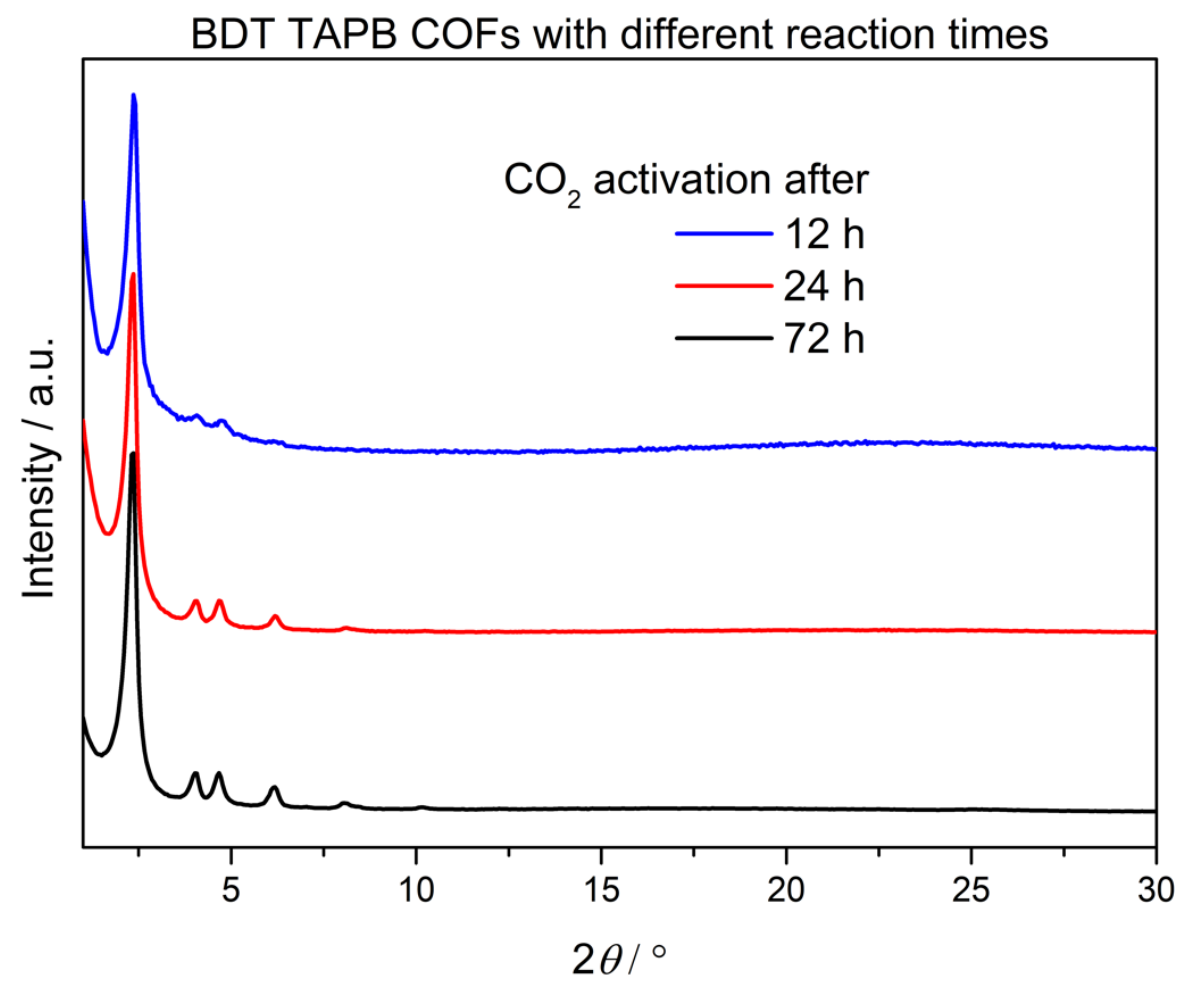

Figure S12. Employing short reaction times followed by $\mathrm{CO}_{2}$ activation yielded crystalline material. Notably, the crystallinity further increases over time.

Having shown that there are distinct differences between robust and fragile COFs concerning their stability and tolerance towards different solvents, we investigated whether the activation of a nonporous framework could also be achieved by solvents, which did not affect the framework's crystallinity. We therefore decided to examine a robust BDT-OMe TAPB-COF network after the steps of $\mathrm{scCO}_{2}$ activation, 1,4-dioxane treatment for the layer displacement, and finally toluene treatment of the short-range ordered powder to investigate the ability of toluene to restore crystallinity. In Figure S13 the different stages of BDT-OMe TAPB-COF activation, amorphization and reactivation are shown in a bottom-up order. The $\mathrm{scCO}_{2}$ activated BDT-OMe TAPB-COF sample (black) shows high crystallinity, indicated by the sharp, intense reflections. In comparison, after 1,4-dioxane solvent treatment for $24 \mathrm{~h}$ and vacuum-drying, the crystallinity is drastically reduced (blue). The sample was finally transferred to a vial filled with toluene for $72 \mathrm{~h}$ to allow for reactivation by this tolerated solvent and to restore crystallinity by reforming the stacked network. As demonstrated with PXRD, the crystallinity is improved (wine) in comparison to the only 1,4-dioxane treated COF (blue), nevertheless, the crystallinity was still only moderate. 
This was observed although toluene was an applicable solvent during the BDT-OMe TAPB-COF work-up procedure (Figure S5). To investigate whether $\mathrm{scCO}_{2}$-reactivation can restore the COF's crystallinity, the sample then was $\mathrm{scCO}_{2}$ activated for $2 \mathrm{~h}$. The restored crystallinity is indicated by the sharp and distinct reflections (red), showing that even in the case of robust $\mathrm{COFs}, \mathrm{scCO}_{2}$ is a unique treatment to recreate crystallinity in the TAPB frameworks. 


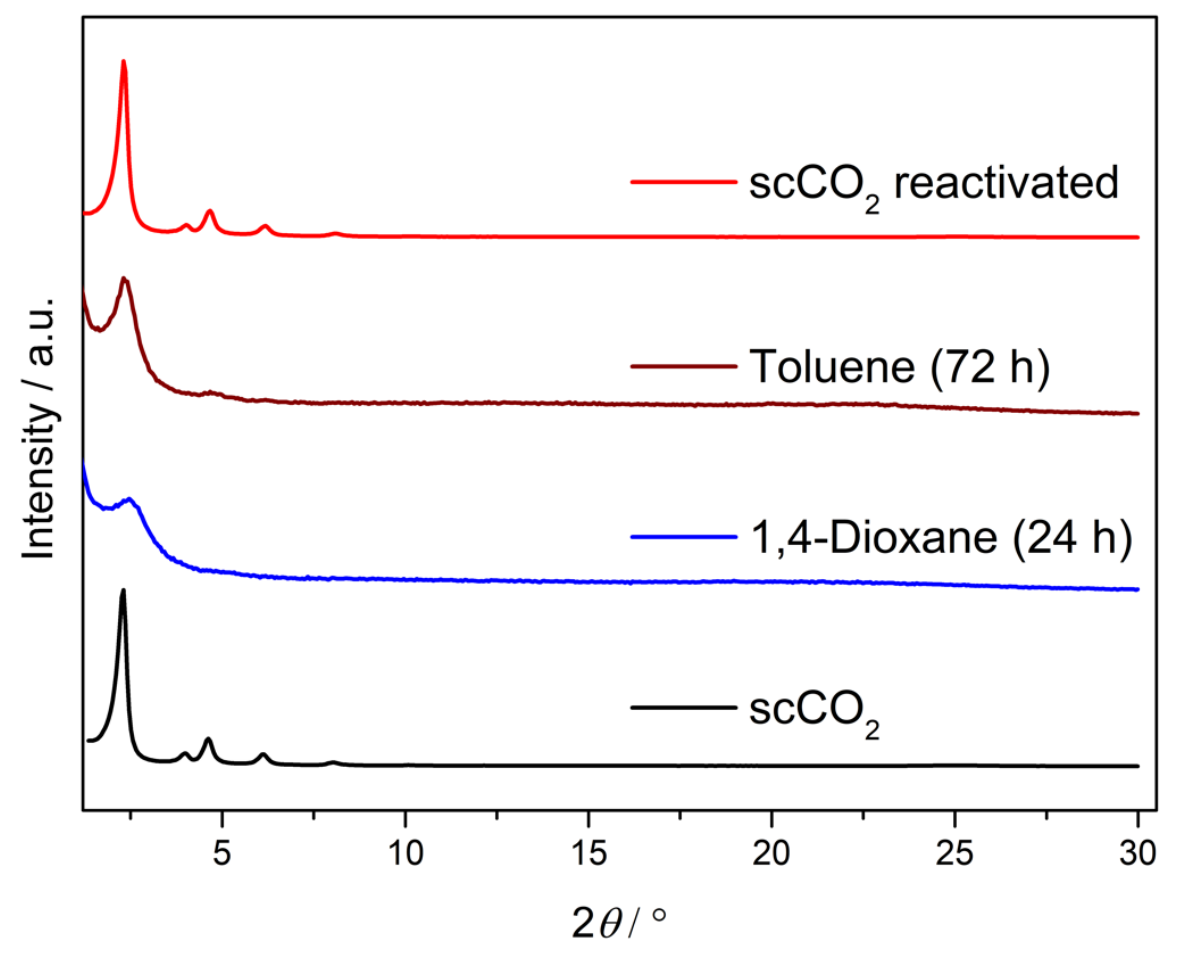

Figure S13. A BDT-OMe TAPB-COF was treated with $\mathrm{scCO}_{2}$ to result in a highly crystalline framework (black). Afterwards, the sample was treated with 1,4-dioxane and vacuum-dried to obtain a poorly crystalline powder with short-range order (blue). A treatment with toluene for $72 \mathrm{~h}$ did not restore the high crystallinity (wine). The sample finally was $\mathrm{scCO}_{2}$ activated for $2 \mathrm{~h}$ resulting in a highly crystalline framework (red).

Besides toluene, EtOH was a suitable washing solvent for the robust TAPB-COFs. In analogy to the toluene reactivation shown in Figure S13, we tried to establish EtOH reactivation, as EtOH has a lower boiling point than toluene. The treatment of a $\mathrm{scCO}_{2}$ activated robust BDT-OPr TAPB sample with 1,4-dioxane resulted in the expected loss of crystallinity. The short-range ordered polymer then was immersed in $\mathrm{EtOH}$ for $72 \mathrm{~h}$ and eventually vacuum-dried prior to PXRD analysis (Figure S14). A reconstitution of the framework's order after immersion in EtOH is well indicated by sharpened reflections. Nevertheless, the peak broadening compared to the $\mathrm{scCO}_{2}$ activated state can be clearly observed. Compared to a $\mathrm{ScCO}_{2}$ reactivation, solvent reactivation in general appears to be slower and less effective. $\mathrm{ScCO}_{2}$ reactivation can be conducted within a very short period of only $2 \mathrm{~h}$ allowing for access to highly crystalline and open porous reactivated TAPB COF frameworks. 


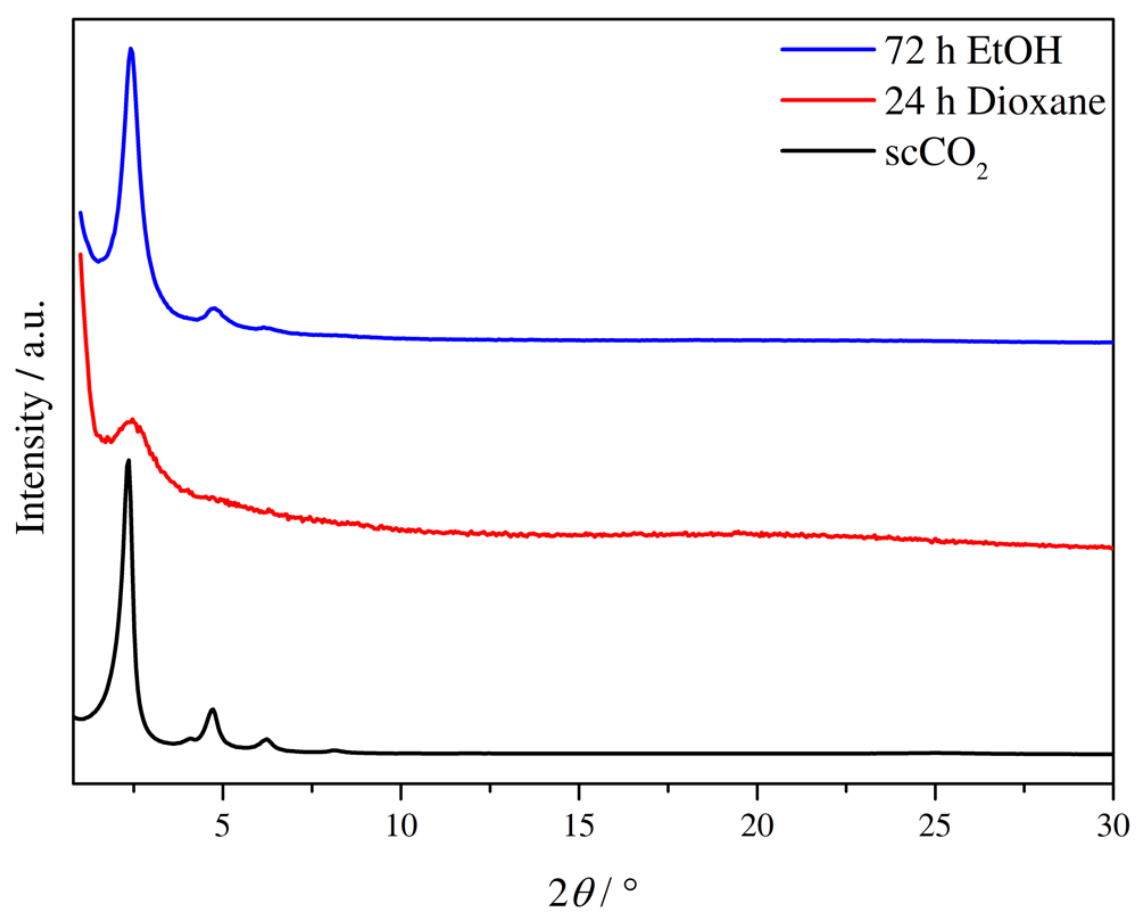

Figure S14. PXRD patterns of a BDT-OPr TAPB-COF after $\mathrm{scCO}_{2}$ activation (black), after a $24 \mathrm{~h}$ immersion in 1,4-dioxane and vacuum drying (red) and a $72 \mathrm{~h}$ immersion in $\mathrm{EtOH}$ prior to final vacuum drying (blue). 
The activation via $\mathrm{scCO}_{2}$ allows for the realization of highly crystalline COFs that were still highly crystalline after one month storage under ambient conditions.
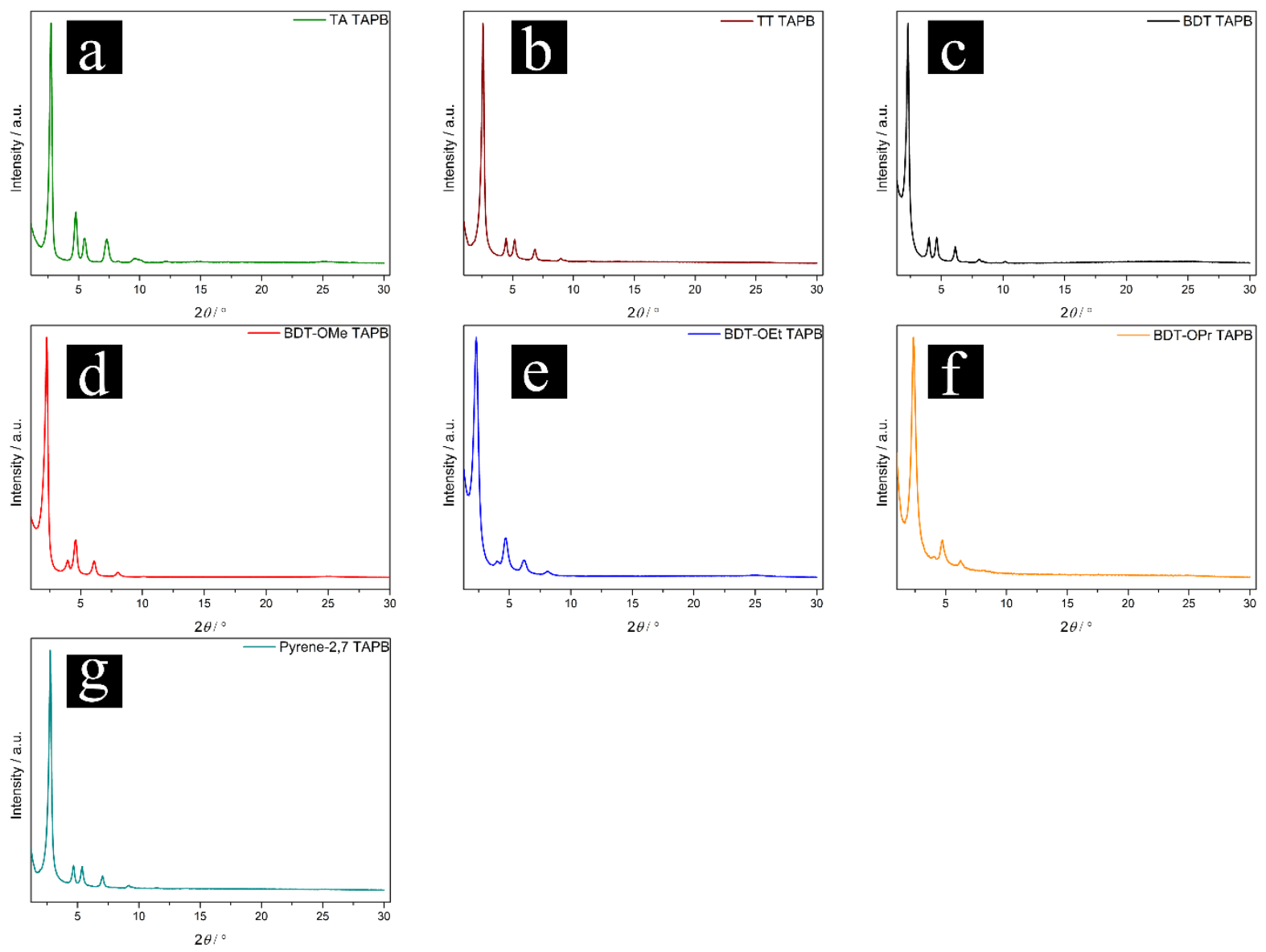

Figure S15: PXRD patterns of $\mathrm{scCO}_{2}$ activated TAPB COFs after one month storage at ambient conditions. a) TA TAPB-COF, b) TT TAPB-COF, c) BDT TAPB-COF, d) BDT-OMe TAPBCOF, e) BDT-OEt TAPB-COF, f) BDT-OPr TAPB-COF and g) Pyrene-2,7 TAPB-COF.

During time-dependent PXRD studies of the fragile BDT TAPB-COF and the robust BDT-OMe TAPB-COF being exposed to ethanol or 1,4-dioxane vapors in a plastic bag, the reflection corresponding to the plastic bag for creation of saturated vapors remained stable. On the other hand, the reflection at $2 \theta=25.1^{\circ}$ attributed to the COF interlayer distance shifts towards smaller 
values of ${ }^{\circ} 2 \theta$ during the exposure. This indicates an expansion of the stacking distance of adjacent layers (Figure S16).
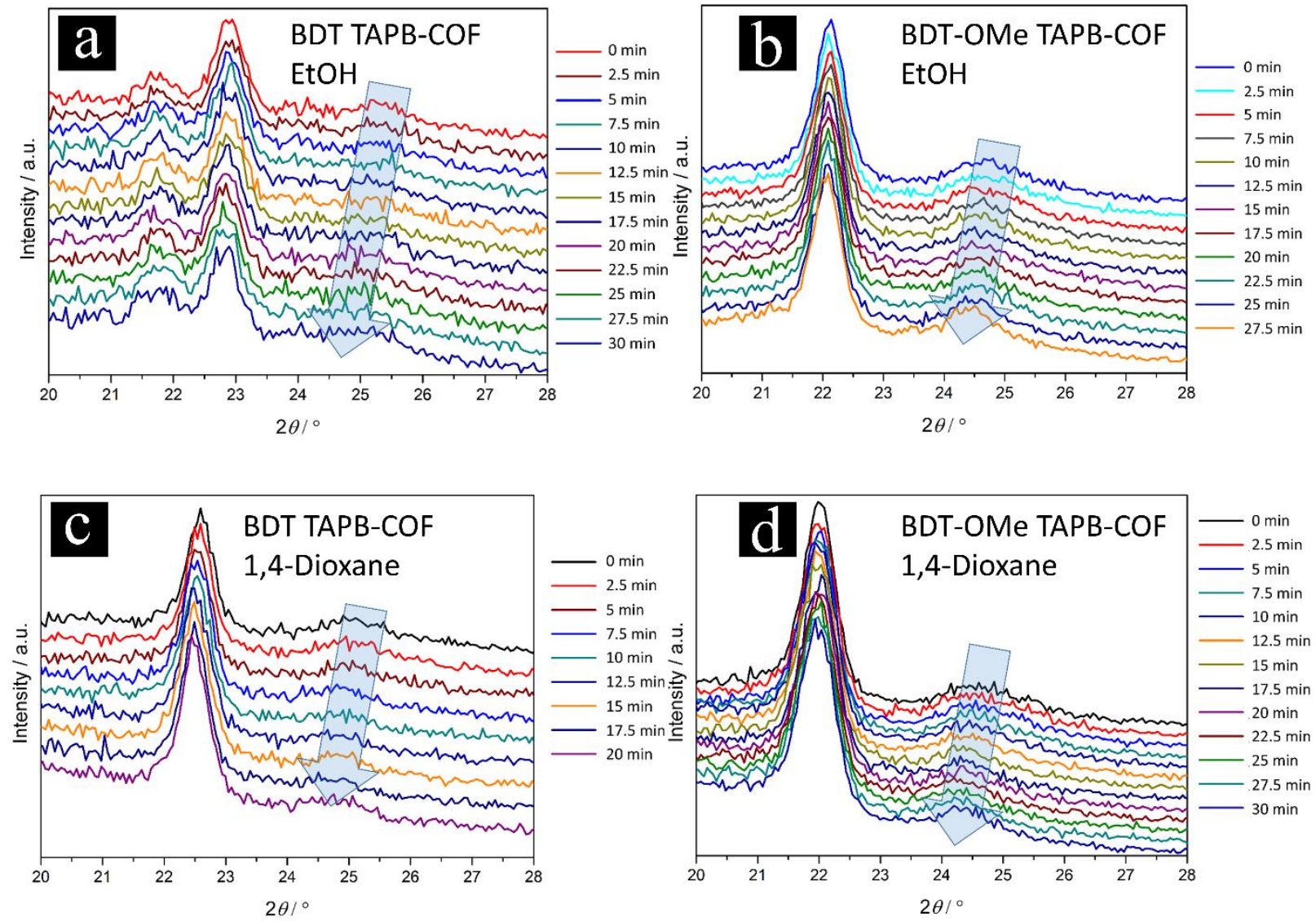

Figure S16. Time-dependent PXRD patterns of COFs in a plastic bag (reflection at $2 \theta=21-23^{\circ}$ ) a) BDT TAPB-COF under time dependent PXRD during EtOH vapor exposure. b). BDT-OMe TAPB-COF under time dependent PXRD during EtOH vapor exposure. c) BDT TAPB-COF under time dependent PXRD during 1,4-dioxane vapor exposure and d) BDT-OMe TAPB-COF under time dependent PXRD during 1,4-dioxane vapor exposure.

To investigate the apparent effects of solvents on the frameworks in more detail, we performed PXRD measurements of $\mathrm{scCO}_{2}$ activated, solvent immersed and $\mathrm{scCO}_{2}$ reactivated $\mathrm{COF}$ samples. We found that the solvent molecules enlarge the stacking distance from roughly $3.52 \AA$ ( $2 \theta=$ $\left.25.3^{\circ} 2 \theta\right)$ up to $3.91 \AA\left(2 \theta=22.7^{\circ} 2 \theta\right)$ (Figure S17-18). 

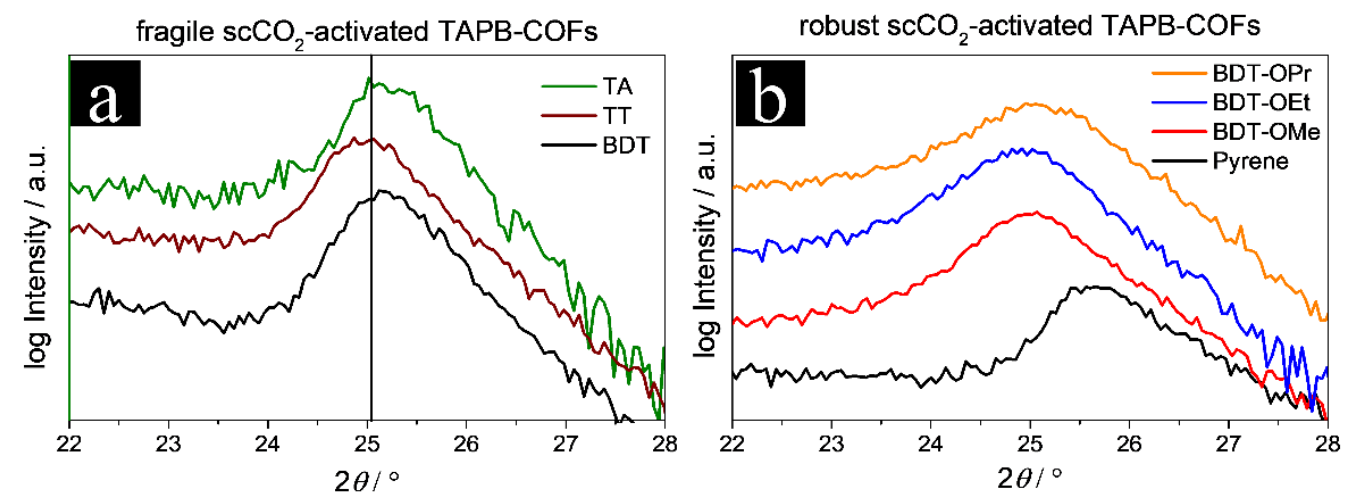

Figure S17. PXRD patterns of the (001) reflection of TAPB-COFs. a) and b) show the influence of the linear dialdehyde part and the TAPB on the $\pi$-stacking distance of adjacent TAPB-COF layers. For small linear dialdehydes, the stacking distance is mainly guided by TAPB. Nevertheless, small deviations due to the influence of the linear dialdehyde are visible. Connecting the strongly aggregating pyrene building blocks and TAPB results in a shift of the (001) reflection corresponding to the closer $\pi$-stacking distance of adjacent Pyrene-2,7 TAPB-COF layers. The pyrene dialdehyde induces a closer stacking resulting in a shift of the (001) reflections from $2 \theta=$ 25.1 (preferred distance for TAPB) to $2 \theta=25.7^{\circ}$. 

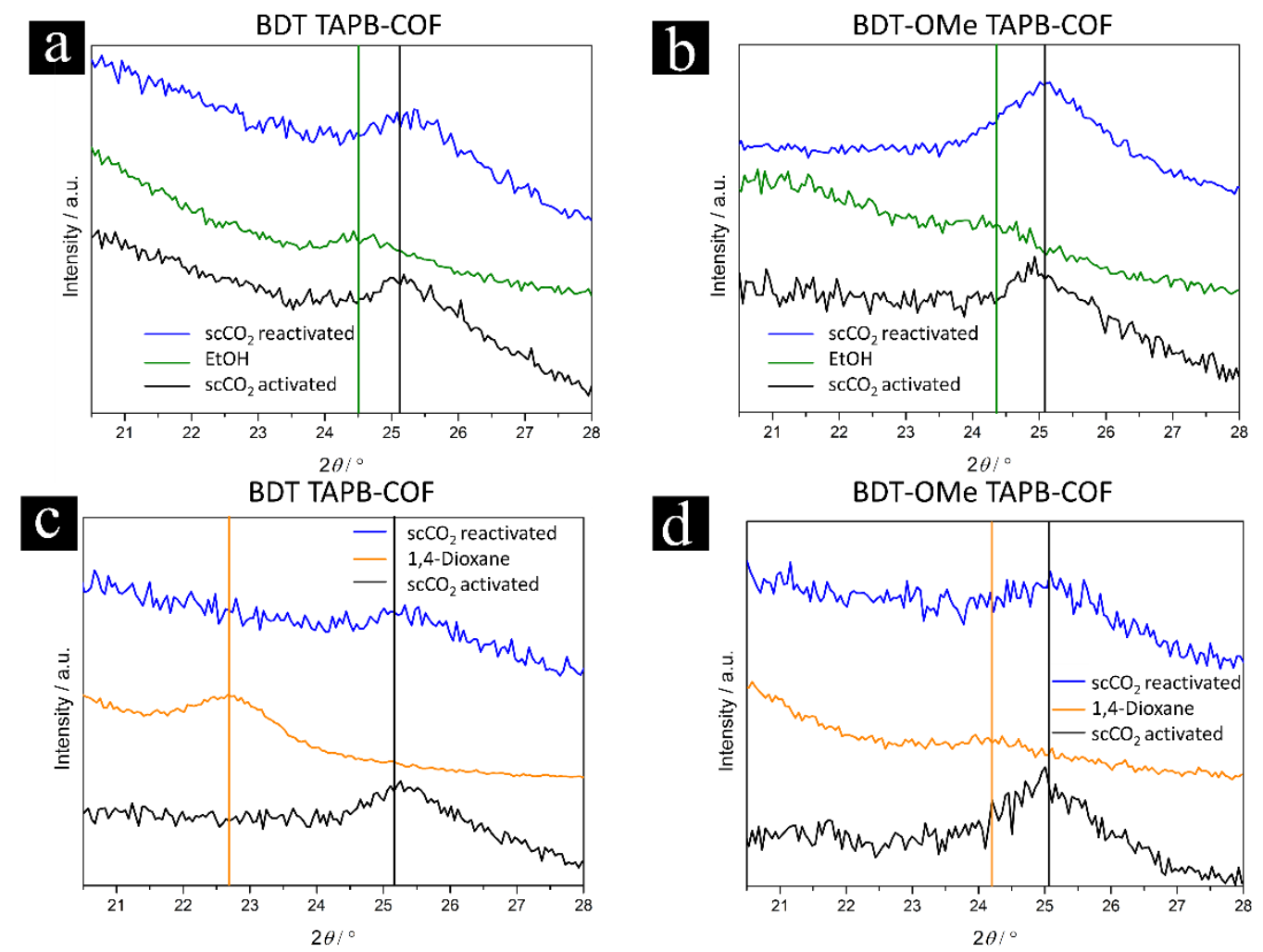

Figure S18. a) to d) show the influence of solvent wetting of the fragile BDT TAPB-COF (a, c) and the robust BDT-OMe TAPB-COF $(b, d)$ on the stacking distance. It is of less importance whether the solvent influence results in a short-range ordered polymer (BDT TAPB-COF in a)) or allows for regaining high order after vacuum-drying (BDT-OMe TAPB-COF with EtOH); during the wetting, the stacking distance is enlarged. The $\mathrm{ScCO}_{2}$ activated $\mathrm{COFs}$ show a reflection at $2 \theta$ $=25.1^{\circ}$ representing the stacking distance. Upon solvent wetting with a solvent droplet, the reflection is shifted towards smaller values of $2 \theta$, indicating an enlarged stacking distance, for ethanol and 1,4-dioxane. After $\mathrm{scCO}_{2}$ reactivation, the original state of $2 \theta=25.1^{\circ}$ is restored.

We also investigated the influence on the stacking distance with the less volatile toluene, towards which the robust BDT-OMe TAPB-COF was highly tolerant. We were able to detect shifted stacking distances (Figure S19). 

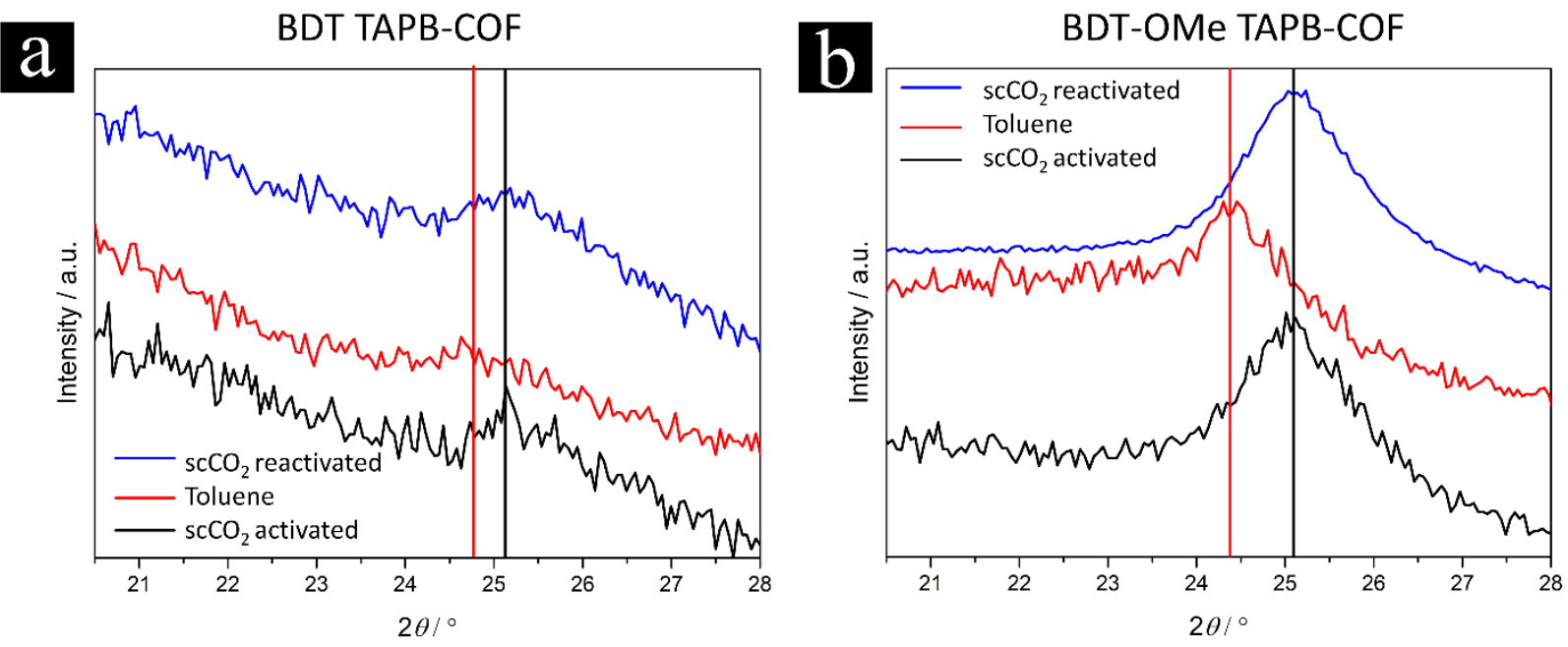

Figure S19. Influence of toluene on the stacking distance in case of the fragile BDT TAPB-COF (a) and the robust BDT-OMe TAPB-COF (b). In both cases, the stacking distance is enlarged, indicated by the shift of the reflection at $2 \theta=25.1^{\circ}$ in the $\mathrm{scCO}_{2}$-activated and -reactivated cases. 
To investigate the sensitivity towards water and the possibility to reactivate these samples, we studied the behavior of the BDT TAPB-COF. A scCO 2 activated BDT TAPB-COF sample (black) was transferred to a vial with water for $24 \mathrm{~h}$. After being vacuum-dried, the sample was investigated by PXRD, revealing the loss of long-range order (red). After rinsing with 1,4-dioxane, the same sample was $\mathrm{scCO}_{2}$-reactivated, showing the recovery of the high crystallinity (blue).

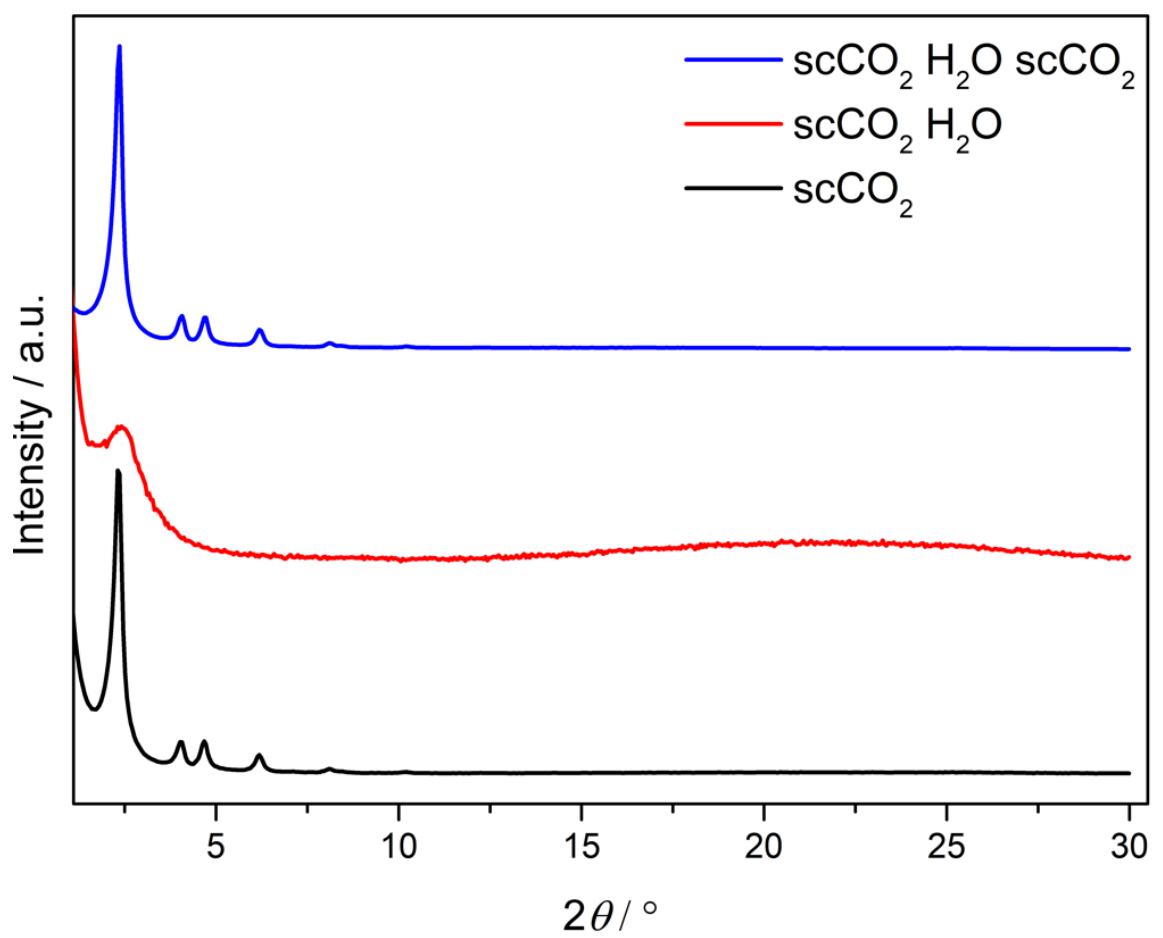

Figure S20. PXRD patterns of BDT TAPB, $\mathrm{scCO}_{2}$ activated (2h, black, crystalline), exposed to water for $24 \mathrm{~h}$ and vacuum-dried (red, mostly short-range ordered) and finally $\mathrm{scCO}_{2}$ reactivated ( $2 \mathrm{~h}$, blue, crystalline). 
Investigations on the utility of the $\mathrm{scCO}_{2}$ activation compared to a gaseous system under similar conditions ( $\mathrm{Ar}, 40{ }^{\circ} \mathrm{C}, 85 \mathrm{bar}, 2 \mathrm{~h}$ ) revealed that in contrast to Ar the supercritical state of $\mathrm{CO}_{2}$ can convert a short-range ordered TAPB-COF powder, whether fragile or robust, into a highly crystalline state.

Furthermore, we subjected a poorly crystalline BDT-OMe TAPB COF powder to $\mathrm{CO}_{2}$ activation under sub-critical conditions. For this activation process, different pressure and temperature corresponding to $\mathrm{CO}_{2}$ in the gas or liquid phases, respectively, were selected. For activation at lower pressure (gas phase), the poorly crystalline COF powder was activated at $40{ }^{\circ} \mathrm{C}$ and 60 bar for 2 hours, the recovered COF powder remained poorly crystalline and porous as indicated in the XRD analysis. Similar results were obtained for activation in lower temperature (liquid phase) namely $20^{\circ} \mathrm{C}$ and pressure 80 bar for 2 hours. Therefore, we conclude that $\mathrm{CO}_{2}$ at a super critical state is vital for converting poorly crystalline COFs to their corresponding crystalline phase.
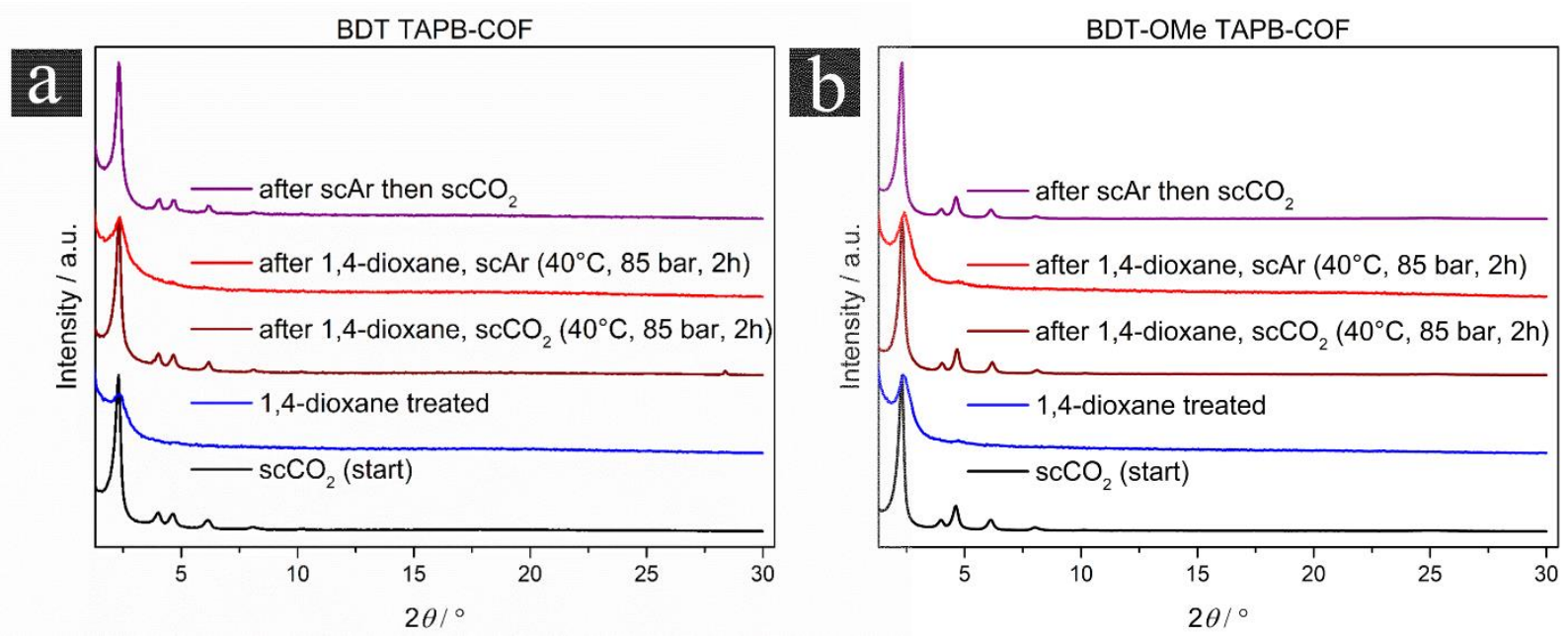

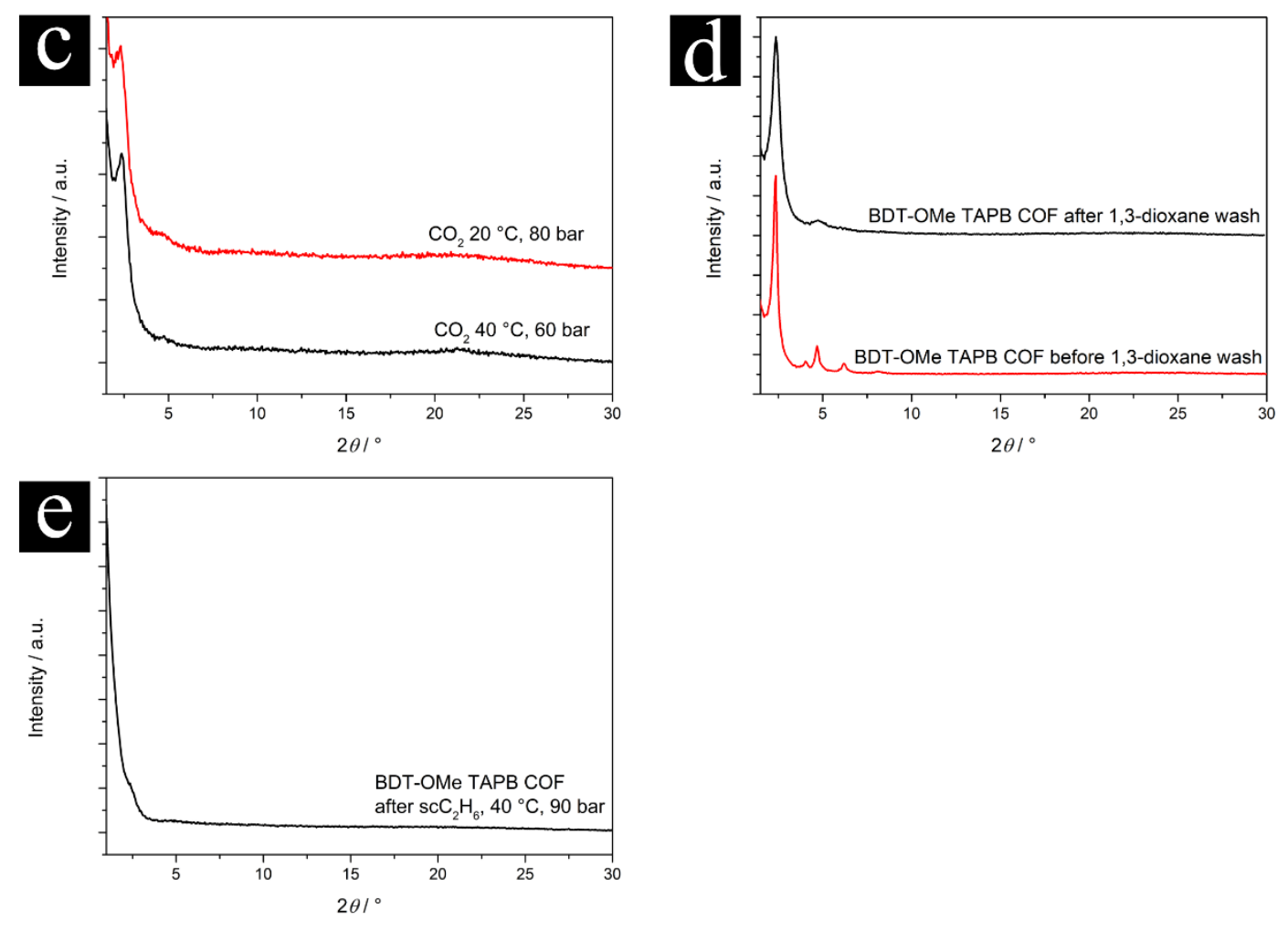

Figure S21. Comparison of the fragile BDT TAPB-COF (a) and the robust BDT-OMe TAPB-COF (b) concerning activation with $\mathrm{scCO}_{2}$ and argon under the same conditions $\left(40{ }^{\circ} \mathrm{C}, 85 \mathrm{bar}, 2 \mathrm{~h}\right)$. $\mathrm{ScCO}_{2}$ activated samples were transformed into the short-range ordered state by treatment with 1,4-dioxane. These powders were activated with $\mathrm{Ar}$ and $\mathrm{scCO}_{2}$ under the same conditions. While the $\mathrm{scCO}_{2}$ activated samples exhibit high crystallinity, the argon activated samples show no improved crystallinity compared to the 1,4-dioxane treated sample. Subsequently, these Ar activated samples could be treated with $\mathrm{scCO}_{2}$ to restore crystallinity. (c) PXRD patterns of $\mathrm{CO}_{2}$ treated poorly crystalline BDT-OMe TAPB COF powder under sub-critical conditions. (d) PXRD patterns of crystalline BDT-OMe TAPB COF powder treated with 1,3-dioxane. (e) PXRD pattern of BDT-OMe TAPB COF powder treated with $\mathrm{scC}_{2} \mathrm{H}_{6}$. 


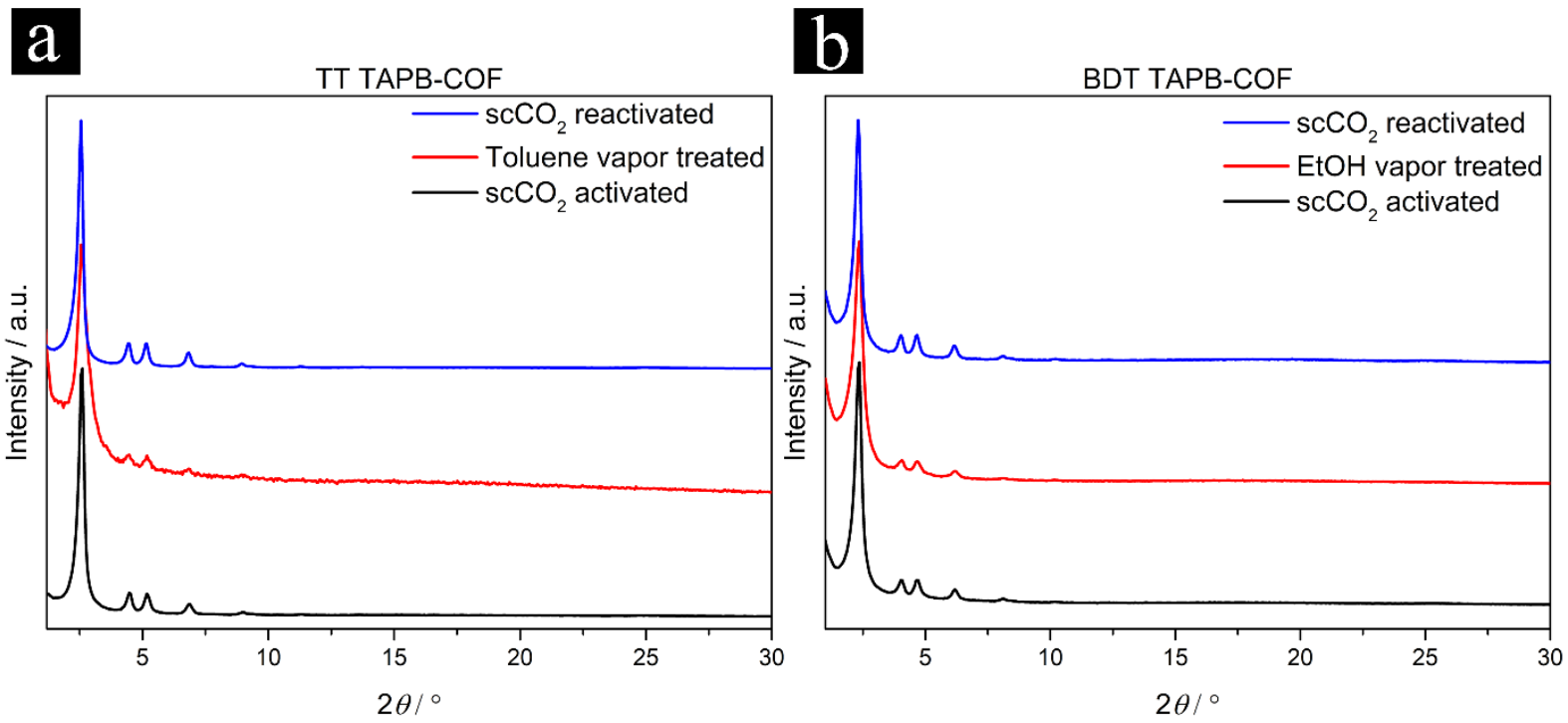

Figure S22 PXRD patterns of TT TAPB-COF (a) and BDT TAPB-COF (b) after $\mathrm{scCO}_{2}$ activation (black), after exposure to EtOH or toluene vapors, respectively, for $24 \mathrm{~h}$ and final vacuum-drying (red), compared to $\mathrm{scCO}_{2}$ reactivated samples (blue). The crystallinity of the powders is still visible even after vapor exposure, although decreased in both cases. 


\section{F. UNIT CELL PARAMETERS AND ATOMIC COORDINATES}

a) TA TAPB-COF

$\mathrm{R}_{\mathrm{wp}}=4.65 \%, \mathrm{R}_{\mathrm{wp}}(\mathrm{w} / \mathrm{o}$ bck $)=5.79 \%, \mathrm{R}_{\mathrm{p}}=3.66 \%$

\begin{tabular}{|c|c|c|c|}
\hline \multicolumn{4}{|c|}{ P6 (168) - hexagonal } \\
\hline \multicolumn{4}{|c|}{$\mathrm{a}=\mathrm{b}=3.38(7) \mathrm{nm}, \mathrm{c}=0.35 \mathrm{~nm}$} \\
\hline \multicolumn{4}{|c|}{$\alpha=\beta=90^{\circ}, \gamma=120^{\circ}$} \\
\hline Atom & $\mathbf{x} / \mathbf{a}$ & $\mathbf{y} / \mathbf{b}$ & $\mathbf{z} / \mathbf{c}$ \\
\hline $\mathrm{C} 1$ & 0.71006 & 0.35719 & 0.46962 \\
\hline $\mathrm{C} 2$ & 0.68591 & 0.37607 & 0.46950 \\
\hline $\mathrm{C} 3$ & 0.75594 & 0.38239 & 0.47057 \\
\hline $\mathrm{C} 4$ & 0.77637 & 0.42195 & 0.31515 \\
\hline C5 & 0.81918 & 0.44556 & 0.32104 \\
\hline C6 & 0.84272 & 0.43000 & 0.47011 \\
\hline $\mathrm{C} 7$ & 0.82279 & 0.39066 & 0.62604 \\
\hline $\mathrm{C} 8$ & 0.77995 & 0.36731 & 0.62885 \\
\hline N9 & 0.88655 & 0.45557 & 0.46841 \\
\hline $\mathrm{C} 10$ & 0.91285 & 0.44293 & 0.49917 \\
\hline $\mathrm{C} 11$ & 0.95737 & 0.47235 & 0.49850 \\
\hline $\mathrm{H} 12$ & 0.70076 & 0.40906 & 0.46968 \\
\hline
\end{tabular}




\begin{tabular}{|l|l|l|l|}
\hline Atom & $\mathbf{x} / \mathbf{a}$ & $\mathbf{y} / \mathbf{b}$ & $\mathbf{z} / \mathbf{c}$ \\
\hline H13 & 0.75960 & 0.43439 & 0.17767 \\
\hline H14 & 0.83441 & 0.47574 & 0.19846 \\
\hline H15 & 0.84005 & 0.37860 & 0.76036 \\
\hline H16 & 0.76584 & 0.33813 & 0.76859 \\
\hline H17 & 0.90268 & 0.41054 & 0.51507 \\
\hline C18 & 0.45771 & 0.47262 & 0.49937 \\
\hline C19 & 0.48512 & 0.45774 & 0.49845 \\
\hline H20 & 0.42506 & 0.45104 & 0.49991 \\
\hline H21 & 0.47323 & 0.42495 & 0.49885 \\
\hline
\end{tabular}




\section{b) TT TAPB-COF}

$\mathrm{R}_{\mathrm{wp}}=4.94 \%, \mathrm{R}_{\mathrm{wp}}(\mathrm{w} / \mathrm{o}$ bck $)=7.44 \%, \mathrm{R}_{\mathrm{p}}=3.8 \%$

\begin{tabular}{|c|c|c|c|}
\hline \multicolumn{4}{|c|}{ P6 (168) - hexagonal } \\
\hline \multicolumn{4}{|c|}{$\mathrm{a}=\mathrm{b}=3.97(3)(0) \mathrm{nm}, \mathrm{c}=0.37 \mathrm{~nm}$} \\
\hline \multicolumn{4}{|c|}{$\alpha=\beta=90^{\circ}, \gamma=120^{\circ}$} \\
\hline Atom & $\mathbf{x} / \mathbf{a}$ & $\mathbf{y} / \mathbf{b}$ & $\mathbf{z} / \mathbf{c}$ \\
\hline $\mathrm{C} 1$ & 0.70717 & 0.35510 & 0.45837 \\
\hline $\mathrm{C} 2$ & 0.68514 & 0.37325 & 0.45741 \\
\hline $\mathrm{C} 3$ & 0.74998 & 0.37810 & 0.46742 \\
\hline $\mathrm{C} 4$ & 0.76981 & 0.41500 & 0.31484 \\
\hline $\mathrm{C} 5$ & 0.80975 & 0.43681 & 0.33398 \\
\hline C6 & 0.83094 & 0.42210 & 0.49457 \\
\hline $\mathrm{C} 7$ & 0.81156 & 0.38525 & 0.64526 \\
\hline $\mathrm{C} 8$ & 0.77157 & 0.36366 & 0.63405 \\
\hline N9 & 0.87178 & 0.44610 & 0.51099 \\
\hline $\mathrm{C} 10$ & 0.89649 & 0.43506 & 0.57448 \\
\hline $\mathrm{C} 11$ & 0.93763 & 0.46305 & 0.58214 \\
\hline H12 & 0.69989 & 0.40590 & 0.45582 \\
\hline H13 & 0.75294 & 0.42703 & 0.17473 \\
\hline
\end{tabular}




\begin{tabular}{|l|l|l|l|}
\hline Atom & $\mathbf{x} / \mathbf{a}$ & $\mathbf{y} / \mathbf{b}$ & $\mathbf{z} / \mathbf{c}$ \\
\hline H14 & 0.82542 & 0.46702 & 0.21749 \\
\hline H15 & 0.82847 & 0.37282 & 0.77758 \\
\hline H16 & 0.75595 & 0.33394 & 0.76074 \\
\hline H17 & 0.88621 & 0.40344 & 0.62462 \\
\hline C18 & 0.45155 & 0.48668 & 0.58560 \\
\hline C19 & 0.48354 & 0.48321 & 0.58698 \\
\hline S20 & 0.48793 & 0.44355 & 0.58170 \\
\hline H21 & 0.41972 & 0.46429 & 0.58680 \\
\hline
\end{tabular}




\section{c) BDT TAPB-COF}

$\mathrm{R}_{\mathrm{wp}}=5.90 \%, \mathrm{R}_{\mathrm{wp}}(\mathrm{w} / \mathrm{o}$ bck $)=9.04 \%, \mathrm{R}_{\mathrm{p}}=4.38 \%$

\begin{tabular}{|c|c|c|c|}
\hline \multicolumn{4}{|c|}{ P6 (168) - hexagonal } \\
\hline \multicolumn{4}{|c|}{$\mathrm{a}=\mathrm{b}=4.36(6) \mathrm{nm}, \mathrm{c}=0.36 \mathrm{~nm}$} \\
\hline \multicolumn{4}{|c|}{$\alpha=\beta=90^{\circ}, \gamma=120^{\circ}$} \\
\hline Atom & $\mathbf{x} / \mathbf{a}$ & $\mathbf{y} / \mathbf{b}$ & $\mathbf{z} / \mathbf{c}$ \\
\hline $\mathrm{C} 1$ & 0.70311 & 0.35319 & 0.46869 \\
\hline $\mathrm{C} 2$ & 0.68300 & 0.36922 & 0.46838 \\
\hline $\mathrm{C} 3$ & 0.74163 & 0.37418 & 0.47151 \\
\hline $\mathrm{C} 4$ & 0.75900 & 0.40745 & 0.31764 \\
\hline C5 & 0.79494 & 0.42718 & 0.32720 \\
\hline C6 & 0.81448 & 0.41396 & 0.47816 \\
\hline $\mathrm{C} 7$ & 0.79755 & 0.38083 & 0.63150 \\
\hline $\mathrm{C} 8$ & 0.76158 & 0.36132 & 0.63098 \\
\hline N9 & 0.85124 & 0.43544 & 0.48153 \\
\hline $\mathrm{C} 10$ & 0.87340 & 0.42504 & 0.51848 \\
\hline $\mathrm{C} 11$ & 0.91049 & 0.45009 & 0.52117 \\
\hline S12 & 0.92755 & 0.49648 & 0.51906 \\
\hline $\mathrm{C} 13$ & 0.96951 & 0.50076 & 0.52462 \\
\hline
\end{tabular}




\begin{tabular}{|l|l|l|l|}
\hline Atom & $\mathbf{x} / \mathbf{a}$ & $\mathbf{y} / \mathbf{b}$ & $\mathbf{z} / \mathbf{c}$ \\
\hline C14 & 0.96887 & 0.46952 & 0.52612 \\
\hline C15 & 0.93413 & 0.44040 & 0.52557 \\
\hline C16 & 1.00067 & 0.53196 & 0.52550 \\
\hline H17 & 0.69560 & 0.39693 & 0.46883 \\
\hline H18 & 0.74511 & 0.41806 & 0.17930 \\
\hline H19 & 0.80795 & 0.45264 & 0.20696 \\
\hline H20 & 0.81186 & 0.37056 & 0.76670 \\
\hline H21 & 0.74956 & 0.33676 & 0.76943 \\
\hline H22 & 0.86512 & 0.39792 & 0.53676 \\
\hline H23 & 0.92813 & 0.41383 & 0.52697 \\
\hline H24 & 1.00097 & 0.55622 & 0.52463 \\
\hline
\end{tabular}




\section{d) BDT-OMe TAPB-COF}

$\mathrm{R}_{\mathrm{wp}}=6.71 \%, \mathrm{R}_{\mathrm{wp}}(\mathrm{w} / \mathrm{o}$ bck $)=10.7 \%, \mathrm{R}_{\mathrm{p}}=6.65 \%$

\begin{tabular}{|c|c|c|c|}
\hline \multicolumn{4}{|c|}{ P6 (168) - hexagonal } \\
\hline \multicolumn{4}{|c|}{$\mathrm{a}=\mathrm{b}=4.38 \mathrm{~nm}, \mathrm{c}=0.37 \mathrm{~nm}$} \\
\hline \multicolumn{4}{|c|}{$\alpha=\beta=90^{\circ}, \gamma=120^{\circ}$} \\
\hline Atom & $\mathbf{x} / \mathbf{a}$ & $\mathbf{y} / \mathbf{b}$ & $\mathbf{z} / \mathbf{c}$ \\
\hline $\mathrm{C} 1$ & 0.70178 & 0.35152 & 0.49635 \\
\hline $\mathrm{C} 2$ & 0.68253 & 0.36630 & 0.49636 \\
\hline $\mathrm{C} 3$ & 0.74032 & 0.37227 & 0.51144 \\
\hline $\mathrm{C} 4$ & 0.75830 & 0.40338 & 0.38664 \\
\hline $\mathrm{C} 5$ & 0.79218 & 0.42125 & 0.37237 \\
\hline C6 & 0.81263 & 0.41056 & 0.48015 \\
\hline $\mathrm{C} 7$ & 0.79523 & 0.37948 & 0.60608 \\
\hline $\mathrm{C} 8$ & 0.76100 & 0.36142 & 0.62053 \\
\hline N9 & 0.84842 & 0.43201 & 0.49601 \\
\hline $\mathrm{C} 10$ & 0.87381 & 0.42824 & 0.49700 \\
\hline $\mathrm{C} 11$ & 0.91119 & 0.45365 & 0.49668 \\
\hline $\mathrm{S} 12$ & 0.93219 & 0.49697 & 0.49656 \\
\hline C13 & 0.97183 & 0.50124 & 0.49666 \\
\hline
\end{tabular}




\begin{tabular}{|l|l|l|l|}
\hline Atom & $\mathbf{x} / \mathbf{a}$ & $\mathbf{y} / \mathbf{b}$ & $\mathbf{z} / \mathbf{c}$ \\
\hline C14 & 0.96914 & 0.47245 & 0.49670 \\
\hline C15 & 0.93466 & 0.44621 & 0.49682 \\
\hline C16 & 1.00240 & 0.52908 & 0.49670 \\
\hline H17 & 0.69423 & 0.39324 & 0.49638 \\
\hline H18 & 0.74375 & 0.41427 & 0.29219 \\
\hline H19 & 0.80462 & 0.44637 & 0.26659 \\
\hline H20 & 0.80812 & 0.36702 & 0.70498 \\
\hline H21 & 0.74856 & 0.33630 & 0.72625 \\
\hline H22 & 0.87059 & 0.40340 & 0.49833 \\
\hline H23 & 0.92848 & 0.42034 & 0.49703 \\
\hline O24 & 0.44263 & 0.00260 & 0.48554 \\
\hline C25 & 0.44564 & 0.03340 & 0.37114 \\
\hline H26 & 0.45538 & 0.03878 & 0.10364 \\
\hline H27 & 0.46248 & 0.05328 & 0.54602 \\
\hline H28 & 0.42135 & 0.03149 & 0.37701 \\
\hline
\end{tabular}




\section{e) BDT-OEt TAPB-COF}

$\mathrm{R}_{\mathrm{wp}}=4.90 \%, \mathrm{R}_{\mathrm{wp}}(\mathrm{w} / \mathrm{o}$ bck $)=7.31 \%, \mathrm{R}_{\mathrm{p}}=3.63 \%$

\begin{tabular}{|c|c|c|c|}
\hline \multicolumn{4}{|c|}{ P6 (168) - hexagonal } \\
\hline \multicolumn{4}{|c|}{$\mathrm{a}=\mathrm{b}=4.37 \mathrm{~nm}, \mathrm{c}=0.39 \mathrm{~nm}$} \\
\hline \multicolumn{4}{|c|}{$\alpha=\beta=90^{\circ}, \gamma=120^{\circ}$} \\
\hline Atom & $\mathbf{x} / \mathbf{a}$ & $\mathbf{y} / \mathbf{b}$ & $\mathrm{z} / \mathrm{c}$ \\
\hline $\mathrm{C} 1$ & 0.70178 & 0.35152 & 0.49635 \\
\hline $\mathrm{C} 2$ & 0.68253 & 0.36630 & 0.49636 \\
\hline C3 & 0.74032 & 0.37227 & 0.51144 \\
\hline $\mathrm{C} 4$ & 0.75830 & 0.40338 & 0.38664 \\
\hline $\mathrm{C} 5$ & 0.79218 & 0.42125 & 0.37237 \\
\hline C6 & 0.81263 & 0.41056 & 0.48015 \\
\hline $\mathrm{C} 7$ & 0.79523 & 0.37948 & 0.60608 \\
\hline $\mathrm{C} 8$ & 0.76100 & 0.36142 & 0.62053 \\
\hline N9 & 0.84842 & 0.43201 & 0.49601 \\
\hline $\mathrm{C} 10$ & 0.87381 & 0.42824 & 0.49700 \\
\hline $\mathrm{C} 11$ & 0.91119 & 0.45365 & 0.49668 \\
\hline $\mathrm{S} 12$ & 0.93219 & 0.49697 & 0.49656 \\
\hline $\mathrm{C} 13$ & 0.97183 & 0.50124 & 0.49666 \\
\hline
\end{tabular}




\begin{tabular}{|l|l|l|l|}
\hline Atom & $\mathbf{x} / \mathbf{a}$ & $\mathbf{y} / \mathbf{b}$ & $\mathbf{z} / \mathbf{c}$ \\
\hline C14 & 0.96914 & 0.47245 & 0.49670 \\
\hline C15 & 0.93466 & 0.44621 & 0.49682 \\
\hline C16 & 1.00240 & 0.52908 & 0.49670 \\
\hline H17 & 0.69531 & 0.39573 & 0.49638 \\
\hline H18 & 0.74236 & 0.41497 & 0.28495 \\
\hline H19 & 0.80571 & 0.44839 & 0.25830 \\
\hline H20 & 0.80948 & 0.36627 & 0.71230 \\
\hline H21 & 0.74747 & 0.33428 & 0.73454 \\
\hline H22 & 0.87029 & 0.4011 & 0.49845 \\
\hline H23 & 0.92791 & 0.41795 & 0.49705 \\
\hline O24 & 0.44263 & 0.00260 & 0.48554 \\
\hline C25 & 0.44564 & 0.03340 & 0.37114 \\
\hline C26 & 0.41577 & 0.03512 & 0.35453 \\
\hline H27 & 0.45774 & 0.03894 & 0.10667 \\
\hline H28 & 0.46372 & 0.05541 & 0.54689 \\
\hline H29 & 0.39291 & 0.00937 & 0.43965 \\
\hline H30 & 0.41143 & 0.04076 & 0.08165 \\
\hline H31 & 0.41819 & 0.05668 & 0.52849 \\
\hline
\end{tabular}




\section{f) BDT-OPr TAPB-COF}

$\mathrm{R}_{\mathrm{wp}}=4.15 \%, \mathrm{R}_{\mathrm{wp}}(\mathrm{w} / \mathrm{o}$ bck $)=8.35 \%, \mathrm{R}_{\mathrm{p}}=3.42 \%$

\begin{tabular}{|c|c|c|c|}
\hline \multicolumn{4}{|c|}{ P6 (168) - hexagonal } \\
\hline \multicolumn{4}{|c|}{$\mathrm{a}=\mathrm{b}=4.24 \mathrm{~nm}, \mathrm{c}=0.39 \mathrm{~nm}$} \\
\hline \multicolumn{4}{|c|}{$\alpha=\beta=90^{\circ}, \gamma=120^{\circ}$} \\
\hline Atom & $\mathbf{x} / \mathbf{a}$ & $\mathbf{y} / \mathbf{b}$ & $\mathrm{z} / \mathrm{c}$ \\
\hline $\mathrm{C} 1$ & 0.70178 & 0.35152 & 0.49635 \\
\hline $\mathrm{C} 2$ & 0.68253 & 0.36630 & 0.49636 \\
\hline C3 & 0.74032 & 0.37227 & 0.51144 \\
\hline $\mathrm{C} 4$ & 0.7583 & 0.40338 & 0.38664 \\
\hline $\mathrm{C} 5$ & 0.79218 & 0.42125 & 0.37237 \\
\hline C6 & 0.81263 & 0.41056 & 0.48015 \\
\hline $\mathrm{C} 7$ & 0.79523 & 0.37948 & 0.60608 \\
\hline $\mathrm{C} 8$ & 0.76100 & 0.36142 & 0.62053 \\
\hline N9 & 0.84842 & 0.43201 & 0.49601 \\
\hline $\mathrm{C} 10$ & 0.87381 & 0.42824 & 0.49700 \\
\hline $\mathrm{C} 11$ & 0.91119 & 0.45365 & 0.49668 \\
\hline $\mathrm{S} 12$ & 0.93219 & 0.49697 & 0.49656 \\
\hline $\mathrm{C} 13$ & 0.97183 & 0.50124 & 0.49666 \\
\hline
\end{tabular}




\begin{tabular}{|l|l|l|l|}
\hline C14 & 0.96914 & 0.47245 & 0.49670 \\
\hline C15 & 0.93466 & 0.44621 & 0.49682 \\
\hline C16 & 1.00240 & 0.52908 & 0.49670 \\
\hline H17 & 0.69531 & 0.39573 & 0.49638 \\
\hline H18 & 0.74236 & 0.41497 & 0.28495 \\
\hline H19 & 0.80571 & 0.44839 & 0.25830 \\
\hline H20 & 0.80948 & 0.36627 & 0.71230 \\
\hline H21 & 0.74747 & 0.33428 & 0.73454 \\
\hline H22 & 0.87029 & 0.40110 & 0.49845 \\
\hline H23 & 0.92791 & 0.41795 & 0.49705 \\
\hline O24 & 0.44263 & 0.00260 & 0.48554 \\
\hline C25 & 0.44564 & 0.03340 & 0.37114 \\
\hline C26 & 0.41577 & 0.03512 & 0.35453 \\
\hline C27 & 0.45774 & 0.03894 & 0.10667 \\
\hline H28 & 0.46372 & 0.05541 & 0.54689 \\
\hline H29 & 0.41143 & 0.04076 & 0.08165 \\
\hline H30 & 0.41819 & 0.05668 & 0.52849 \\
\hline C31 & 0.62725 & 0.62201 & 0.36724 \\
\hline H32 & 0.63830 & 0.63504 & 0.10801 \\
\hline
\end{tabular}




\begin{tabular}{|l|l|l|l|}
\hline Atom & $\mathbf{x} / \mathbf{a}$ & $\mathbf{y} / \mathbf{b}$ & $\mathbf{z} / \mathbf{c}$ \\
\hline H33 & 0.64692 & 0.63650 & 0.58034 \\
\hline H34 & 0.60237 & 0.62247 & 0.42280 \\
\hline
\end{tabular}

g) Pyrene-2,7 TAPB-COF

$\mathrm{R}_{\mathrm{wp}}=7.50 \%, \mathrm{R}_{\mathrm{wp}}(\mathrm{w} / \mathrm{o}$ bck $)=9.78 \%, \mathrm{R}_{\mathrm{p}}=5.67 \%$

\begin{tabular}{|l|l|l|l|}
\hline \multicolumn{4}{|l|}{ P6 (168)- hexagonal } \\
\hline \multicolumn{2}{|l|}{$\mathrm{a}=\mathrm{b}=4.41 \mathrm{~nm}, \mathrm{c}=0.35 \mathrm{~nm}$} \\
\hline \multicolumn{2}{|l|}{$\beta=90^{\circ}, \gamma=120^{\circ}$} & $\mathbf{z} / \mathbf{c}$ \\
\hline Atom & $\mathbf{x} / \mathbf{a} / \mathbf{b}$ & 0.38442 \\
\hline C1 & 0.25827 & 0.63099 & 0.53313 \\
\hline C2 & 0.2403 & 0.64663 & 0.527 \\
\hline C3 & 0.20435 & 0.62962 & 0.527 \\
\hline C4 & 0.18533 & 0.59627 & 0.38578 \\
\hline C5 & 0.20283 & 0.58034 & 0.23712 \\
\hline C6 & 0.2388 & 0.59761 & 0.2332 \\
\hline N7 & 0.14848 & 0.58002 & 0.38793 \\
\hline C8 & 0.12708 & 0.54717 & 0.36186 \\
\hline C9 & 0.08957 & 0.53358 & 0.3625 \\
\hline
\end{tabular}




\begin{tabular}{|l|l|l|l|}
\hline Atom & $\mathbf{x} / \mathbf{a}$ & $\mathbf{y} / \mathbf{b}$ & $\mathbf{z} / \mathbf{c}$ \\
\hline C10 & 0.07601 & 0.55584 & 0.36352 \\
\hline C11 & 0.04036 & 0.54266 & 0.36288 \\
\hline C12 & 0.01795 & 0.50674 & 0.36232 \\
\hline C13 & 0.0314 & 0.48427 & 0.36162 \\
\hline C14 & 0.06712 & 0.49785 & 0.36091 \\
\hline C15 & 0.02673 & 0.56478 & 0.36259 \\
\hline C16 & 0.00889 & 0.44859 & 0.36167 \\
\hline C17 & 0.29686 & 0.64934 & 0.38513 \\
\hline C18 & 0.31629 & 0.6855 & 0.38525 \\
\hline H19 & 0.25367 & 0.67156 & 0.66601 \\
\hline H20 & 0.19103 & 0.64196 & 0.64373 \\
\hline H21 & 0.18897 & 0.55524 & 0.1089 \\
\hline H22 & 0.25108 & 0.58505 & 0.09773 \\
\hline H23 & 0.1363 & 0.52905 & 0.34963 \\
\hline H24 & 0.09326 & 0.58342 & 0.36381 \\
\hline H25 & 0.0775 & 0.48064 & 0.35998 \\
\hline H26 & 0.04363 & 0.59242 & 0.36286 \\
\hline H27 & 0.01887 & 0.43105 & 0.36121 \\
\hline
\end{tabular}




\begin{tabular}{|l|l|l|l|}
\hline Atom & $\mathbf{x} / \mathbf{a}$ & $\mathbf{y} / \mathbf{b}$ & $\mathbf{z} / \mathbf{c}$ \\
\hline H28 & 0.30315 & 0.70004 & 0.38517 \\
\hline
\end{tabular}

\section{G. MODEL COMPOUNDS}

For obtaining more insights into the anticipated COF layers, we chose model compound structures containing mono-functionalized 4-aminophenyl-diphenyl-1,3,5-benzene (MAPB) and the different linear dialdehydes used in this study, respectively. The reactions of the dialdehyde $(0.1 \mathrm{mmol})$ and the MAPB $(0.3 \mathrm{mmol})$ were conducted under argon in $2.5 \mathrm{~mL}$ of a mixture of $\mathrm{CHCl}_{3}$ and 1,4-dioxane (v:v 4:1). As a reaction vessel, a $6 \mathrm{~mL}$ tube was sealed and placed in an oven at $100{ }^{\circ} \mathrm{C}$ for $16 \mathrm{~h}$ with molecular sieve beads $(4 \mathrm{x}, 2 \mathrm{~mm}, 10 \mathrm{mesh}, 0.3 \mathrm{~nm})$, respectively. The mixture was filtered and washed with anhydrous $\mathrm{EtOH}$ to yield only short-range ordered powders. Finally, $5 \mathrm{mg}$ of each powder was dissolved in anhydrous DMF $(0.5 \mathrm{~mL})$ yielding a saturated mixture. $1.0 \mathrm{~mL}$ of $\mathrm{CHCl}_{3}$ was allowed to enter the mixture through the vapor phase. The resulting single crystals were collected, and their structures determined by single-crystal X-ray diffraction with consideration of co-crystallized solvent molecules. Notably, BDT-OPr MAPB did not result in single crystals that could be investigated. The resulting single crystal data were used to investigate in closer detail the arrangement of the linear part facing two capping groups (single molecule arrangement of the respective model compound). A significant distance of the bulky capping groups is achieved by an opposite arrangement of the imine groups being linked to the linear part. Furthermore, for sulfur-containing linear linkers (BDT, BDT-OMe and BDT-OEt) it is evident that the nitrogen atom of the imine bond is always localized on the same side as the sulfur atoms. 


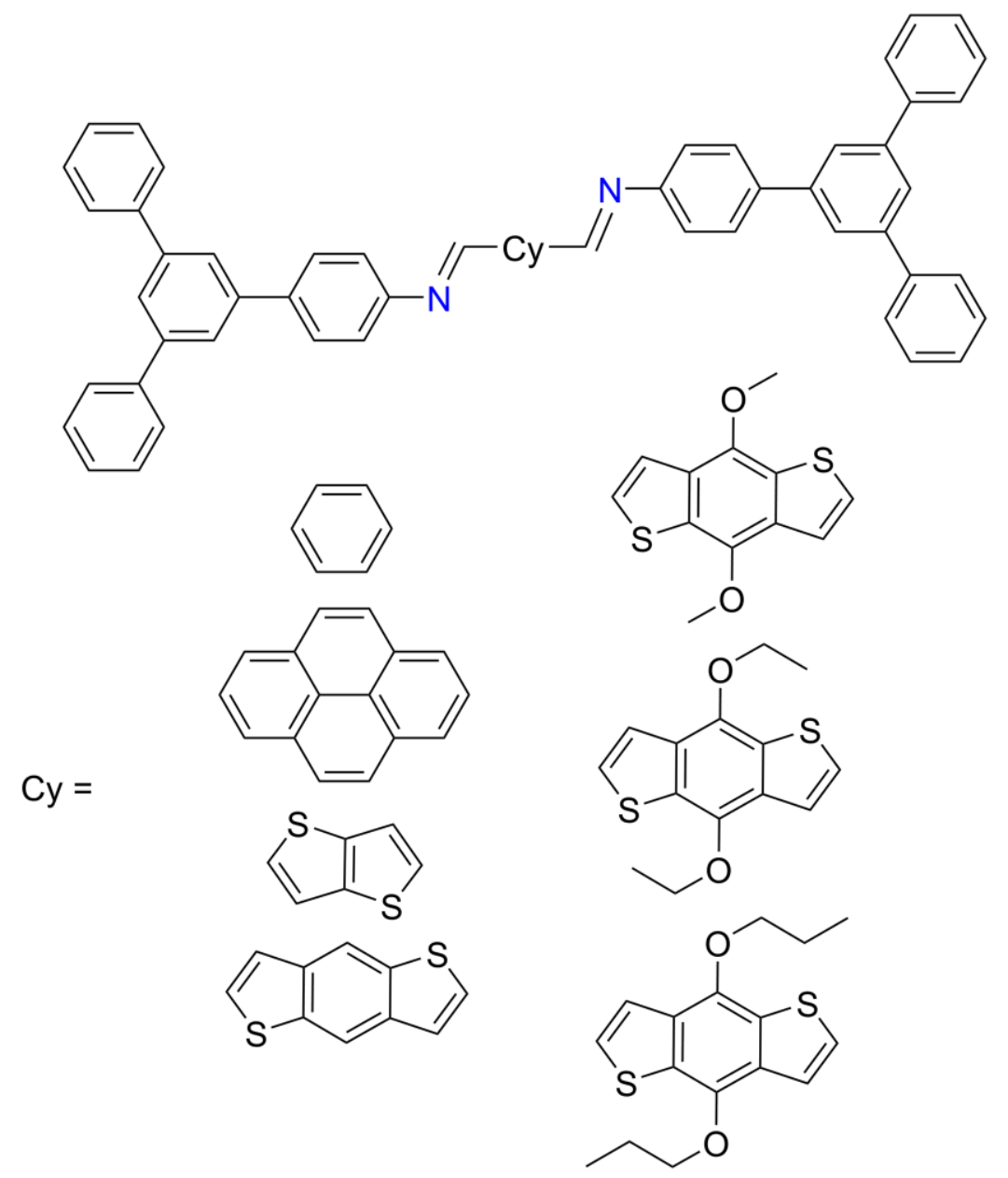

Figure S23. Molecular schemes of model compounds that were synthesized and grown as single crystals.

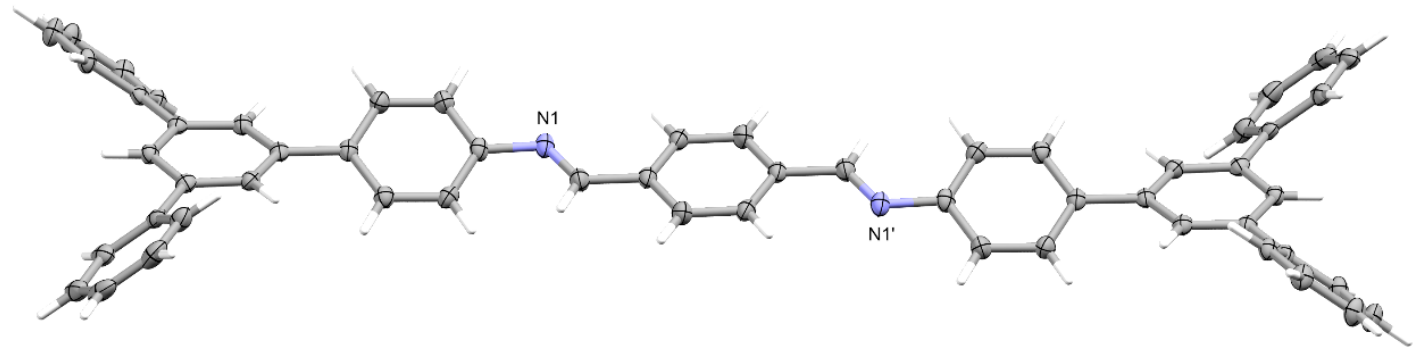

Figure S24. The molecular arrangement of TA MAPB, obtained from single crystal data. 


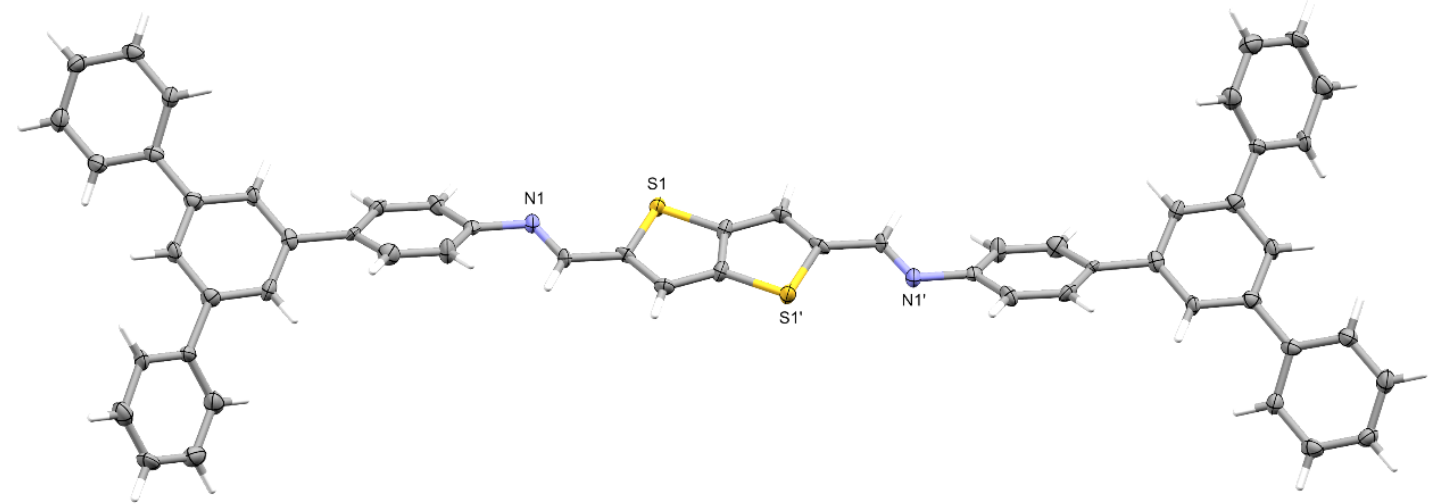

Figure S25. The molecular arrangement of TT MAPB, obtained from single crystal data.

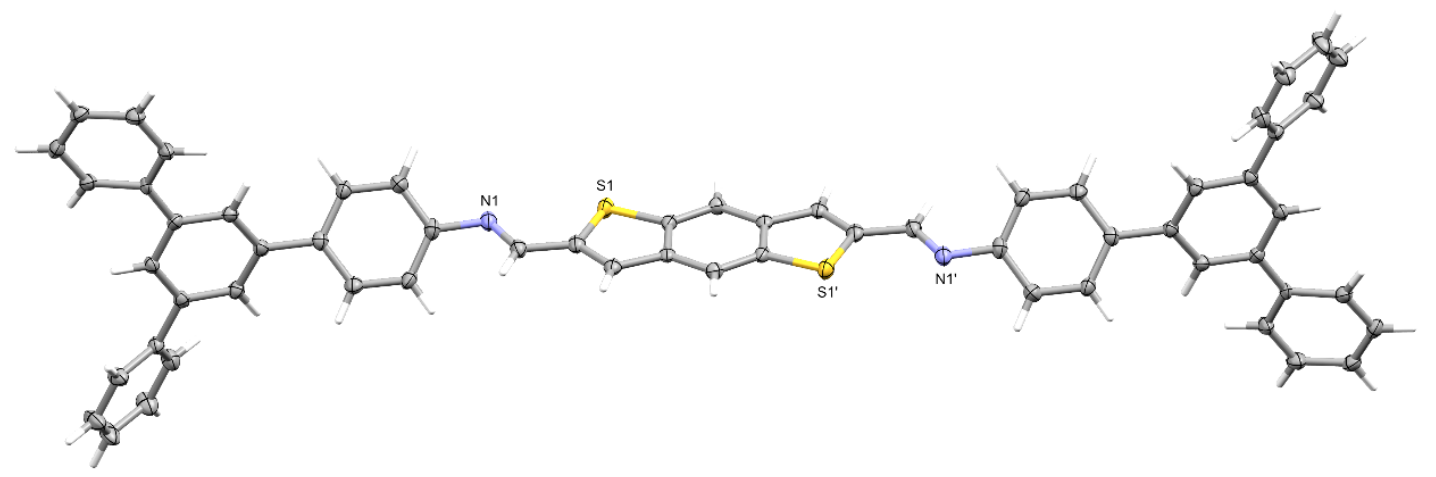

Figure S26. The molecular arrangement of BDT MAPB, obtained from single crystal data.

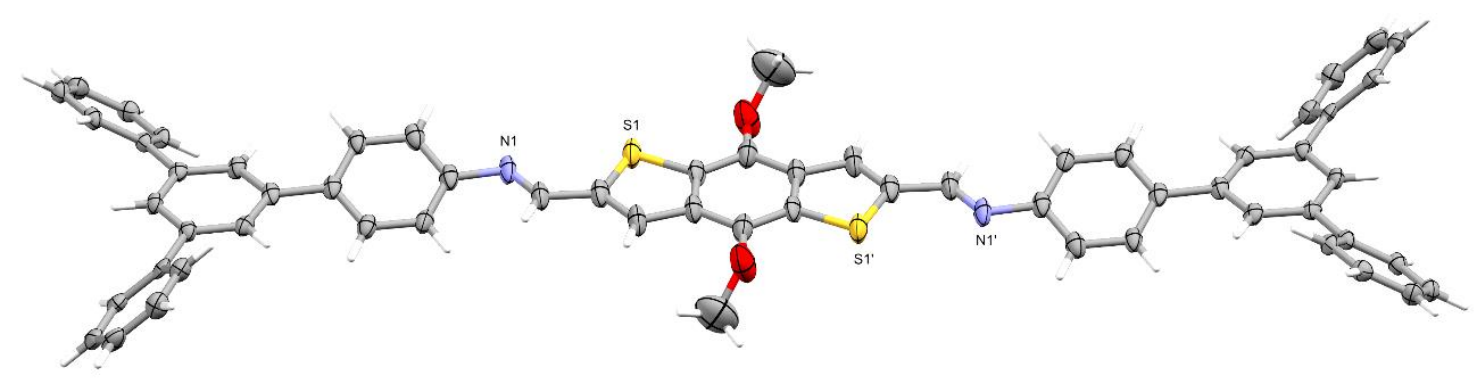

Figure S27. The molecular arrangement of BDT-OMe MAPB, obtained from single crystal data. 


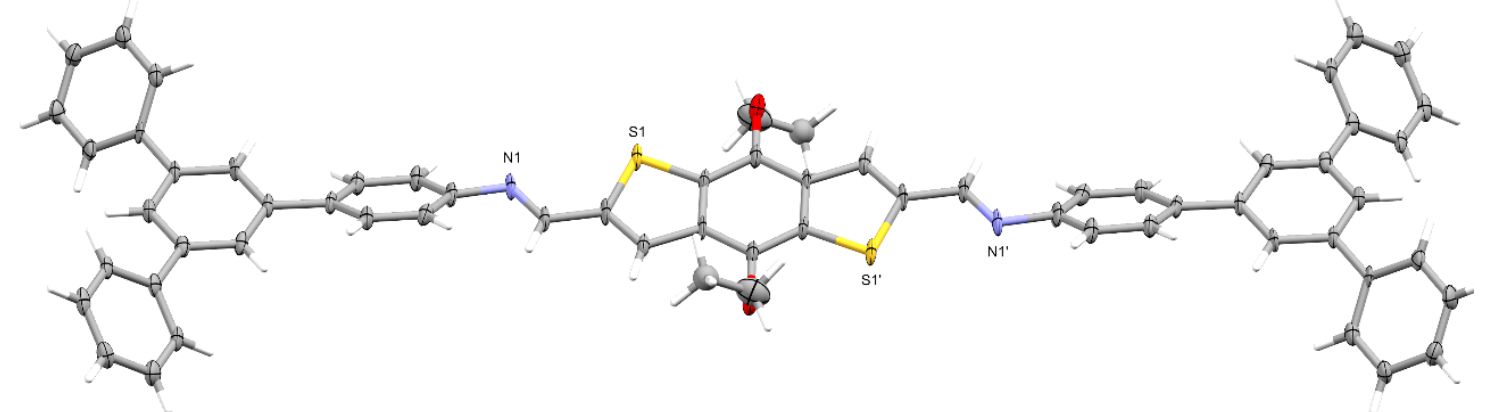

Figure S28. The molecular arrangement of BDT-OEt MAPB, obtained from single crystal data..

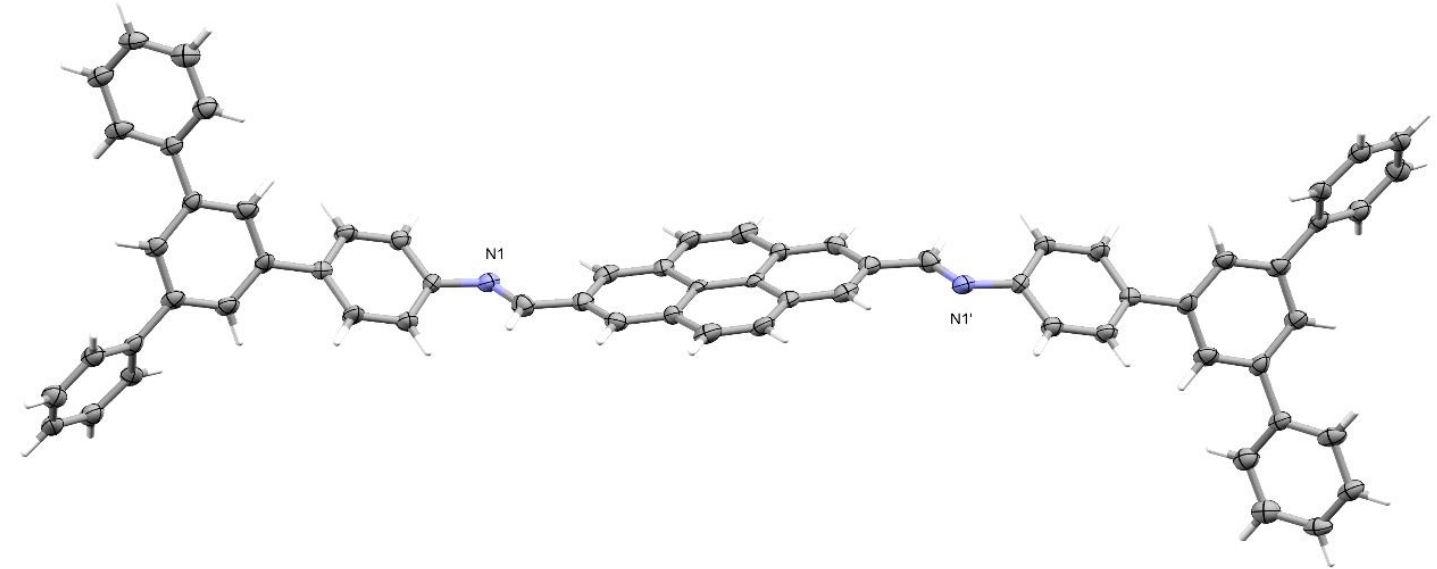

Figure S29. The molecular arrangement of Pyrene-2,7 MAPB, obtained from single crystal data. 
The corresponding parameters are summarized in Table S1.

Table S1: Summary of the single crystal data of the MAPB capped linear dialdehydes.

\begin{tabular}{|c|c|c|c|c|c|c|}
\hline & BDT MAPB & $\begin{array}{l}\text { ВDT-OMe } \\
\text { МАРВ }\end{array}$ & $\begin{array}{l}\text { BDT-OEt } \\
\text { МАРB }\end{array}$ & $\begin{array}{l}\text { Pyrene-2,7 } \\
\text { MAPB }\end{array}$ & TA MAPB & TТ МАРB \\
\hline CCDC \# & 1812440 & 1812441 & 1812442 & 1895731 & 1812444 & 1812443 \\
\hline net formula & $\mathrm{C}_{63} \mathrm{H}_{47} \mathrm{~N}_{3} \mathrm{OS}_{2}$ & $\mathrm{C}_{62} \mathrm{H}_{44} \mathrm{~N}_{2} \mathrm{O}_{2} \mathrm{~S}_{2}$ & $\mathrm{C}_{71} \mathrm{H}_{63} \mathrm{Cl}_{3} \mathrm{~N}_{4} \mathrm{O}_{4} \mathrm{~S}_{2}$ & ${ }_{2} \mathrm{C}_{66} \mathrm{H}_{44} \mathrm{~N}_{2}$ & $\mathrm{C}_{66.50} \mathrm{H}_{52} \mathrm{~N}_{2}$ & $\mathrm{C}_{64} \mathrm{H}_{54} \mathrm{~N}_{2} \mathrm{O}_{4} \mathrm{~S}_{2}$ \\
\hline$M_{\mathrm{r}} / \mathrm{g} \mathrm{mol}^{-1}$ & 926.15 & 913.11 & 1206.72 & 865.03 & 879.10 & 979.21 \\
\hline crystal & $0.10 \times 0.03$ & $\times 0.10 \times 0.03$ & $\times 0.10 \times 0.02>$ & $\times 0.100 \times 0.020$ & $0.10 \times 0.04 \times$ & $\langle 0.10 \times 0.07 \times$ \\
\hline size/mm & 0.02 & 0.03 & 0.01 & $\times 0.010$ & 0.04 & 0.05 \\
\hline $\begin{array}{l}\text { crystal } \\
\text { system }\end{array}$ & triclinic & triclinic & triclinic & monoclinic & triclinic & triclinic \\
\hline space group & $\mathrm{P}-1$ & $\mathrm{P}-1$ & $\mathrm{P}-1$ & P $12{ }_{1} / \mathrm{c} 1$ & $\mathrm{P}-1$ & $\mathrm{P}-1$ \\
\hline$a / \AA ̊$ & $9.4004(4)$ & $10.0992(5)$ & $10.0629(1)$ & $9.2615(9)$ & $9.9620(4)$ & $11.18(2)$ \\
\hline$b / \AA$ & $11.0528(5)$ & $12.3535(6)$ & $12.379(3)$ & $55.194(6)$ & $13.7057(5)$ & $13.88(2)$ \\
\hline$c / \AA$ & $24.8340(10)$ & $25.0363(9)$ & $25.104(5)$ & $9.7156(10)$ & $18.6233(7)$ & $16.93(3)$ \\
\hline $\boldsymbol{\alpha} /{ }^{\circ}$ & $85.538(2)$ & $85.671(2)$ & $86.773(7)$ & 90 & $89.0380(10)$ & $74.23(4)$ \\
\hline$\beta /{ }^{\circ}$ & $84.1100(10)$ & $80.923(2)$ & $81.159(7)$ & $115.710(3)$ & $78.2490(10)$ & $85.68(3)$ \\
\hline$y / 0$ & $65.6660(10)$ & $78.079(2)$ & $78.540(7)$ & 90 & $74.177(2)$ & $87.32(4)$ \\
\hline$V / \AA^{3}$ & 2336.83(17) & $3014.9(2)$ & $3027.3(11)$ & 4474.8(8) & $2393.11(16)$ & 2520.(8) \\
\hline
\end{tabular}




\begin{tabular}{|c|c|c|c|c|c|c|}
\hline & ВDТ МАРВ & $\begin{array}{l}\text { ВDT-OMe } \\
\text { МАРВ }\end{array}$ & $\begin{array}{l}\text { BDT-OEt } \\
\text { MAPB }\end{array}$ & $\begin{array}{l}\text { Pyrene-2,7 } \\
\text { MAPB }\end{array}$ & TA MAPB & ТТ МАРВ \\
\hline$Z$ & 2 & 2 & 2 & 4 & 2 & 2 \\
\hline $\begin{array}{l}\text { calc. } \\
\text { density/g } \\
\mathrm{cm}^{-3}\end{array}$ & 1.316 & 1.006 & 1.324 & 1.284 & 1.220 & 1.291 \\
\hline$\mu / \mathbf{m m}^{-1}$ & 0.163 & 0.127 & 0.275 & 0.074 & 0.070 & 0.159 \\
\hline $\begin{array}{l}\text { refls. } \\
\text { measured }\end{array}$ & 25569 & 10869 & 33091 & 25001 & 24704 & 6655 \\
\hline$R_{\text {int }}$ & 0.0626 & 0.0689 & 0.1117 & 0.1366 & 0.0393 & 0.0000 \\
\hline mean $\sigma(I) / I$ & 0.0710 & 0.1059 & 0.1296 & 0.2140 & 0.0534 & 0.0843 \\
\hline$\theta$ range & $3.136-25.350$ & $3.170-25.349$ & $3.191-25.027$ & $3.139-25.027$ & $3.245-26.372$ & $3.262-26.368$ \\
\hline $\begin{array}{l}\text { observed } \\
\text { refls. }\end{array}$ & 6017 & 6186 & 5985 & 3603 & 7128 & 5248 \\
\hline $\begin{array}{l}x, y \text { (weight. } \\
\text { scheme) }\end{array}$ & $0.0492,1.4248$ & $0.1347,0.0$ & $0.1248,1.7749$ & $\begin{array}{l}0.0158 \\
7.4624\end{array}$ & $\begin{array}{l}0.0776 \\
2.5018\end{array}$ & $0.0072,8.5537$ \\
\hline $\begin{array}{l}\text { refls in } \\
\text { refinement }\end{array}$ & 8521 & 10869 & 10528 & 7266 & 9714 & 6655 \\
\hline parameters & 734 & 615 & 766 & 614 & 639 & 681 \\
\hline restraints & 78 & 0 & 42 & 0 & 87 & 0 \\
\hline$R\left(F_{\text {obs }}\right)$ & 0.0517 & 0.0739 & 0.0843 & 0.1074 & 0.0664 & 0.0777 \\
\hline
\end{tabular}




\begin{tabular}{|c|c|c|c|c|c|c|}
\hline & ВDT MAPB & $\begin{array}{l}\text { BDT-OMe } \\
\text { МАРВ }\end{array}$ & $\begin{array}{l}\text { BDT-OEt } \\
\text { MAPB }\end{array}$ & $\begin{array}{l}\text { Pyrene-2,7 } \\
\text { MAPB }\end{array}$ & ТА МАРВ & TT МАРB \\
\hline $\boldsymbol{R}_{\mathrm{w}}\left(\boldsymbol{F}^{2}\right)$ & 0.1275 & 0.2268 & 0.2439 & 0.2181 & 0.1816 & 0.1678 \\
\hline$S$ & 1.013 & 0.971 & 1.035 & 1.075 & 1.033 & 1.152 \\
\hline shift/errorm & 0.001 & 0.001 & 0.001 & 0.001 & 0.001 & 0.001 \\
\hline $\begin{array}{ll}\max & \text { el. } \\
\operatorname{dens./e} & \AA^{-3}\end{array}$ & 0.502 & 0.413 & 0.805 & 0.260 & 1.028 & 0.426 \\
\hline $\begin{array}{l}\min \\
\operatorname{dens./e} \AA^{-3}\end{array}$ & -0.324 & -0.435 & -0.729 & -0.264 & -0.601 & -0.391 \\
\hline
\end{tabular}




\section{H. FTIR}

For infrared spectroscopy, an ATR-FTIR instrument (attenuated total reflection - Fourier transform infrared spectroscopy) was used.
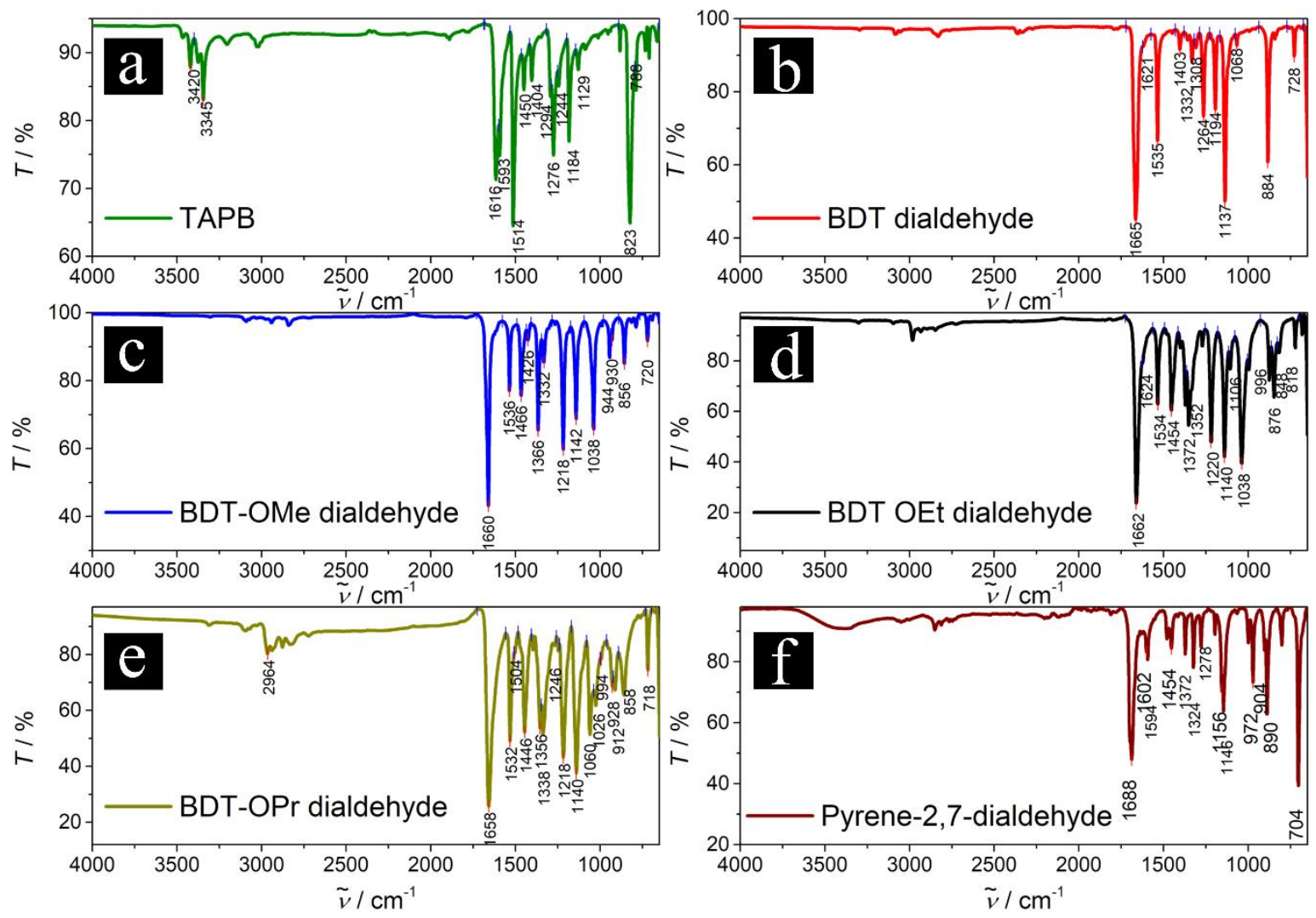

Figure S30. Infrared spectra of TAPB and the synthesized linear monomers used in the COF reactions. a) TAPB, b) BDT dialdehyde, c) BDT-OMe dialdehyde, d) BDT-OEt dialdehyde, e) BDT-OPr dialdehyde, f) pyrene-2,7-dialdehyde. 

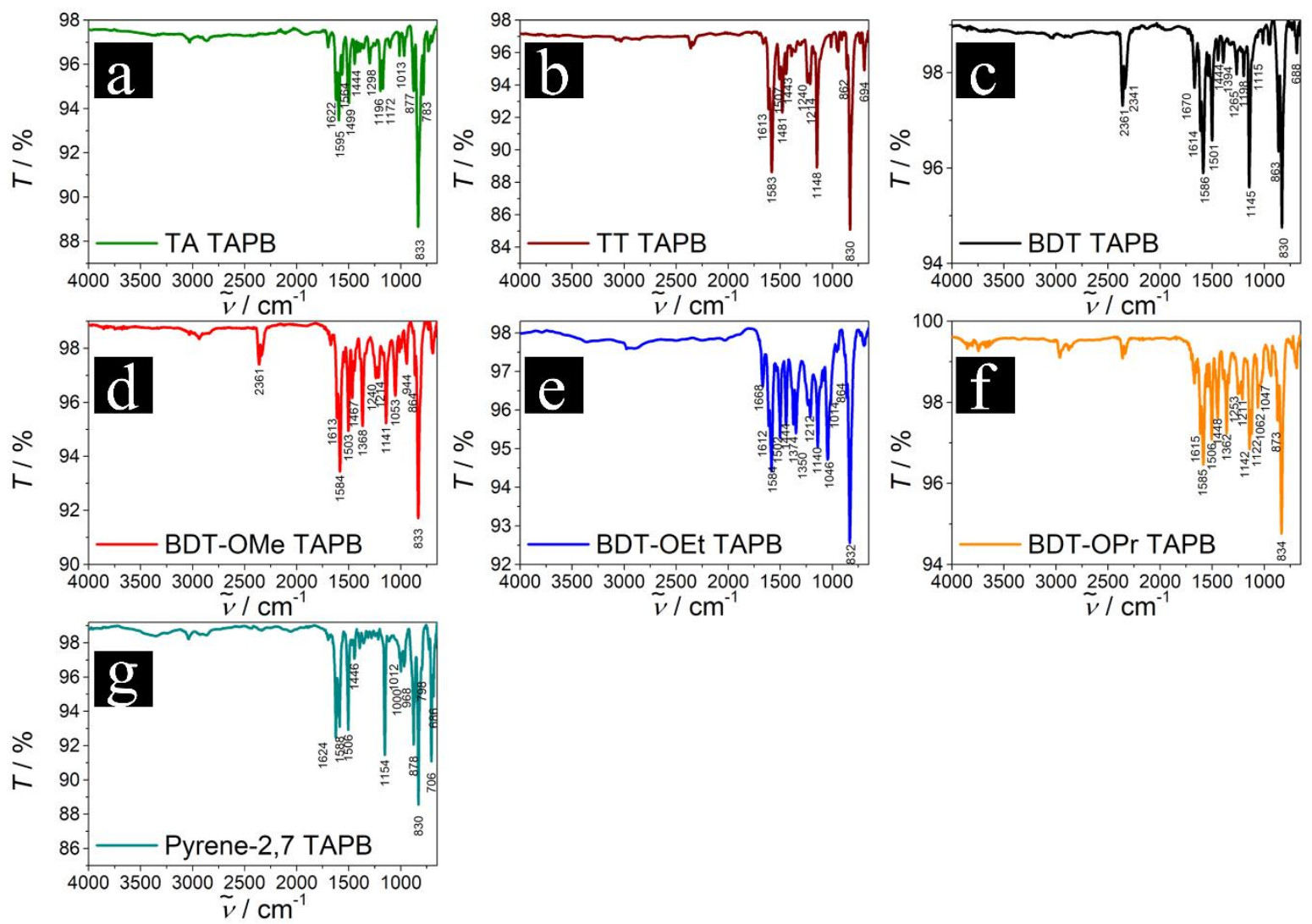
$\stackrel{2}{v} / \mathrm{cm}^{-1}$

Figure S31: Infrared spectra of all synthesized COF structures. a) TA TAPB-COF, b) TT TAPB$\mathrm{COF}, \mathrm{c})$ BDT TAPB-COF, d) BDT-OMe TAPB-COF, e) BDT-OEt TAPB-COF, f) BDT-OPr TAPB-COF, g) Pyrene-2,7 TAPB-COF. 


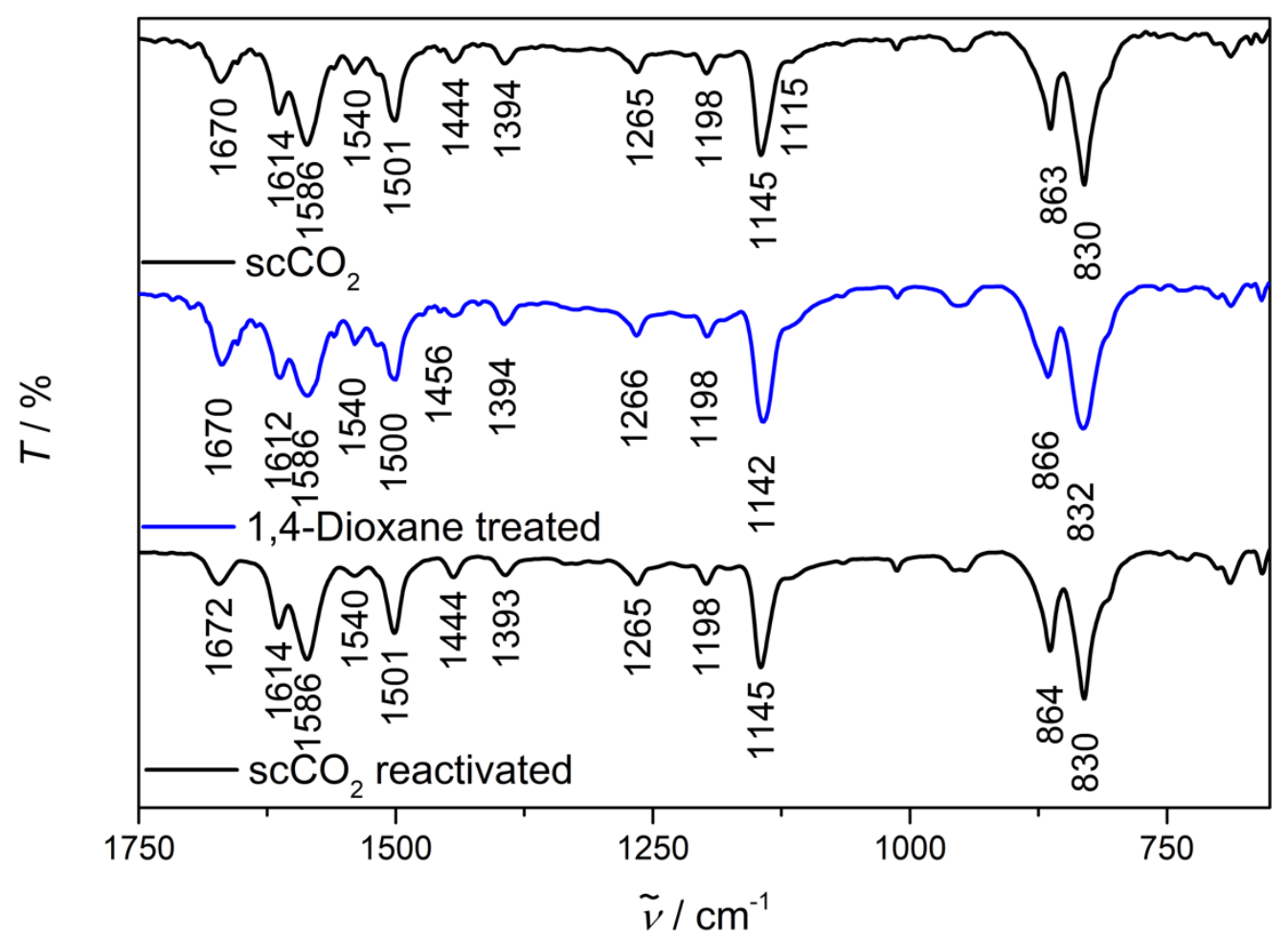

Figure S32. Infrared spectra (selected region) of BDT TAPB-COF, $\mathrm{ScCO}_{2}$ (re-)activated (crystalline, black) and 1,4-dioxane treated (short-range ordered, blue), indicating no chemical decomposition of the framework. 


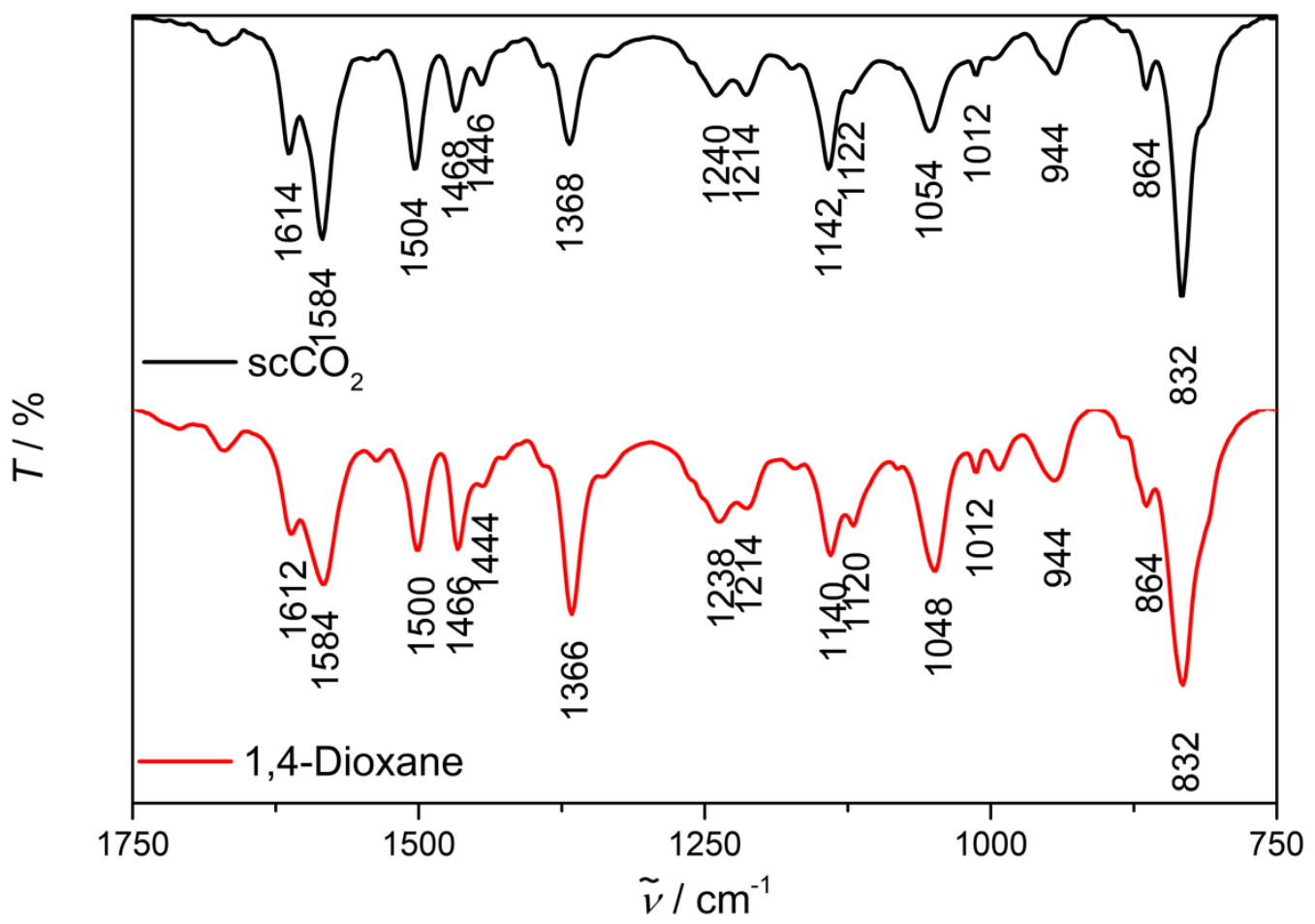

Figure S33. Infrared spectra (selected region) of BDT-OMe TAPB-COFs, $\mathrm{scCO}_{2}$ activated (crystalline, black) and 1,4-dioxane treated (short-range ordered, red).

\section{MORPHOLOGY}

\section{SEM}

The SEM images reveal that the samples consist of mixtures of spherical and rod-like particles that may form large agglomerates (Figure S34 and Figure S35). An exception is the TT TAPB$\mathrm{COF}$, synthesized either in a 1,4-dioxane/mesitylene or an anisole/EtOH mixture, which consists of monodisperse, spherical particles of about $5 \mu \mathrm{m}$ and $2 \mu \mathrm{m}$ in size, respectively. Finally, these particles assemble/condense into superstructures (Figure S34c and Figure S36). 

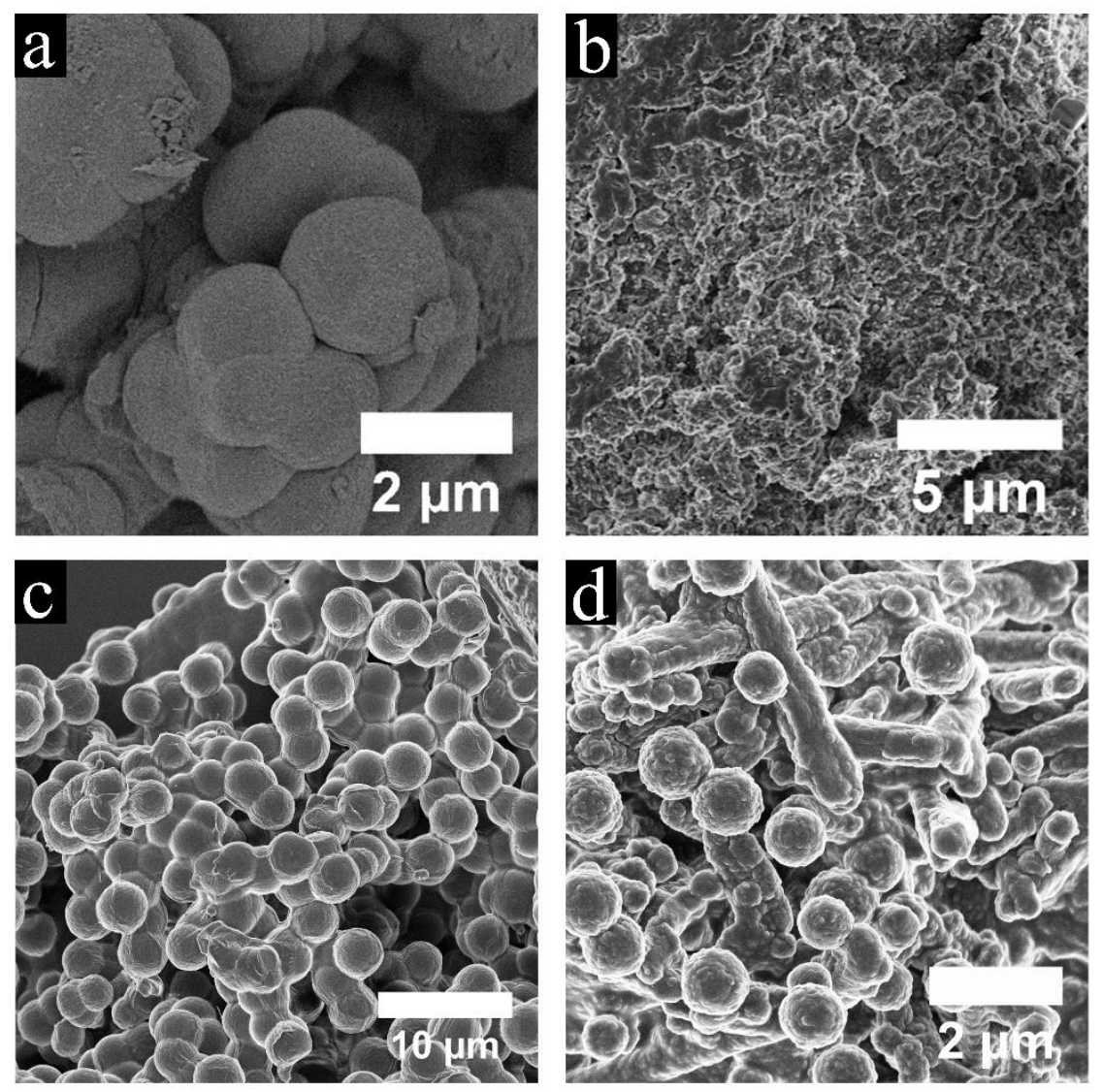

Figure S34. SEM images of $\mathrm{scCO}_{2}$ activated a) TA TAPB-COF, b) Pyrene-2,7 TAPB-COF, c) TT TAPB-COF and d) BDT TAPB-COF. 

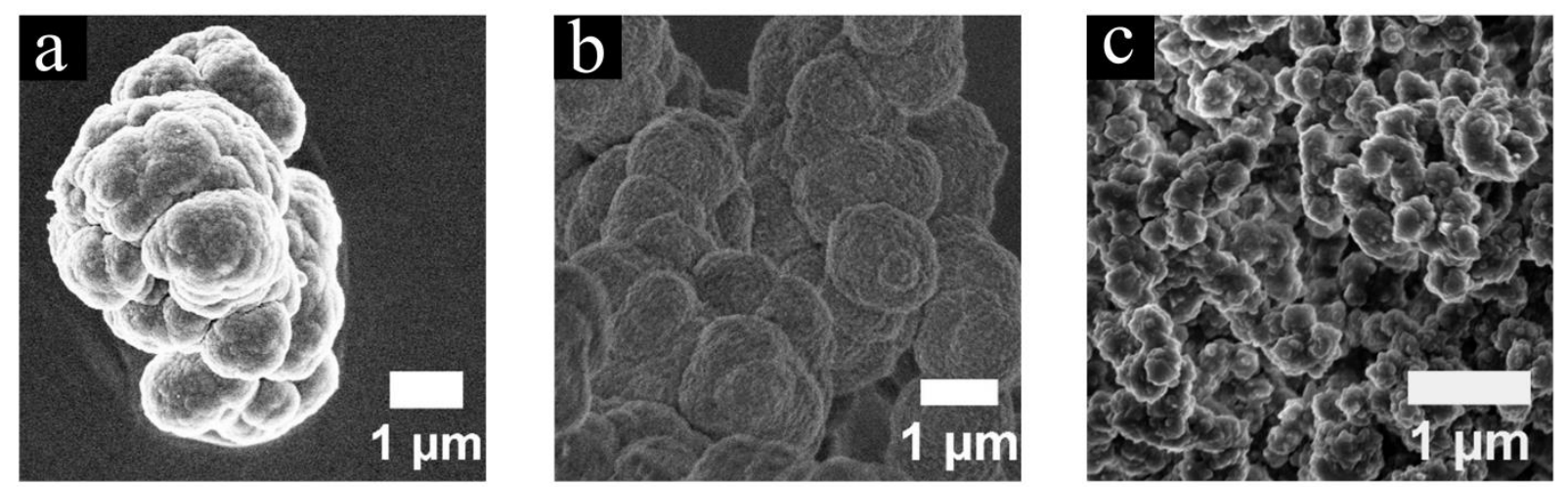

Figure S35. SEM images of a) BDT-OMe TAPB-COF, b) BDT-OEt TAPB-COF and c) BDT-OPr TAPB-COF

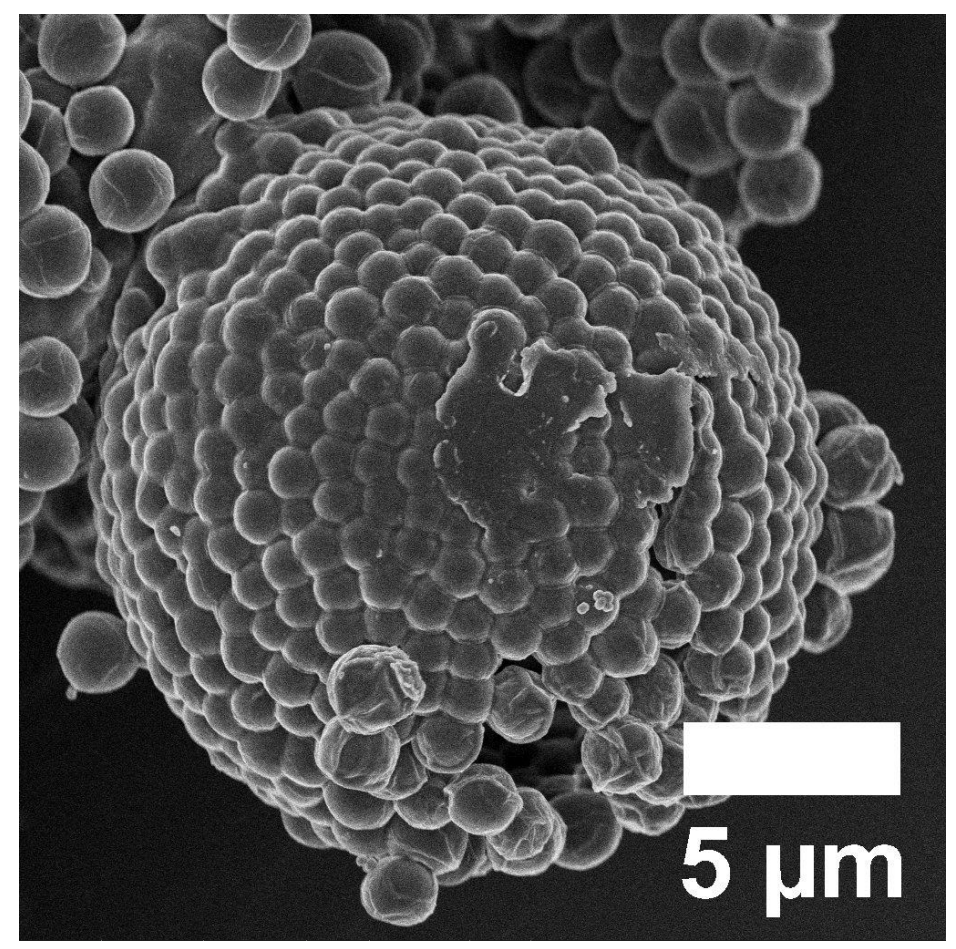

Figure S36. SEM of TT TAPB-COF synthesized with a reaction mixture of anisole/EtOH following a previous report. ${ }^{17}$ The COF particles feature a narrow size distribution around about $2 \mu \mathrm{m}$ in size and undergo self-organization to form spherical superstructures. 


\section{TEM}

The TEM images in Figure S37 reveal highly crystalline TAPB-COFs with domain sizes ranging from about 20 to $200 \mathrm{~nm}$.
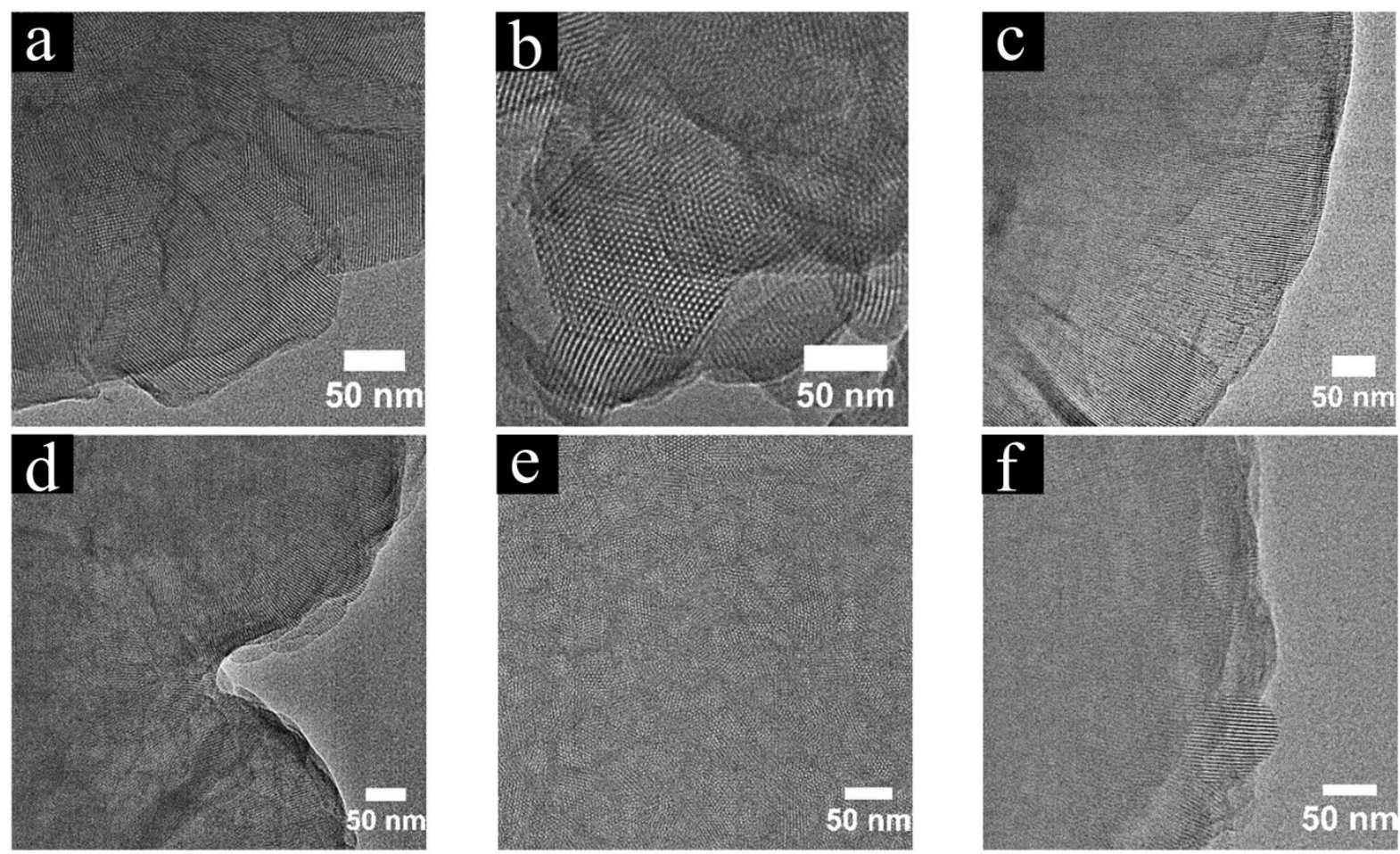

Figure S37. TEM images of $\mathrm{scCO}_{2}$ activated COFs a) TA TAPB, b) Pyrene-2,7 TAPB, c) TT TAPB, d) BDT TAPB, e) BDT-OMe TAPB and f) BDT-OEt TAPB.

Taking images of BDT-OPr TAPB was not possible due to charging and detachment of sample from the grid in the TEM. 

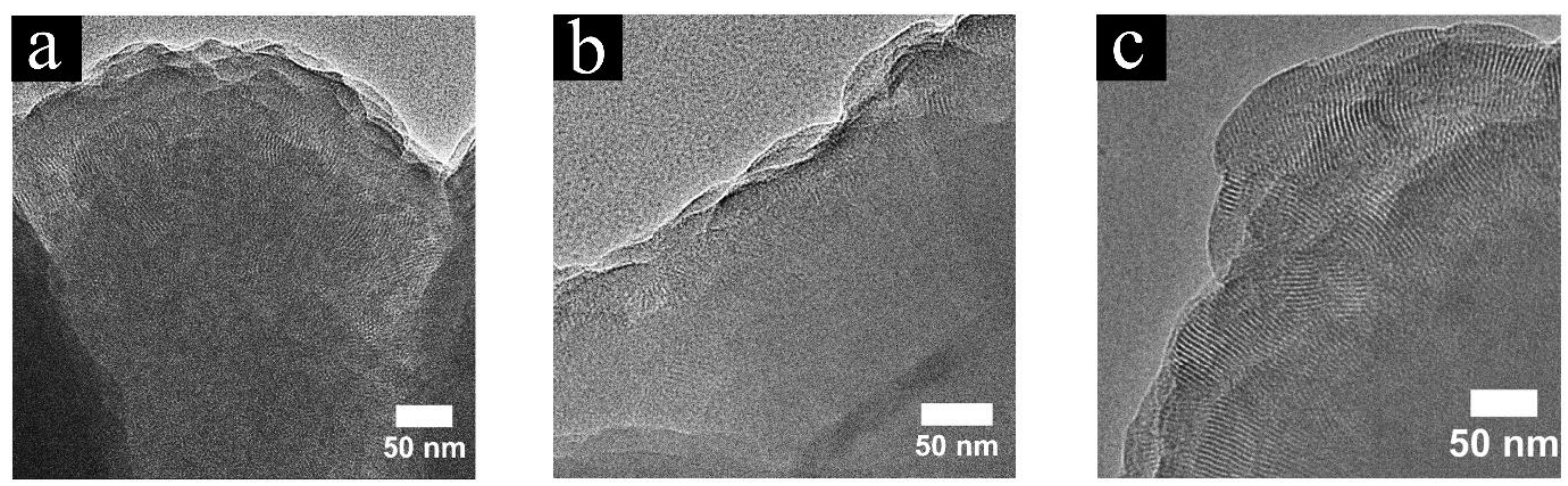

Figure S38. TEM images of BDT TAPB-COF fractions after different work-up treatments, namely vacuum-drying (a), 1,4-dioxane immersion for $24 \mathrm{~h}$ (b), and $\mathrm{scCO}_{2}$ activation (c). While a) and b) only exhibit moderately crystalline and small domain sizes, the $\mathrm{scCO}_{2}$ activated fraction comprises larger domain sizes of up to $100 \mathrm{~nm}$.

\section{GAS SORPTION}

The nitrogen physisorption measurements reveal type IVb isotherms corresponding to mesoporous materials (Figure S39-43). ${ }^{18}$ The pore size distributions show pore sizes between 2.6 and $5.1 \mathrm{~nm}$ (extreme values), depending on the length of the linear linkers. For analyzing the pore size distributions, we used a carbon QSDFT kernel for a cylindrical pore. The resulting pore size distributions show well-defined mesoporosity with a narrow distribution and a small additional micropore feature. The latter might be a result of local structure defects (Figure S39). 
Table S2. BET surface areas, pore volumes and maxima of pore size distributions of the synthesized TAPB-based COFs.

\begin{tabular}{|l|c|c|c|}
\hline TAPB-COF & BET surface are $/ \mathrm{m}^{2} \mathrm{~g}^{-1}$ & Pore volume $/ \mathrm{cm}^{3} \mathrm{~g}^{-1}$ & pore size maxima $/ \mathrm{nm}$ \\
\hline TA & 1070 & 0.8 & 3.3 \\
\hline Pyrene-2,7 & 1210 & 0.81 & 4.0 \\
\hline TT & 1860 & 0.98 & 3.6 \\
\hline BDT & 1530 & 0.85 & 4.1 \\
\hline BDT-OMe & 2080 & 0.98 & 3.9 \\
\hline BDT-OEt & 1580 & 0.93 & 3.8 \\
\hline BDT-OPr & 1290 & 0.87 & 3.7 \\
\hline
\end{tabular}



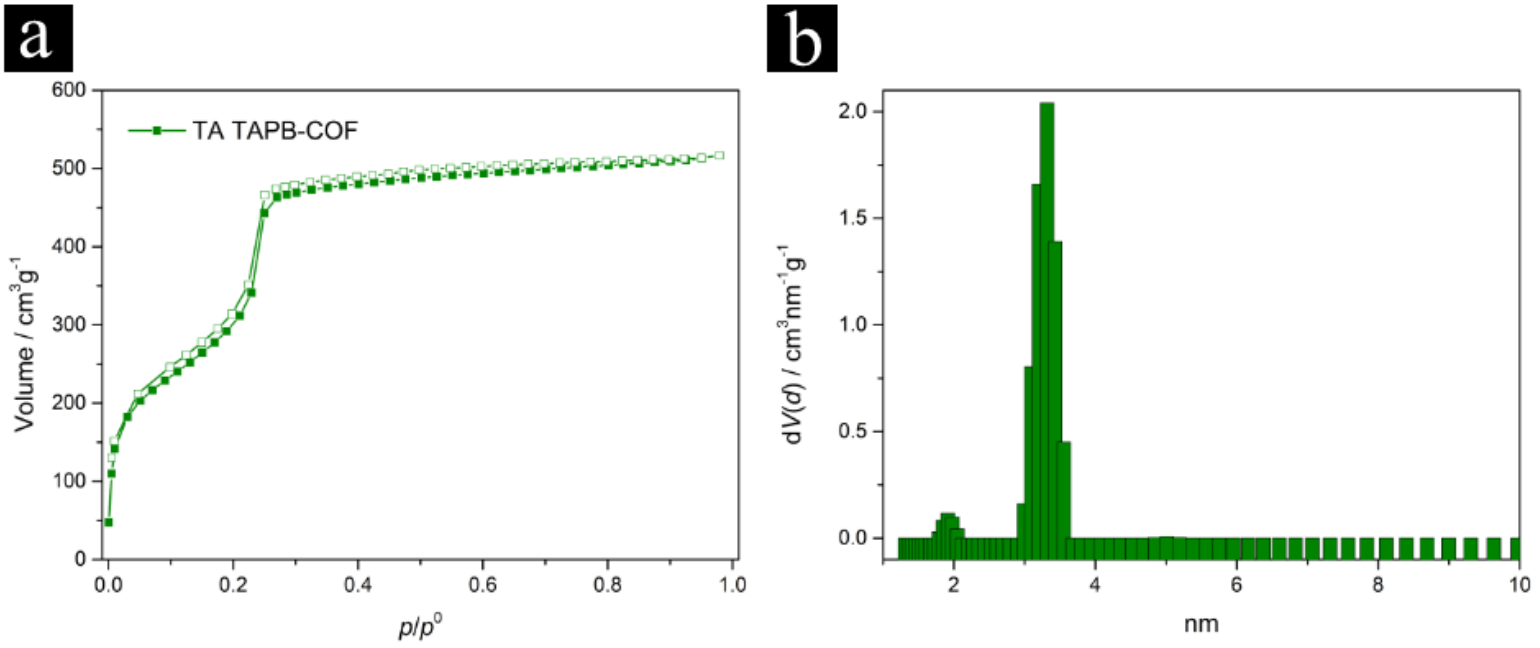

Figure S39. a) Nitrogen physisorption isotherm of $\mathrm{scCO}_{2}$ activated TA TAPB COF. b) Pore size distributions (PSD) of the corresponding nitrogen physisorption isotherm with a QSDFT kernel for carbon results in a narrow mesoporous PSD with a small share of microporosity.
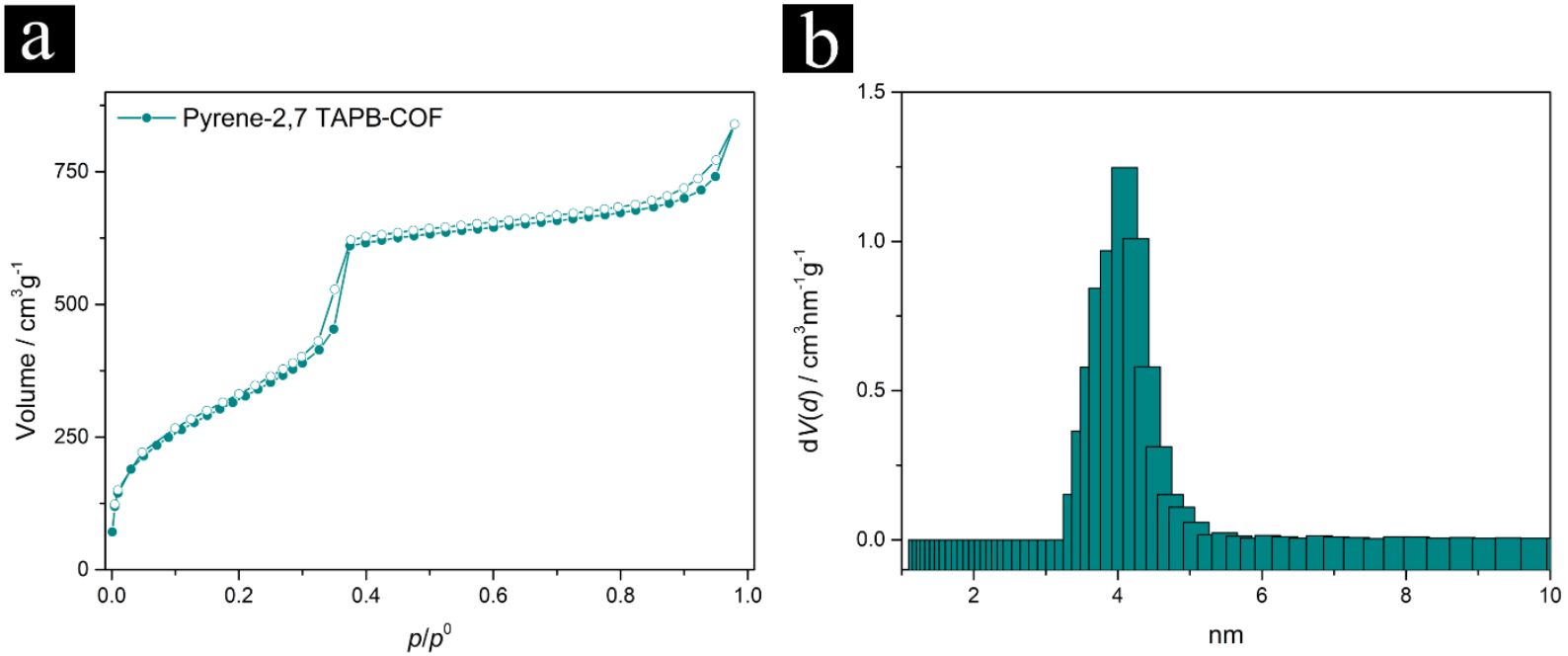

Figure S 40: Nitrogen physisorption isotherm of scCO2 activated Pyrene-2,7 TAPB COF. b) Pore size distributions (PSD) of the corresponding nitrogen physisorption isotherm with a QSDFT, carbon kernel for nitrogen and a hexagonal pore arrangement. 

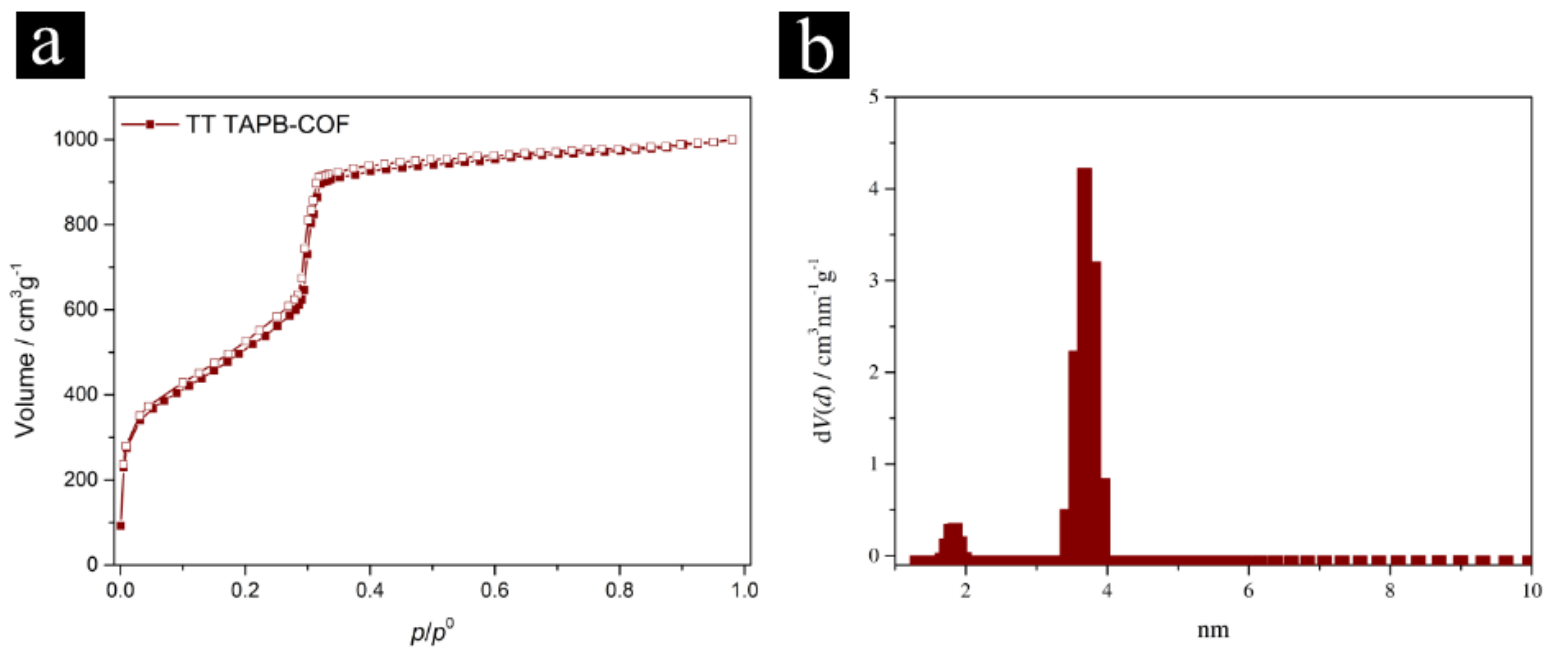

Figure S41: a) Nitrogen physisorption isotherm of $\mathrm{scCO}_{2}$ activated TT TAPB COF. b) Pore size distributions (PSD) of the corresponding nitrogen physisorption isotherm with a QSDFT, carbon kernel for nitrogen and a hexagonal pore arrangement.

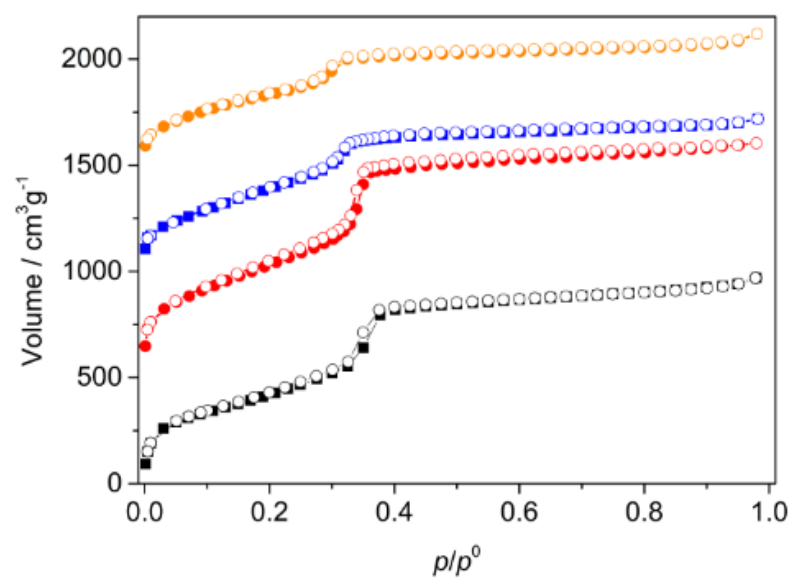

Figure S42: Nitrogen physisorption isotherms of BDT-containing TAPB COFs of different sidechain length. BDT (black), BDT-OMe (red, y+500), BDT-OEt (blue, y+1000) and BDT-OPr (orange, +1500) TAPB COFs. A shift in the steep uptake for $p / p^{0}$ between 0.3 and 0.4 to lower relative pressures is visible and consistent with the increasing lengths of the sidechains reducing the available pore diameter. 


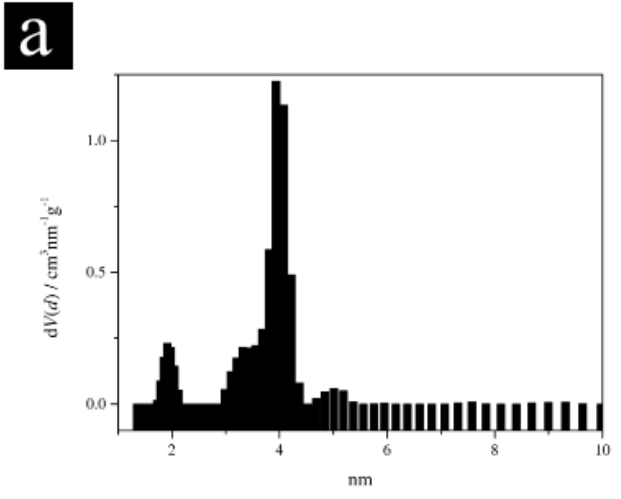

C

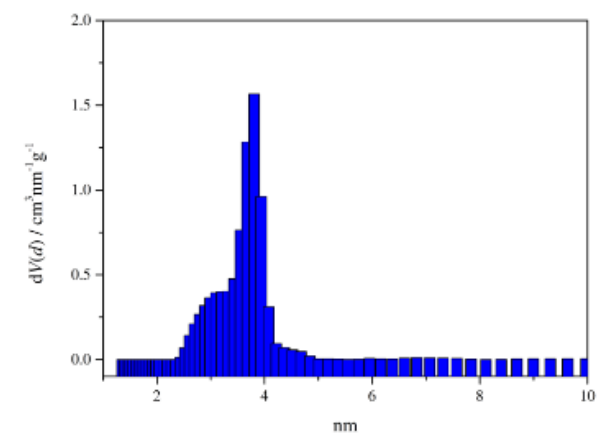

b

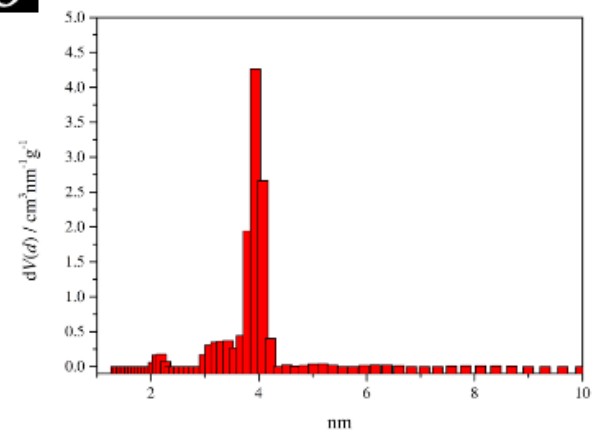

d

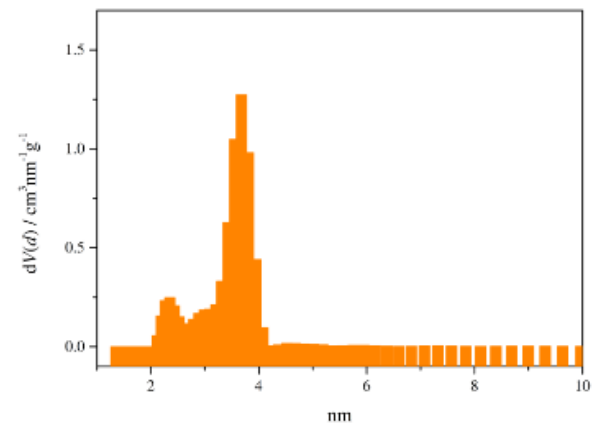

Figure S43: Pore size distributions (PSD) of BDT TAPB-COF (a), BDT-OMe TAPB-COF (b), BDT-OEt TAPB-COF (c) and BDT-OPr TAPB-COF (d) for the corresponding nitrogen physisorption isotherms with a QSDFT carbon kernel for a hexagonal pore arrangement. The main pore size is reduced from BDT TAPB-COF to BDT-OPr TAPB-COF due to the into the pore pointing alkoxy groups of different lengths.

The treatment of TT TAPB-COF with toluene and of BDT TAPB-COF with ethanol resulted, after vacuum-drying, in powders of moderate crystallinity (Figure S7). Nevertheless, the TT TAPBCOF showed moderate porosity (BET surface area $\sim 60 \mathrm{~m}^{2} \mathrm{~g}^{-1}$ ), while the BDT TAPB-COF exhibited reduced porosity of $600 \mathrm{~m}^{2} \mathrm{~g}^{-1}$ (calculated theoretical Connolly surface area of BDT TAPB-COF: $\left.2448 \mathrm{~m}^{2} \mathrm{~g}^{-1}\right)$. 


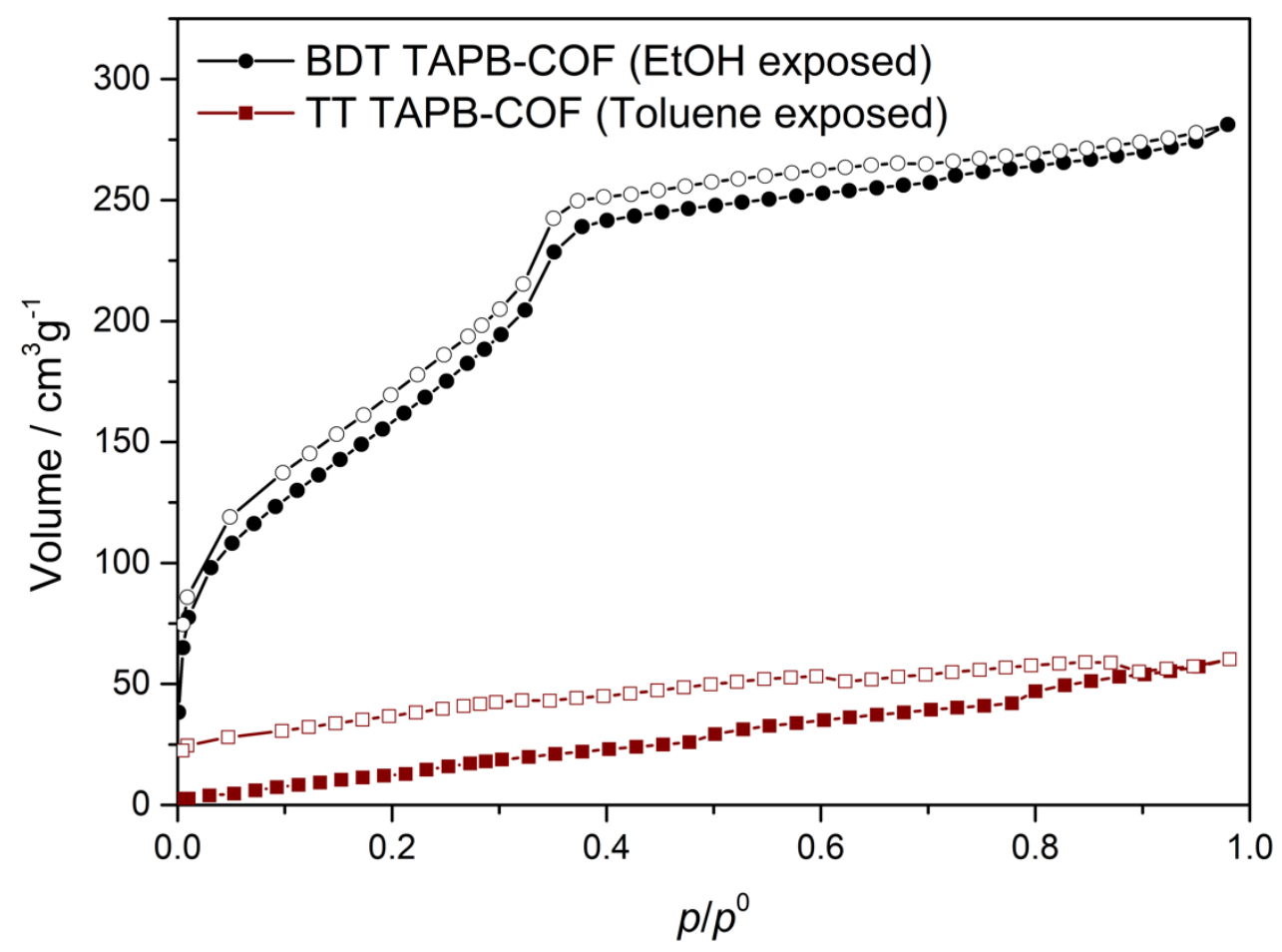

Figure S44: Isotherms of $\mathrm{scCO}_{2}$ activated BDT TAPB-COF and TT TAPB-COF being exposed to EtOH and toluene vapor for $24 \mathrm{~h}$, respectively.

After reactivation by $\mathrm{scCO}_{2}$ the BET surface areas for TT TAPB-COF and BDT TAPB-COF were $1230 \mathrm{~m}^{2} \mathrm{~g}^{-1}$ and $1460 \mathrm{~m}^{2} \mathrm{~g}^{-1}$, respectively.

For all $\mathrm{COFs}$ we were able to regain the desired state of open porosity after $\mathrm{scCO}_{2}$ activation or reactivation. For the fragile $\mathrm{COFs}$, a treatment with toluene resulted in non-porous polymers, while the robust COFs retained their open porosity. All TAPB-COFs lost their structural order upon treatment with 1,4-dioxane. Table S3 gives an overview about the stage of treatment and corresponding BET surface areas of all TAPB-COFs. 
Table S3: Overview of TAPB-based COFs, their treatment and the resulting BET surface areas.

\begin{tabular}{|c|c|c|c|c|}
\hline TAPB-COF Treatment & $\mathrm{scCO}_{2}$ & Toluene & 1,4-Dioxane & $\begin{array}{c}\qquad \mathrm{scCO}_{2} \\
\text { reactivation }\end{array}$ \\
\hline & \multicolumn{4}{|c|}{ BET surface area $/ \mathrm{m}^{2} \mathrm{~g}^{-1}$} \\
\hline TA TAPB-COF & 1070 & Non-porous & Non-porous & 1300 \\
\hline TT TAPB-COF & 1410 & Non-porous & Non-porous & 1340 \\
\hline BDT TAPB-COF & 1120 & Non-porous & Non-porous & 1200 \\
\hline BDT-OMe TAPB-COF & 1440 & 2080 & Non-porous & 1850 \\
\hline BDT-OET TAPB-COF & 1590 & 1860 & Non-porous & 1910 \\
\hline BDT-OPr TAPB-COF & 1660 & 1290 & Non-porous & 1500 \\
\hline Pyrene-2,7 TAPB-COF & 1180 & 1210 & Non-porous & 1280 \\
\hline
\end{tabular}




\section{J. TGA}

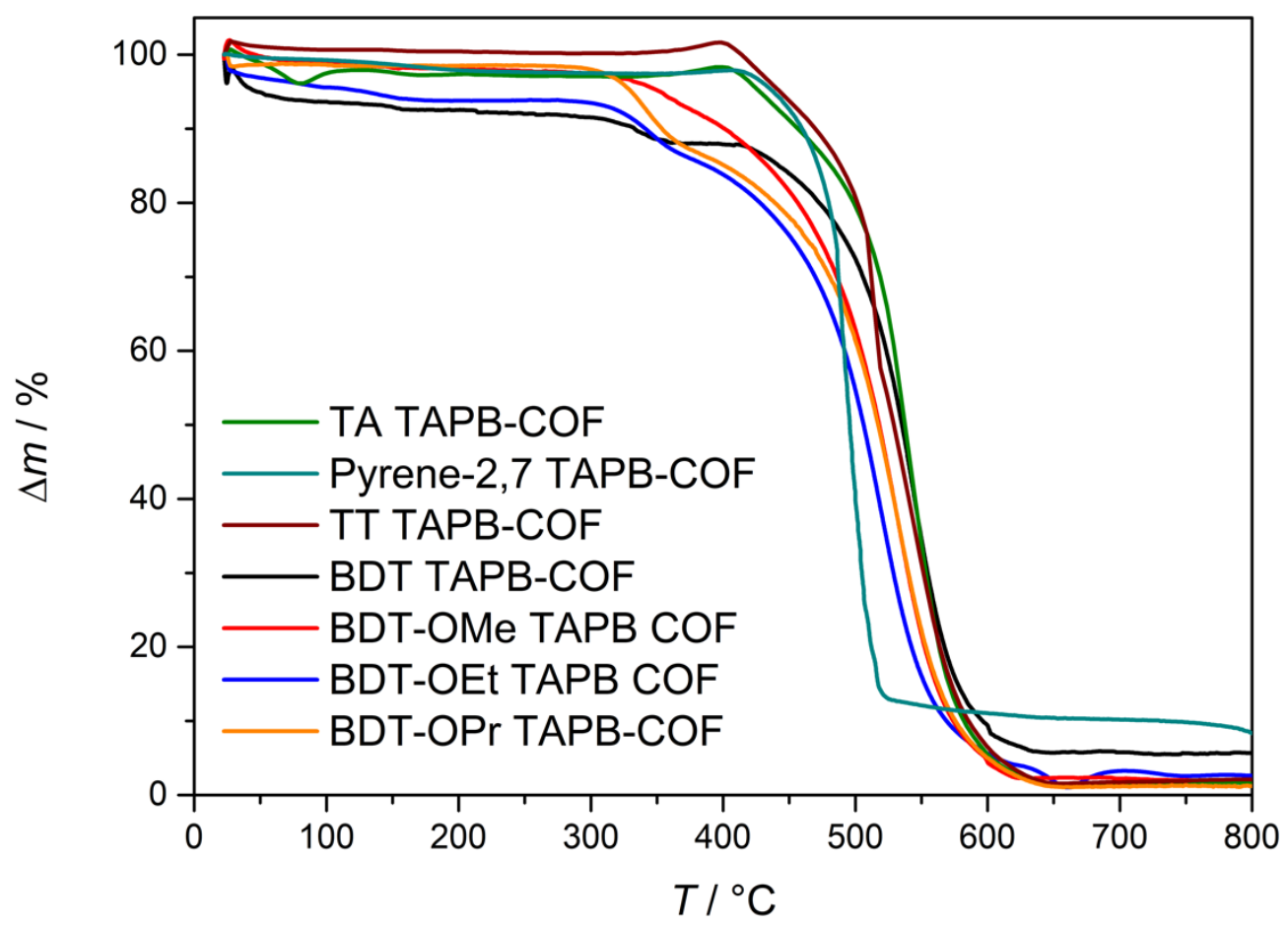

Figure S45: TGA results of $\mathrm{scCO}_{2}$ activated TAPB-COFs. All COFs are stable up to $300{ }^{\circ} \mathrm{C}$ under synthetic air (79.5 vol\% nitrogen, $20.5 \mathrm{vol} \%$ oxygen). Slight variations in combustion behavior can be attributed to the chemical variation in the linear linkers. 


\section{K. UV-VIS SPECTROSCOPY}

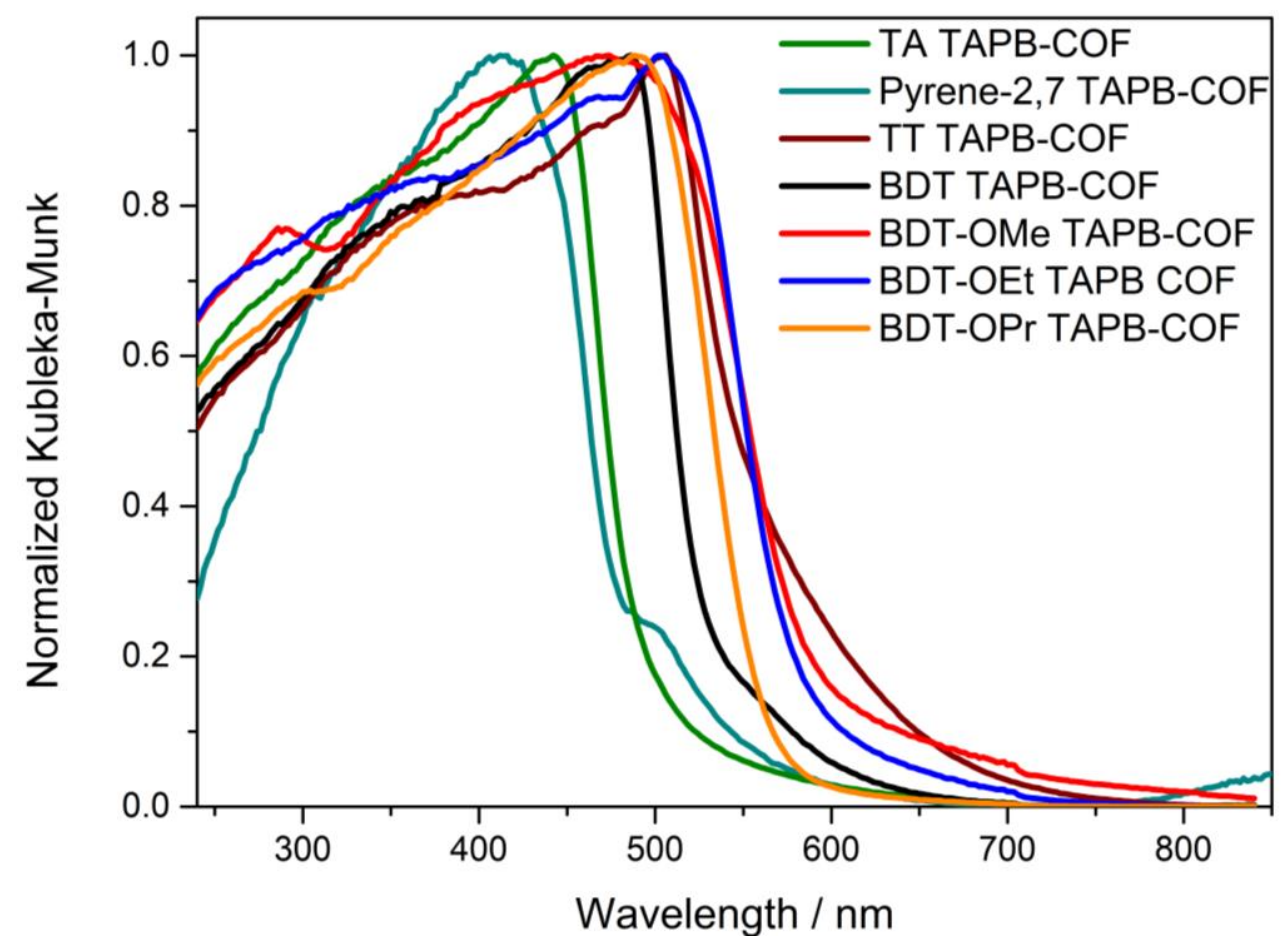

Figure S46: UV-Vis absorption of the $\mathrm{scCO}_{2}$ activated TAPB-COF powders in a normalized Kubelka-Munk plot shows different absorption onsets depending on the linear linker. All COFs have their absorption maximum in the visible range. 


\section{NMR}

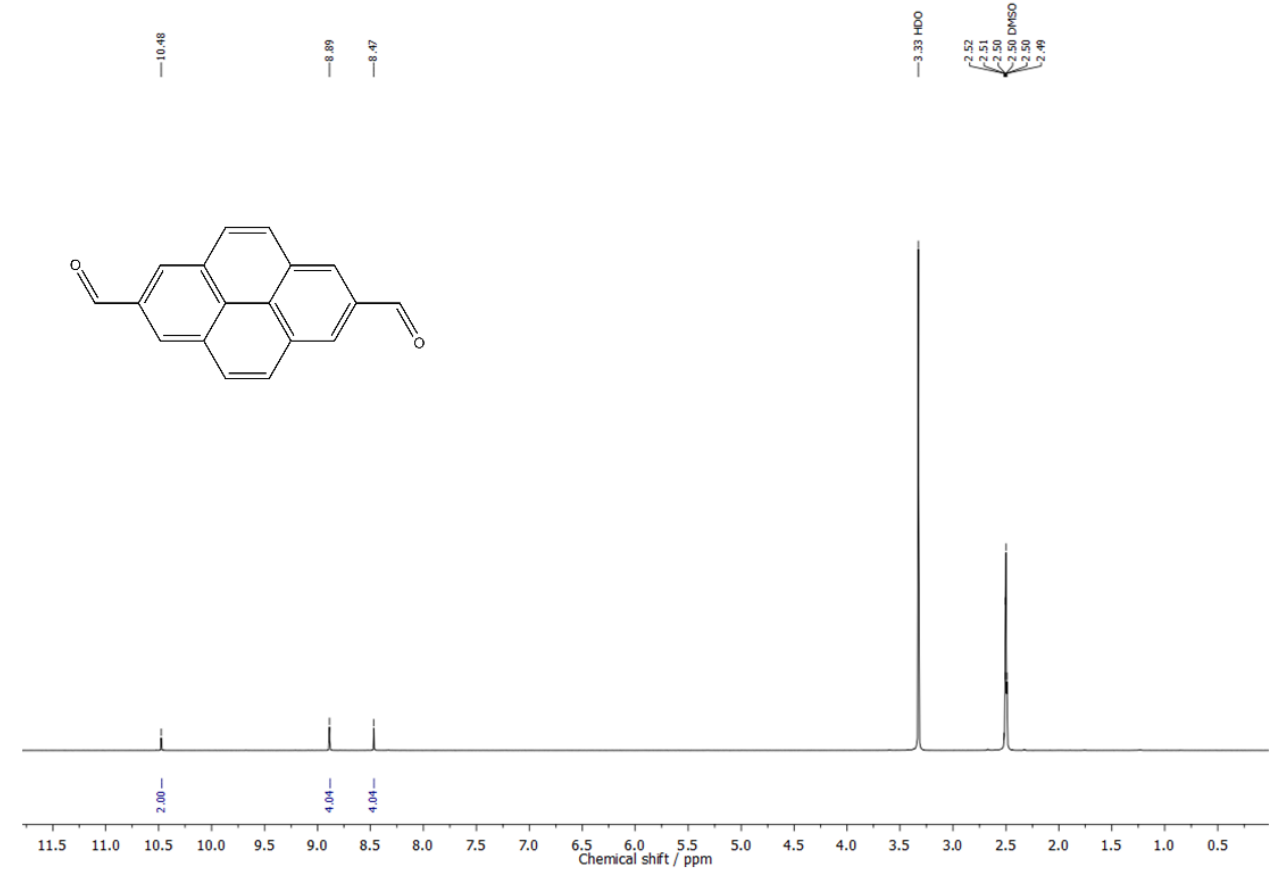

Figure S47: ${ }^{1} \mathrm{H}$ NMR spectrum of pyrene-2,7 dialdehyde in DMSO- $d_{6} . \delta(\mathrm{ppm}): 10.5$ (s, 2H, CHO), $8.9(\mathrm{~s}, 4 \mathrm{H}, \mathrm{CH}), 8.5(\mathrm{~s}, 4 \mathrm{H}, \mathrm{CH})$. 


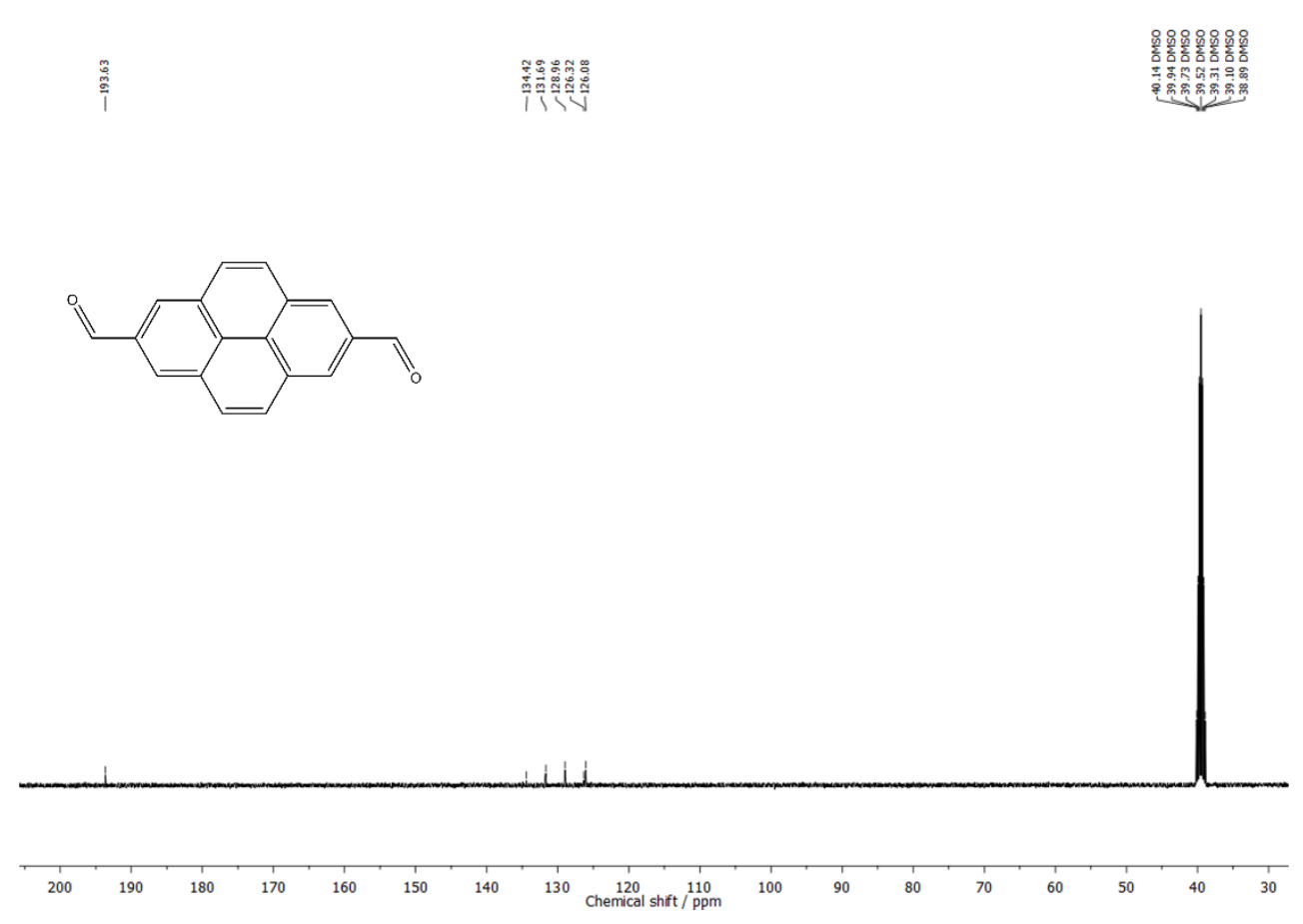

Figure S48: ${ }^{13} \mathrm{C}\left\{{ }^{1} \mathrm{H}\right\}$ NMR spectrum of pyrene-2,7 dialdehyde in DMSO- $d_{6} . \delta(\mathrm{ppm}): 193.6,134.4$, 131.7, 129.0, 126.3, 126.1.

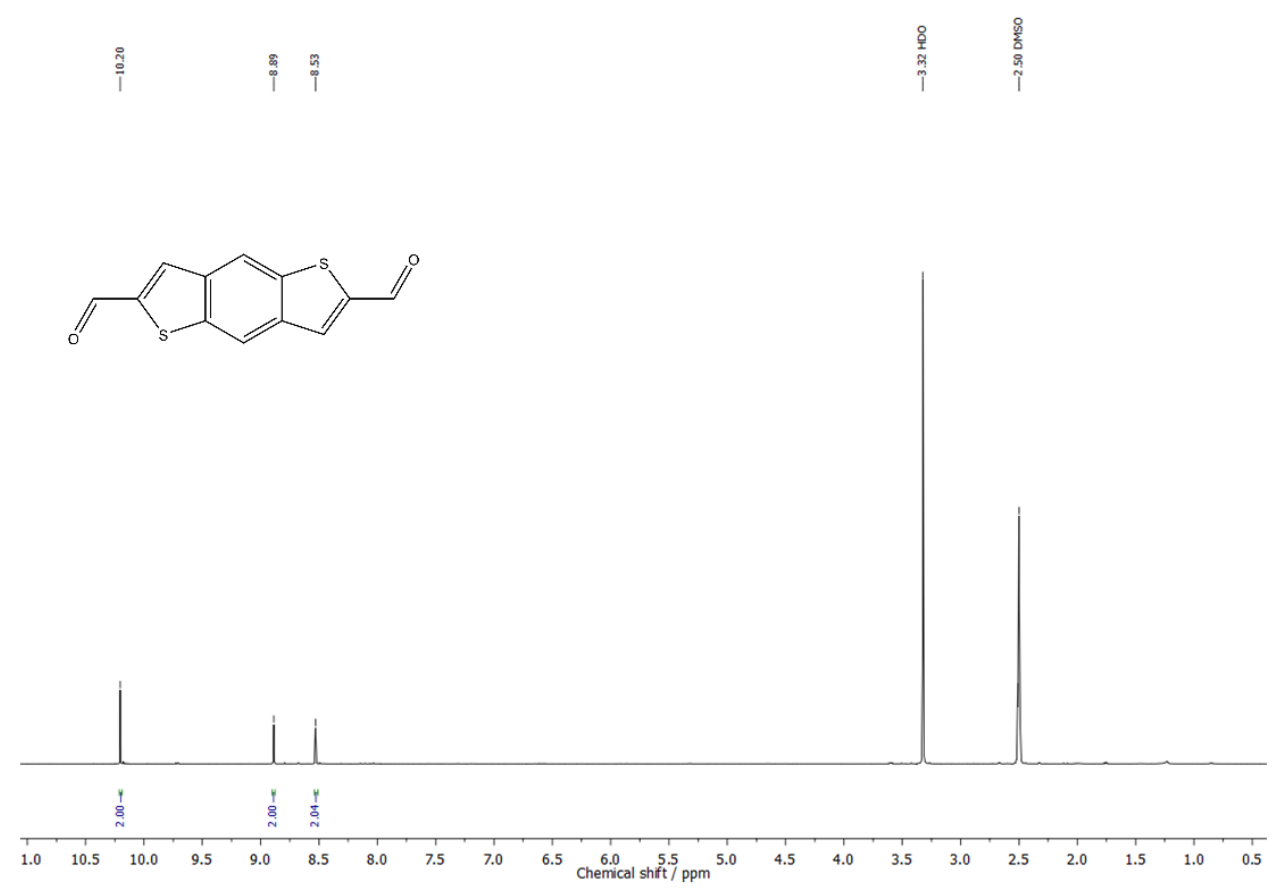

Figure S49: ${ }^{1} \mathrm{H}$ NMR spectrum of BDT dialdehyde in DMSO-d6. $\delta(\mathrm{ppm}): 10.20(\mathrm{~s}, 5.5 \mathrm{~Hz} 2 \mathrm{H}$, $\mathrm{CHO}), 8.89$ (s, 2H, CH), 8.53 (s, 2H, CH). 


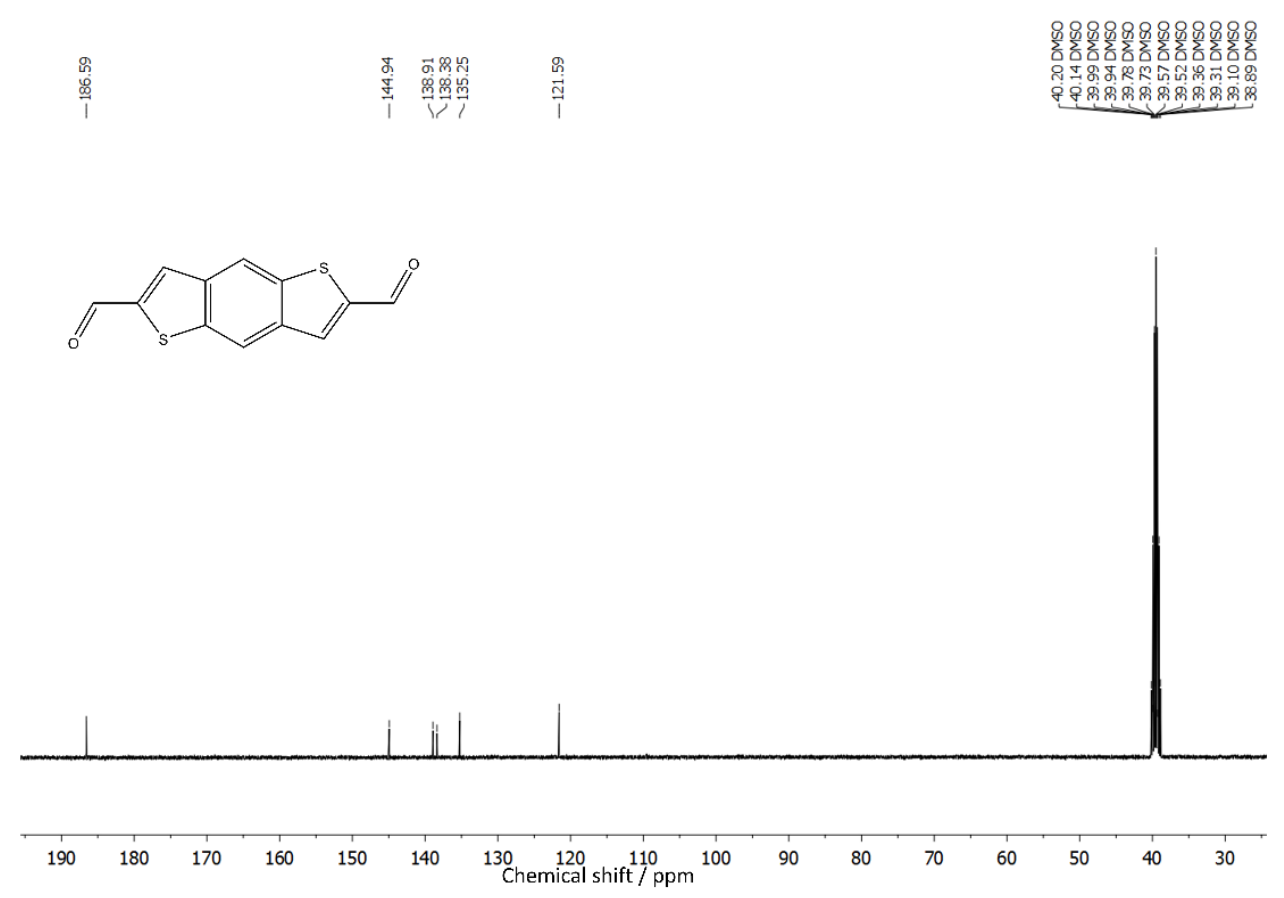

Figure S50: ${ }^{13} \mathrm{C}\left\{{ }^{1} \mathrm{H}\right\}$ NMR spectrum of BDT dialdehyde in DMSO- $d_{6} . \delta(\mathrm{ppm}): 186.6,144.9$, 138.9, 138.4, 135.3, 121.6.

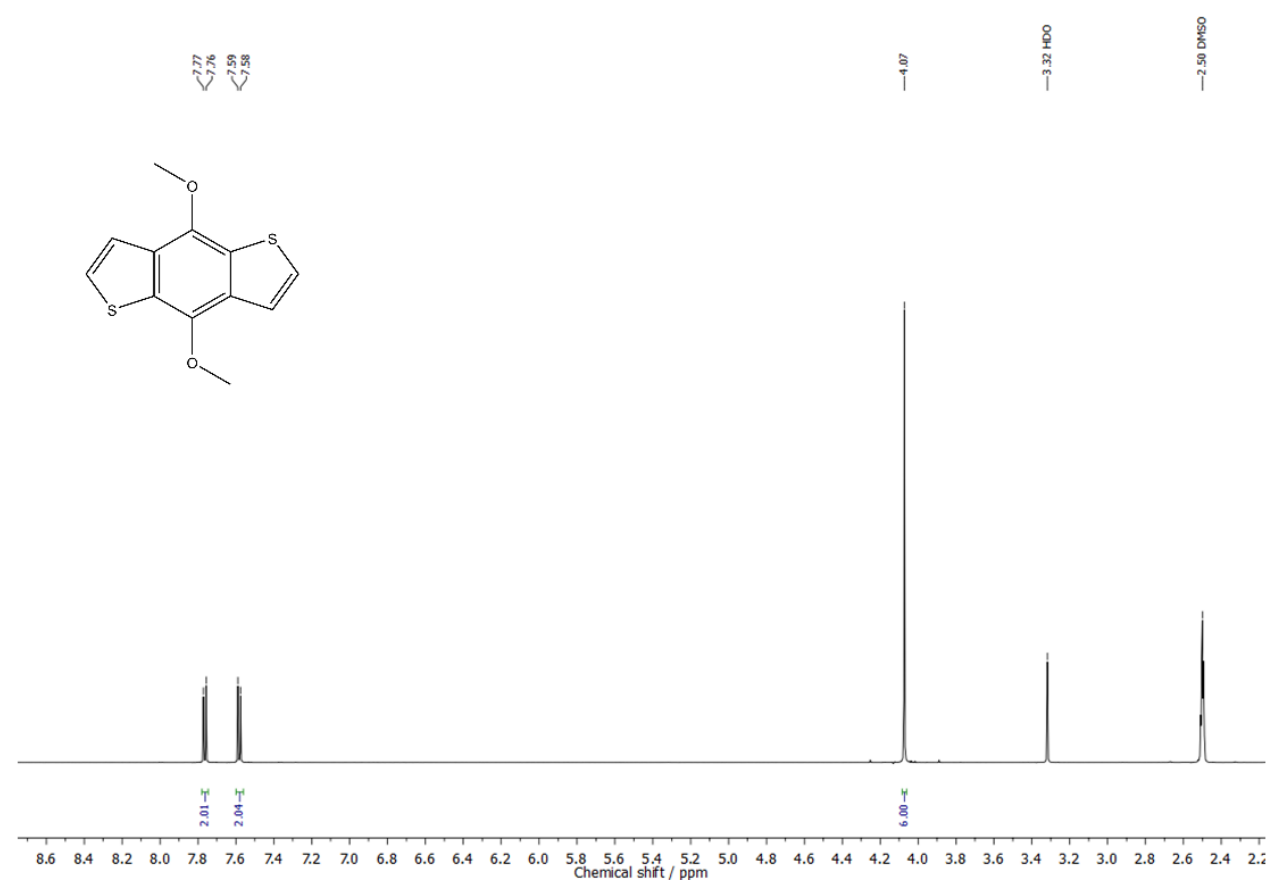

Figure S51: ${ }^{1} \mathrm{H}$ NMR spectrum of BDT-OMe in DMSO- $d_{6} . \delta(\mathrm{ppm}): 7.76(\mathrm{~d}, 5.5 \mathrm{~Hz} 2 \mathrm{H}, \mathrm{SCH})$, $7.58(\mathrm{~d}, 5.5 \mathrm{~Hz} 2 \mathrm{H}, \mathrm{CH}), 4.07$ (s, 6H, $\left.\mathrm{OCH}_{3}\right)$. 


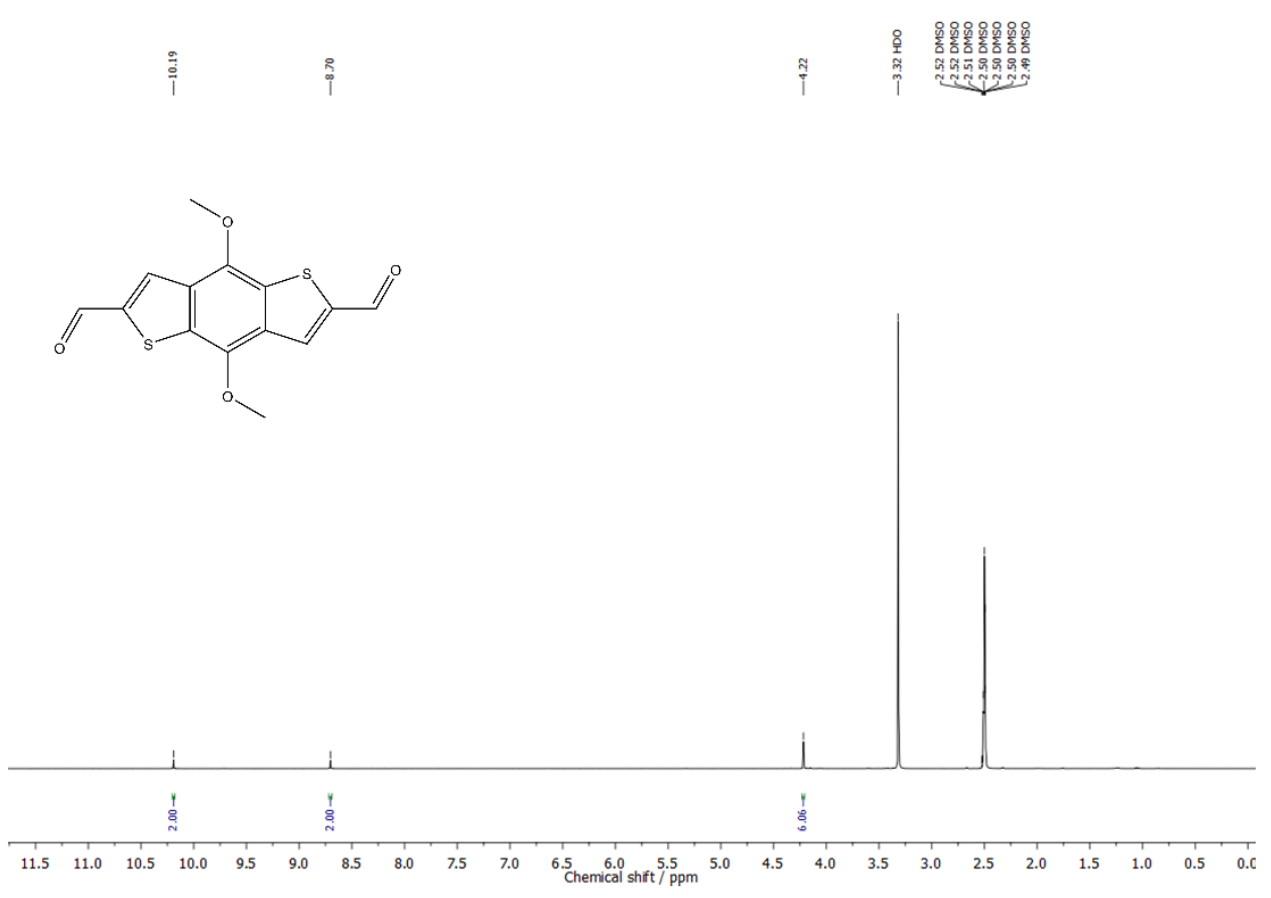

Figure S50: ${ }^{1} \mathrm{H}$ NMR spectrum of BDT-OMe dialdehyde monomer in DMSO- $d_{6} . \delta(\mathrm{ppm}): 10.19$ (s, 2H, CHO), 8.70 (s, 2H, CH), 4.22 (s, 6H, $\mathrm{OCH}_{3}$ ).

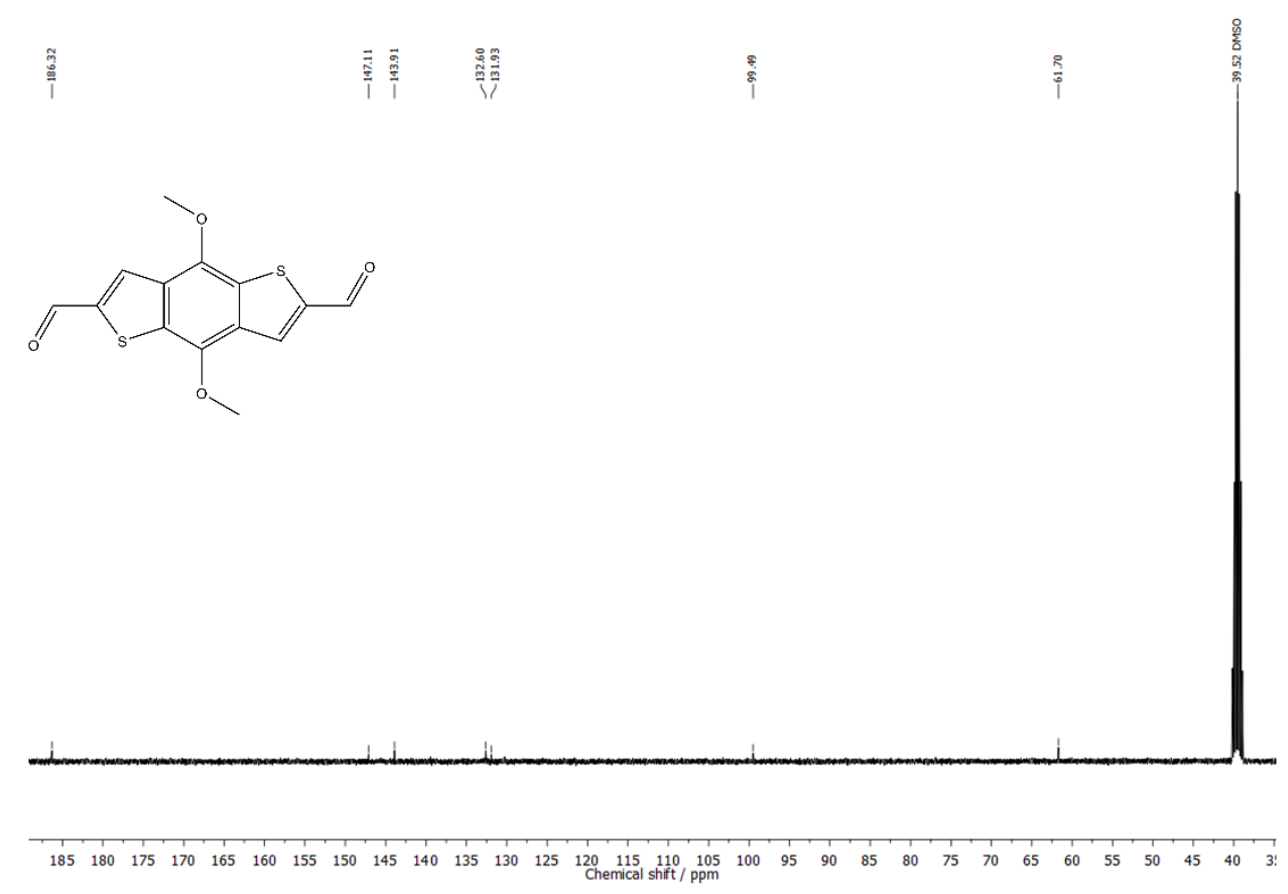

Figure S53: ${ }^{13} \mathrm{C}\left\{{ }^{1} \mathrm{H}\right\}$ NMR spectrum of BDT-OMe dialdehyde monomer in DMSO- $d_{6} . \delta(\mathrm{ppm})$ : 186.3, 147.1, 143.9, 132.6, 131.9, 99.5, 61.7. 


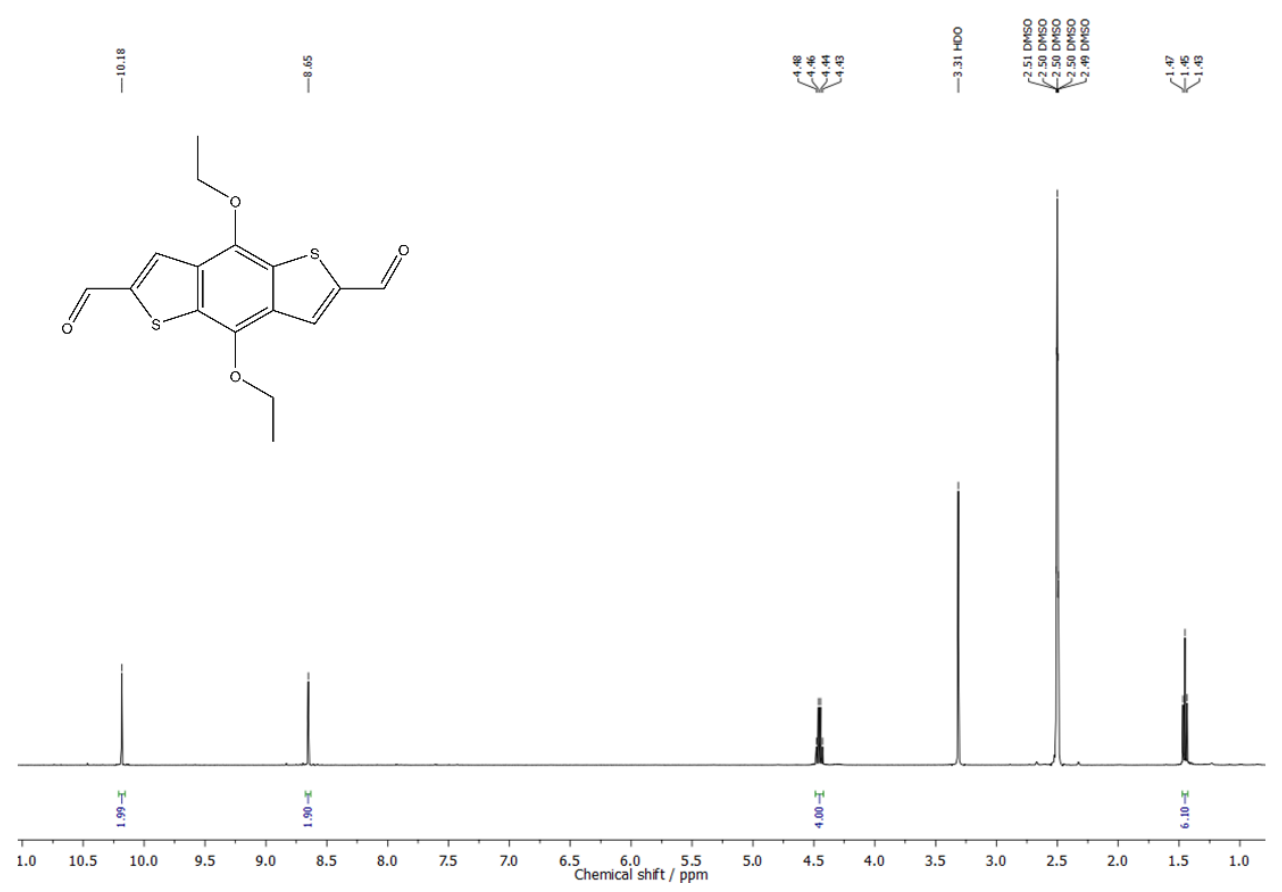

Figure S51: ${ }^{1} \mathrm{H}$ NMR spectrum of BDT-OEt dialdehyde monomer in DMSO- $d_{6} . \delta(\mathrm{ppm})=10.18$ (s, 2H, CHO), 8.65 (s, 2H, CH), 4.45 (q, J = 7.0 Hz, 4H, OCH $), 1.45$ (t, J = 7.0 Hz, 6H, CH $)_{3}$.

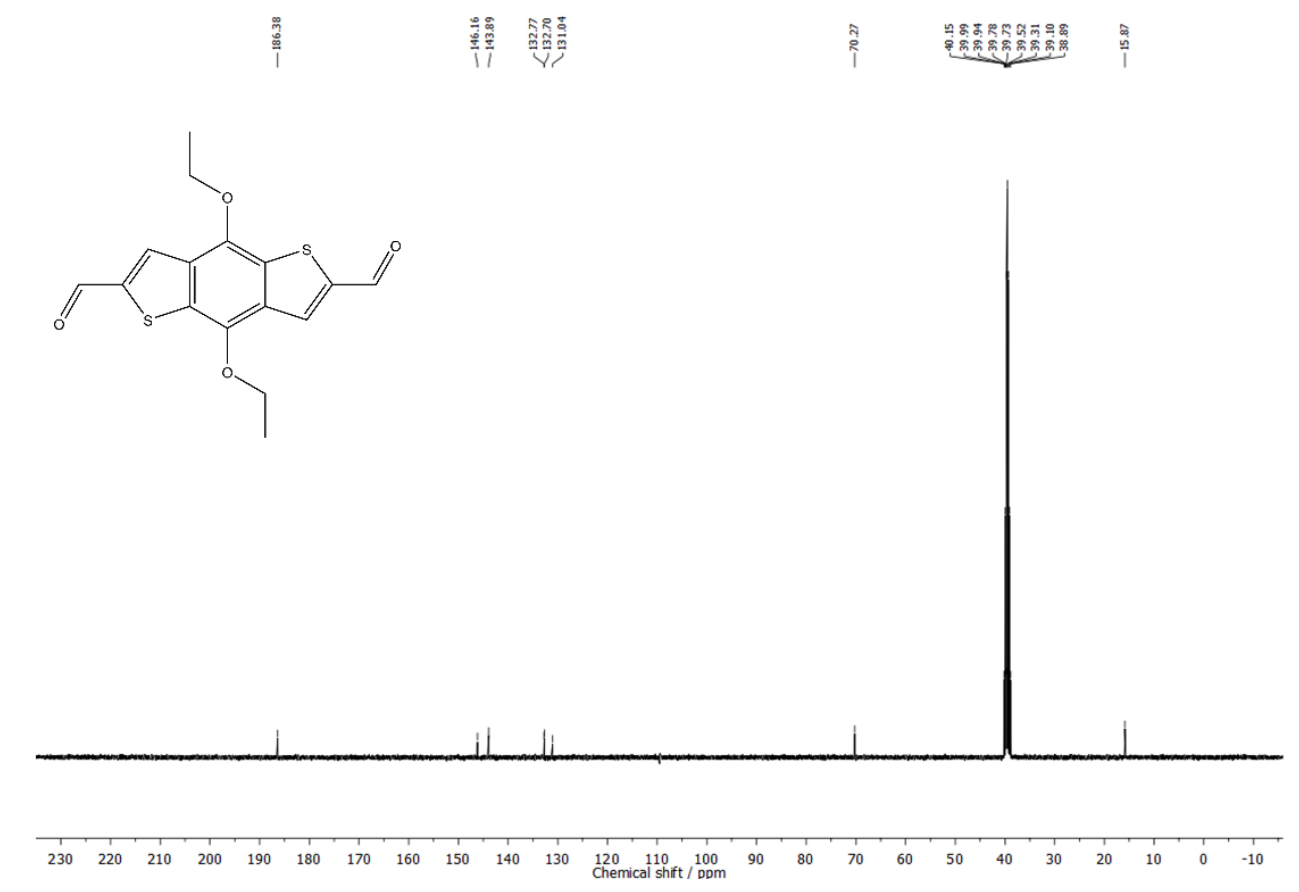

Figure S52: ${ }^{13} \mathrm{C}\left\{{ }^{1} \mathrm{H}\right\}$ NMR spectrum of BDT-OEt dialdehyde monomer in DMSO- $d_{6} . \delta(\mathrm{ppm})$ : $186.4,146.2,143.9,132.8,132.7,131.0,70.3,15.9$. 


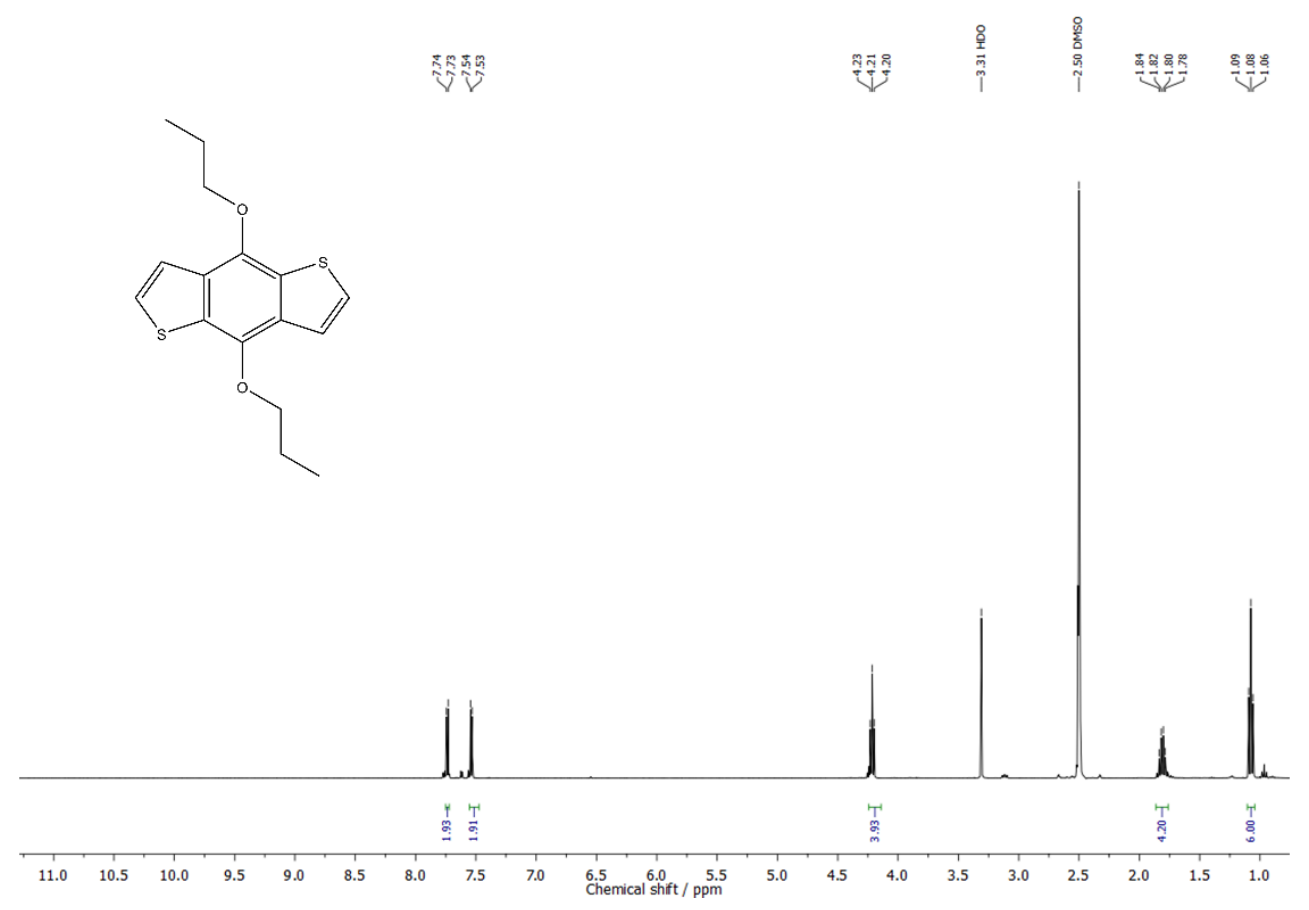

Figure S53: ${ }^{1} \mathrm{H}$ NMR spectrum of BDT-OPr in DMSO- $d_{6} . \delta(\mathrm{ppm}): 7.74(\mathrm{~d}, \mathrm{~J}=5.5 \mathrm{~Hz}, 2 \mathrm{H}, \mathrm{SCH})$, $7.54(\mathrm{~d}, \mathrm{~J}=5.5 \mathrm{~Hz}, 2 \mathrm{H}, \mathrm{CH}), 4.21\left(\mathrm{t}, \mathrm{J}=6.4 \mathrm{~Hz}, 4 \mathrm{H}, \mathrm{OCH}_{2}\right), 1.86-1.78\left(\mathrm{~m}, 4 \mathrm{H}, \mathrm{CH}_{2}\right), 1.08(\mathrm{t}$, $\left.7.4 \mathrm{~Hz}, 6 \mathrm{H}, \mathrm{CH}_{3}\right)$. 


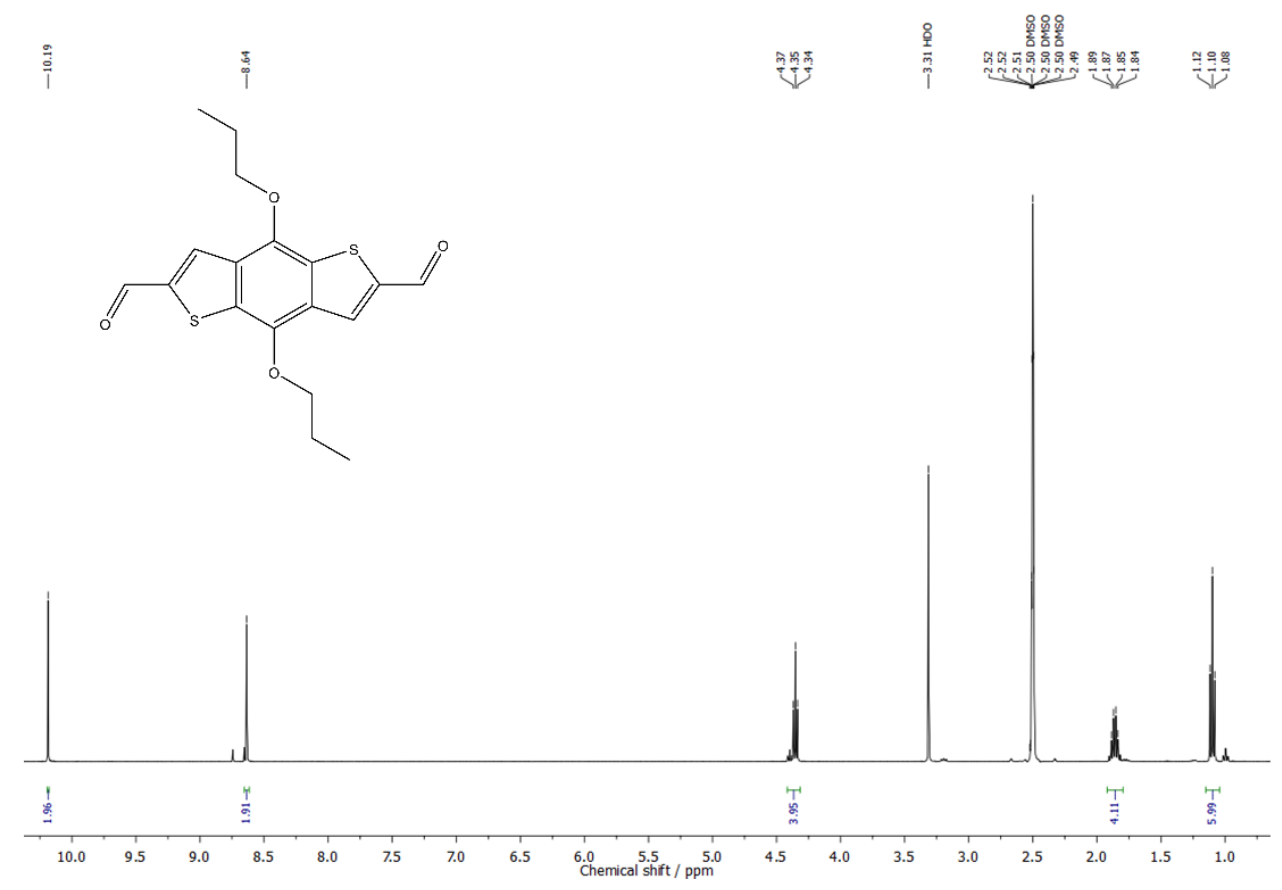

Figure S54: ${ }^{1} \mathrm{H}$ NMR spectrum of BDT-OPr dialdehyde monomer in DMSO- $d_{6} . \delta$ (ppm): 10.19 (s, 2H, CHO), $8.64(\mathrm{~s}, 2 \mathrm{H}, \mathrm{CH}), 4.35\left(\mathrm{t}, J=7.0 \mathrm{~Hz}, 4 \mathrm{H}, \mathrm{OCH}_{2}\right), 1.86$, (m, 4H, $\left.\mathrm{CH}_{2}\right), 1.10(\mathrm{t}, J=$ $\left.7.0 \mathrm{~Hz}, 6 \mathrm{H}, \mathrm{CH}_{3}\right)$. 


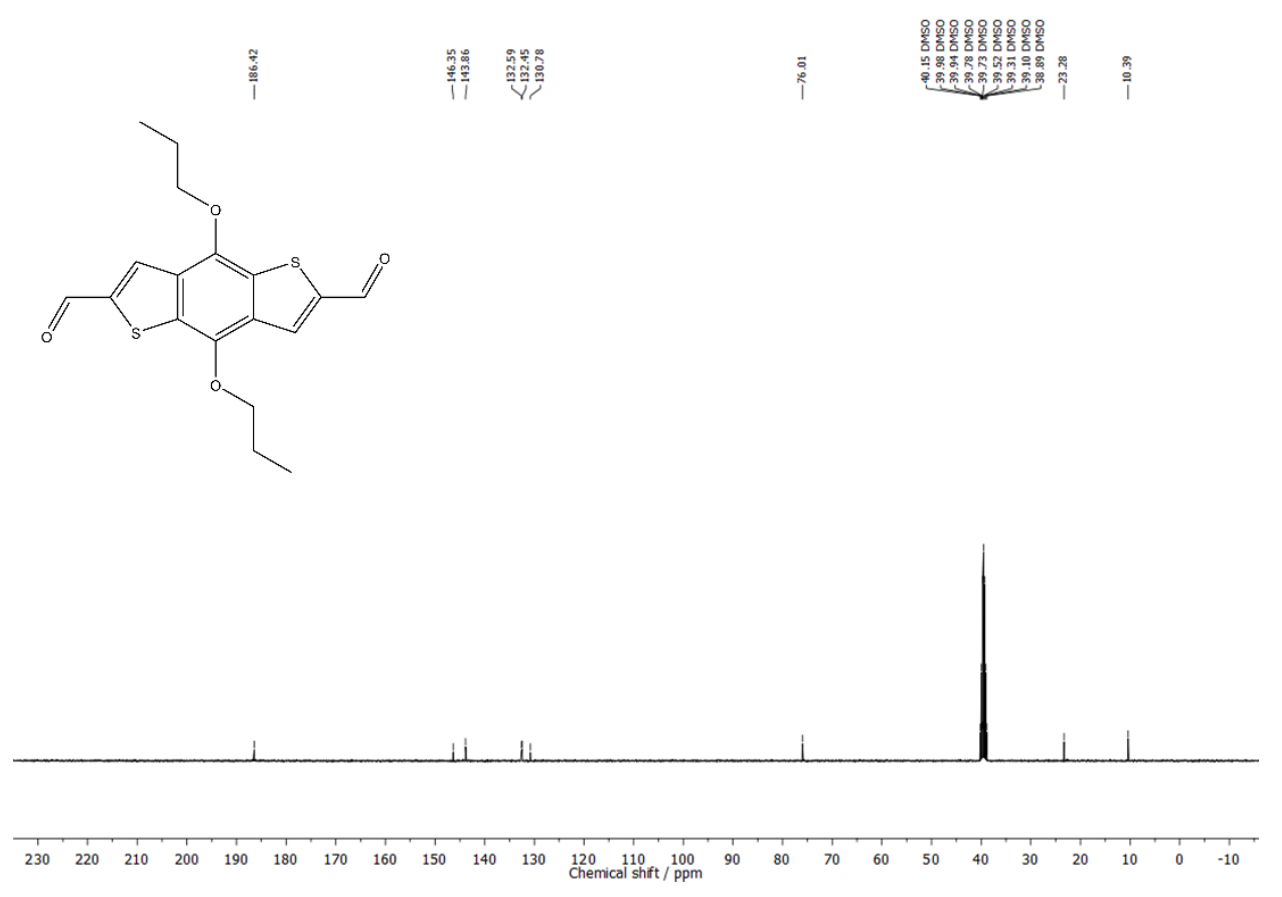

Figure S58: ${ }^{13} \mathrm{C}\left\{{ }^{1} \mathrm{H}\right\}$ NMR spectrum of BDT-OPr dialdehyde monomer in DMSO- $d_{6} . \delta(\mathrm{ppm})$ : $186.4,146.4,143.9,132.6,132.5,130.8,76.0,23.3,10.4$. 


\section{TEORETICAL CALCULATIONS}

\section{Stacked Dimers}

The model compounds $\mathbf{1}$ were used to investigate the effect of alkoxy substitution in stacked dimers.<smiles>[R]c1c2ccsc2c([R])c2ccsc12</smiles>
1a; $\mathrm{R}=\mathrm{H}$
$1 \mathrm{~b} ; \mathrm{R}=\mathrm{OCH}_{3}$
1c; $\mathrm{R}=\mathrm{OC}_{2} \mathrm{H}_{5}$

The parent compound 1a can form two different stacked dimers, which we have denominated "syn" and "anti", and which are shown in Figure S59.

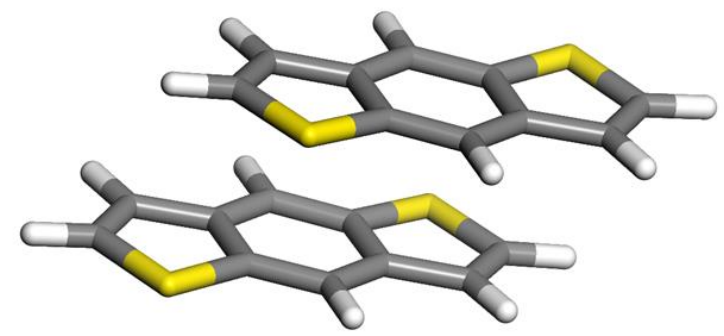

syn, Dimerization energy $=-13.3 \mathrm{kcal} \mathrm{mol}^{-1}(\mathrm{MP} 2)$

$-10.4 \mathrm{kcal} \mathrm{mol}^{-1}$ (B3LYP-D3)

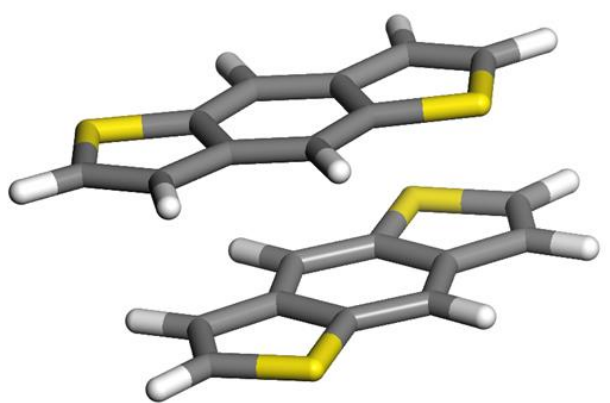

anti, Dimerization energy $=-14.5 \mathrm{kcal} \mathrm{mol}^{-1}(\mathrm{MP} 2)$

$-11.1 \mathrm{kcal} \mathrm{mol}^{-1}$ (B3LYP-D3)

Figure S59: MP2/6-31G(d)-optimized structures of the syn- and anti- stacked dimers of model compound 1a. Geometries and energies are given in the Supporting Information. 
As expected, the anti-dimer is the more stable of the two (by $1.2 \mathrm{kcal} \mathrm{mol}^{-1}$ at MP2/6-31G(d)). The syn-dimer avoids unfavorable electrostatic interactions (see below) by a translation of the relative positions of the two monomers roughly along the direction of the $S_{2}$-axes of the monomers. Figure S60 shows a schematic energy diagram that illustrates the effect of the conformation of the central scaffold and of the substituents on the dimerization energies.

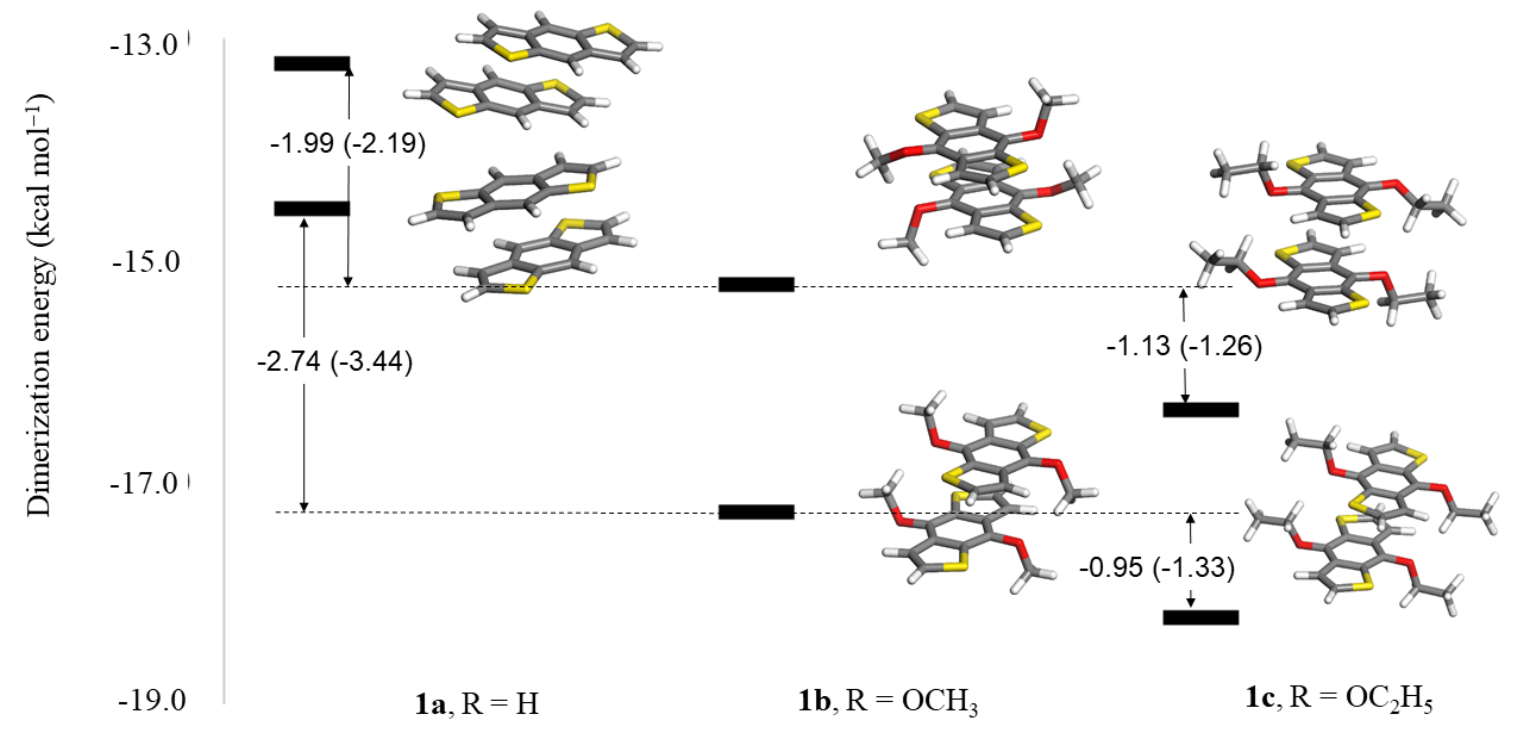

Figure S60: Schematic diagram of the effect of alkoxy-groups on the dimerization of model compounds 1a-c. Both the syn- and anti-dimers are shown. Geometries and energies are given in the Supporting Information. MP2 and B3LYP-D3 (in parentheses) energies are shown.

The anti-dimer is the more stable in every case and the alkoxy groups provide additional stabilization of the dimers. Dimethoxy substitution is most effective for the anti-dimer, simply because the substituents fit better in this conformation. Extending the alkyl substituent from methyl to ethyl provides an extra $\mathrm{kcal} \mathrm{mol}^{-1}$ dimerization energy, presumably because of increased dispersion interactions between the sidechains. These effects are easily understood in terms of a simple electrostatic treatment.

Figure S61 shows the calculated molecular electrostatic potential for the dimethoxy model compound $\mathbf{1 b}$ as top and side views. The isodensity surface indicates that the methoxy-substituents 
provide additional mechanical and electrostatic fixation in stacked dimers, as is also evident in the calculated structures and dimerization energies, which are shown schematically in Figure S60. As a side effect, this extra stabilization also helps fix the monomers relative to each other, providing additional docking sites ${ }^{17}$ to aid crystallization.

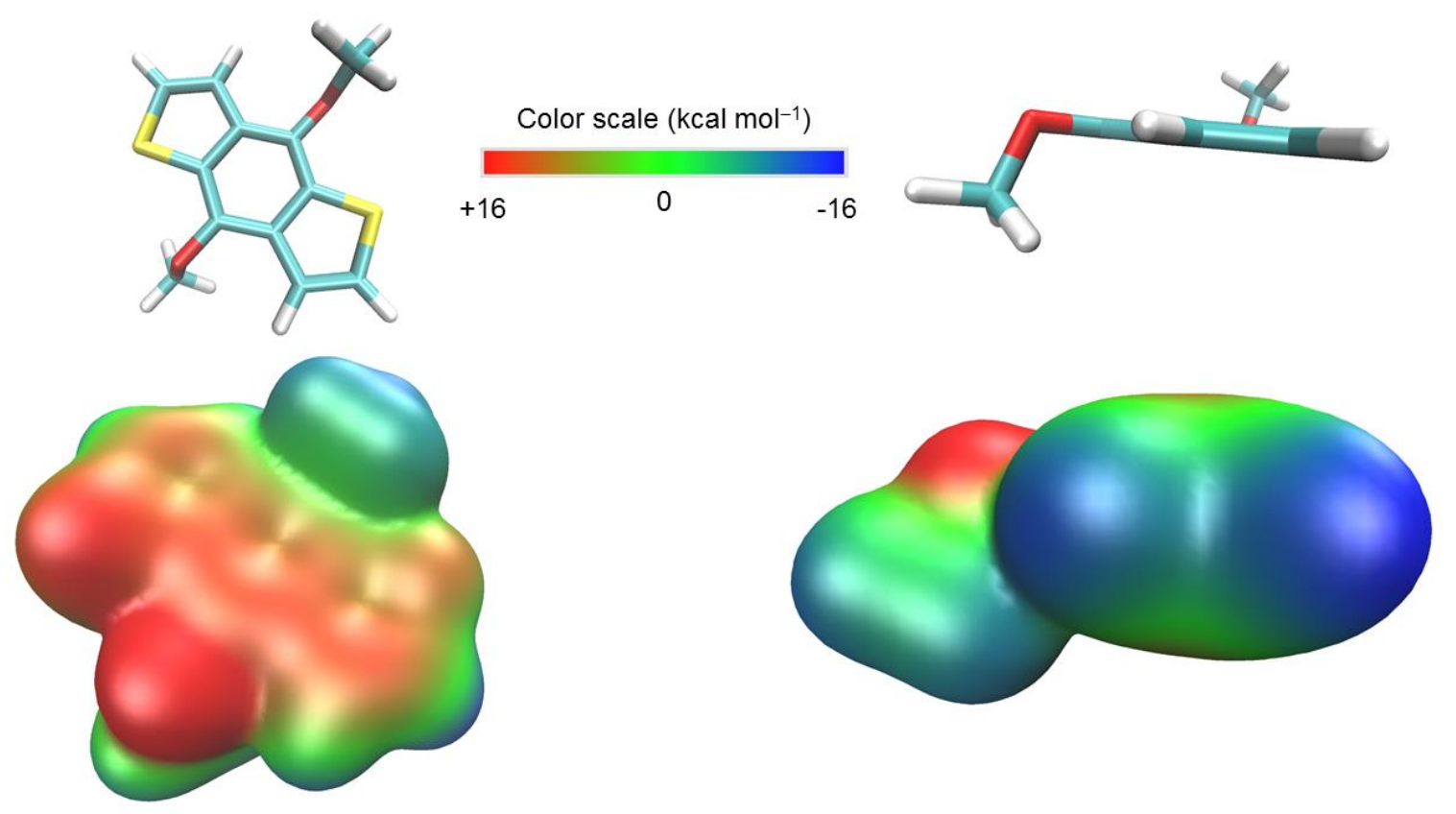

Figure S61: Top and side views of the molecular electrostatic potential projected onto the 0.001 au isodensity surface of model compound $1 b$. 
Both boat and chair 1,4-dioxane can complex to the $\pi$-face of the BDT moiety to give complexes $\mathbf{2}_{\text {boat }}$ and $\mathbf{2}_{\text {chair, }}$ respectively, as shown in Figure S62. However, complexes 3, in which the dioxane complexes edge-on via $\mathrm{CH}-\mathrm{O}$ and $\mathrm{S}-\mathrm{HC}$ hydrogen bonds, are competitive in energy.
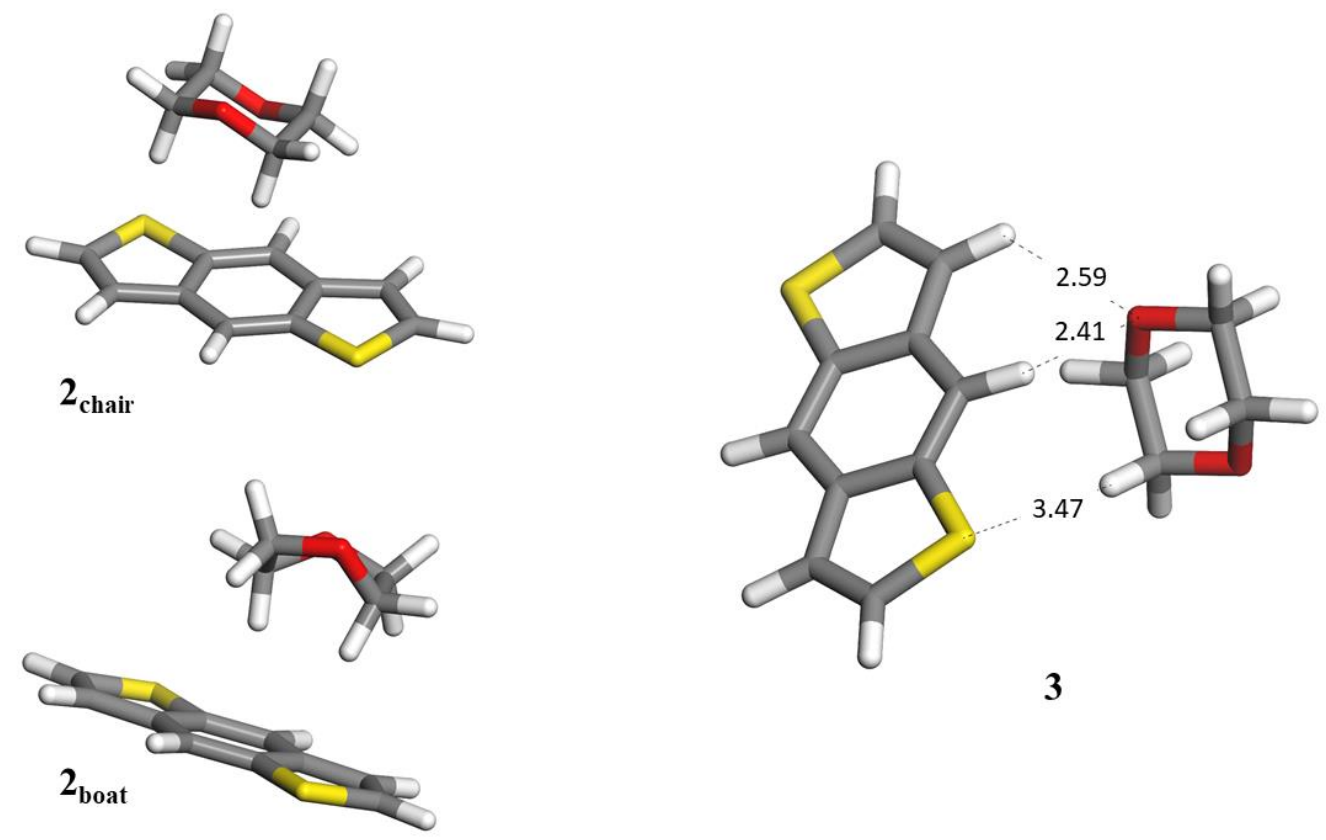

Figure S62: MP2/6-31G(d) optimized structures of complexes of dioxane with 1a.

The complexation energy of dioxane in 3 is calculated to be $-6.3 \mathrm{kcal} \mathrm{mol}^{-1}$ at MP2/6-31G(d) and -6.6 at B3LYP-D3/6-31+G(d), compared with -7.1 and -6.6, respectively, for 2chair. Each BDT unit can accommodate two dioxane molecules to give complex $\mathbf{4}$ or two ethanols to give $\mathbf{5}$, as shown in Figure S63. 


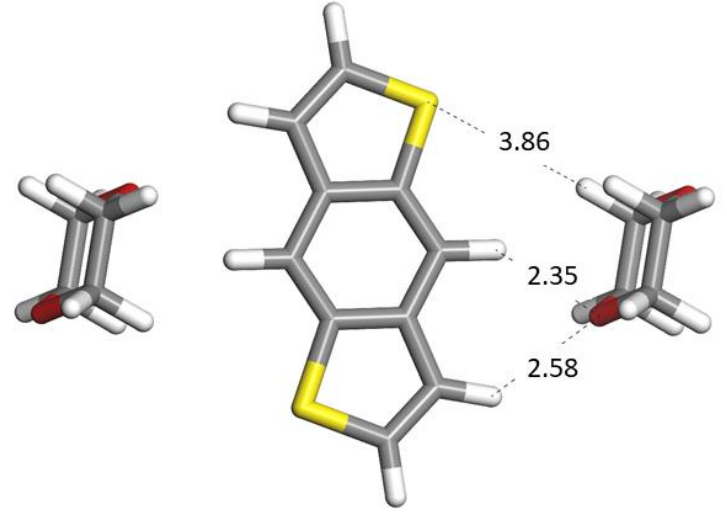

4 (MP2: -11.1 kcal mol-1) (B3LYP-D3: -9.0 kcal mol-1)

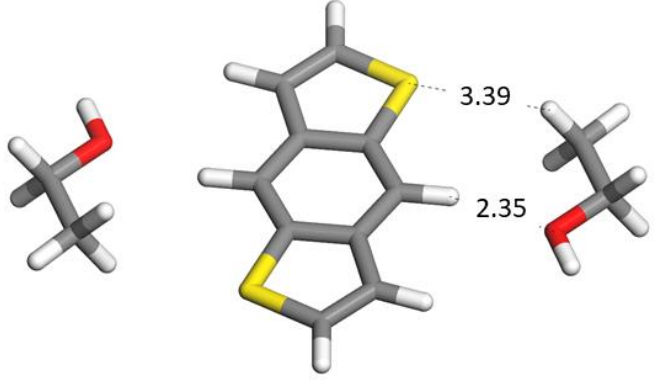

5 (MP2: -7.4 $\mathrm{kcal} \mathrm{mol}^{-1}$ )

(B3LYP-D3: $-6.5 \mathrm{kcal} \mathrm{mol}^{-1}$ )

Figure S63: MP2/6-31G(d) optimized structures of complexes 1a with two dioxane molecules, 4, and two ethanols, 5 .

Because side-on coordination is also possible for stacked oligomers, its effect on the stacking energy determines whether the solvent can dissociate the stacks. Figure S64 shows the MP2/6- 
$31 \mathrm{G}(\mathrm{d})$-optimized structures of $(\mathrm{BDT})_{2}(\text { dioxane })_{4}, \mathbf{6}$, and $(\mathrm{BDT})_{2}(\text { ethanol })_{4}, \mathbf{7}$, stacked dimers.

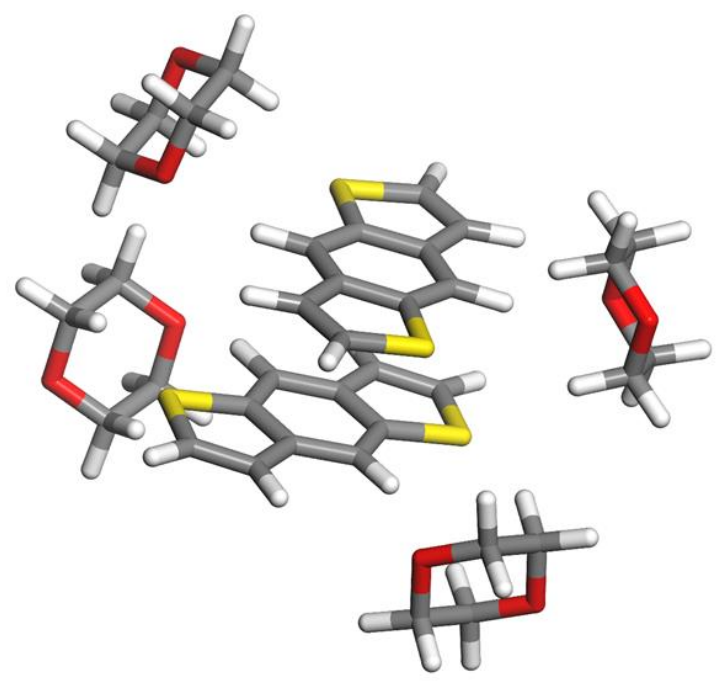

6
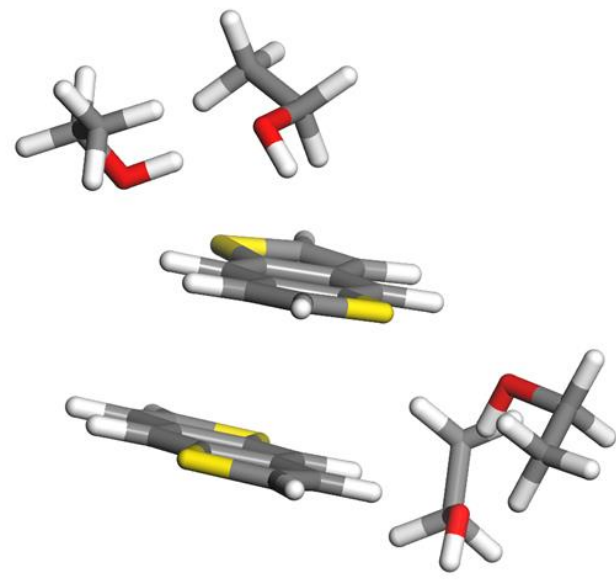

7

Figure S64: MP2/6-31G(d) optimized structures of complexes 1a with two dioxane molecules, 4, and two ethanols, 5 .

The dioxane molecules in $\mathbf{6}$ do not affect the stacking distance (ca. 3.3 $\AA$ ) significantly but rather cause the BDT units to twist relative to each other. This weakens the stacking, so that the dimerization energy $(2 \times \mathbf{4} \rightarrow \mathbf{6})$ is calculated to be $-19.6 \mathrm{kcal} \mathrm{mol}^{-1}$ at B3LYP-D3. This value compares with the same dimerization energy with ethanol $(2 \times \mathbf{5} \rightarrow 7)$ of -35.6 and $-30.9 \mathrm{kcal} \mathrm{mol}^{-1}$ at MP2 and B3LYP-D3, respectively. Thus, even in the absence of further solvent molecules, four dioxanes weaken the stacking interaction significantly. This can be demonstrated by the calculated energies for dissociation of unsolvated dimers by dioxane or ethanol:

$(\mathrm{BDT})_{2}+4 \times$ dioxane $\rightarrow 2 \times 4 \quad \Delta \mathrm{E}=-7.7 \mathrm{kcal} \mathrm{mol}^{-1}(\mathrm{MP} 2) ;-6.8 \mathrm{kcal} \mathrm{mol}^{-1}(\mathrm{~B} 3 \mathrm{LYP}-\mathrm{D} 3)$

$(\mathrm{BDT})_{2}+4 \times$ ethanol $\rightarrow 2 \times \mathbf{5} \quad \Delta \mathrm{E}=-0.2 \mathrm{kcal} \mathrm{mol}^{-1}(\mathrm{MP} 2) ;-1.9 \mathrm{kcal} \mathrm{mol}^{-1}(\mathrm{~B} 3 \mathrm{LYP}-\mathrm{D} 3)$

Thus, side-on coordination by dioxane is able to dissociate BDT stacks, even in the absence of further solvation. 
Model calculations within $C_{s}$-symmetry on the coordination of chair dioxane to typical bonding moieties that occur in the COFs gave the binding energies shown in Table S4. The binding modes found are those shown in the manuscript (see below).

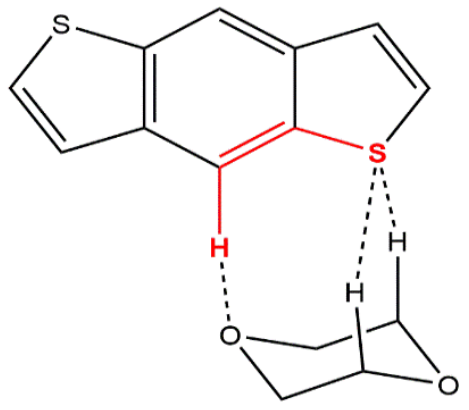

BDT:(dioxane) $C_{s}$

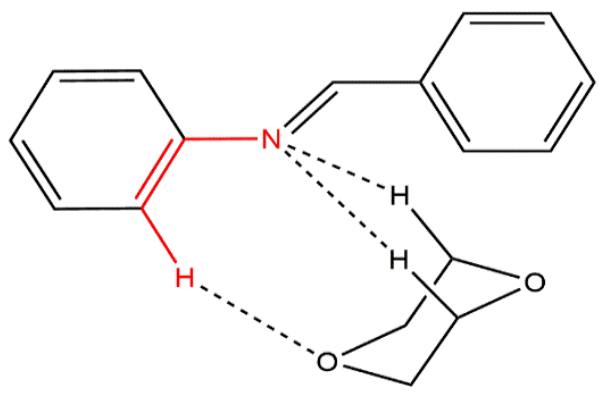

TATB-phenyl:(dioxane) $C_{s}$

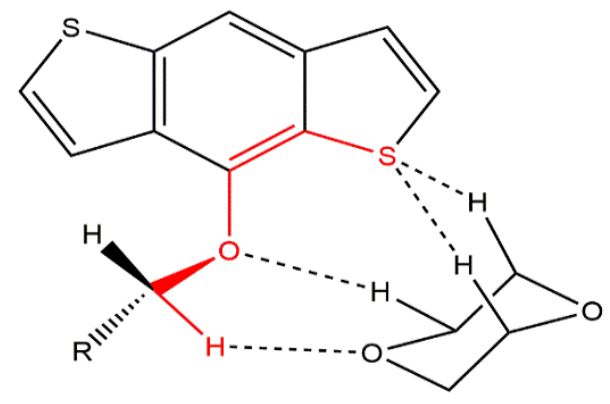

Methoxy BDT:(dioxane)

$C_{1}$

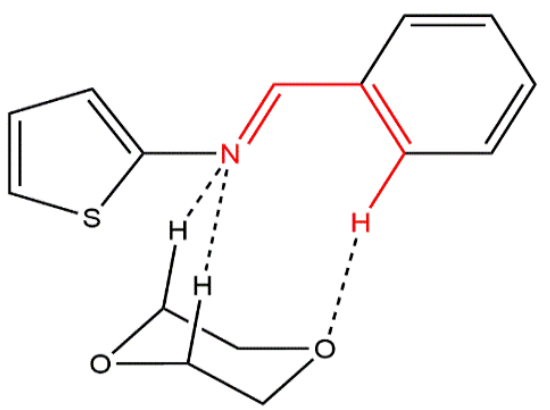

TATB-thiophene:(dioxane)

$C_{s}$

Figure S65: The binding modes found for the coordination of chair dioxane to typical bonding moieties that occur in the COFs.

Table 4: Calculated total (a.u.) zero-point vibrational (ZPE, kcal mol ${ }^{-1}$ ) and interaction (E(int), $\mathrm{kcal} \mathrm{mol}^{-1}$ ) energies.

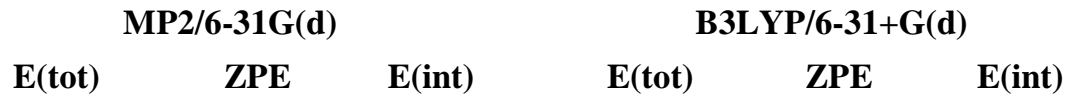

\section{$\mathbf{R}=\mathbf{H}$}

1a Monomer

2a syn-dimer

3a anti-dimer
$-1178.71739 \quad 79.42$

$\begin{array}{ll}-2357.45598 & 158.91\end{array}$

$\begin{array}{ll}-2357.45824 & 159.02\end{array}$

$\begin{array}{rr}-1181.08542 & 79.96 \\ -2362.18814 & 160.39 \\ -2362.18953 & 160.51\end{array}$

$-13.23$

$-14.54$
$-10.38$

$-11.14$ 
$\mathbf{R}=\mathrm{OCH}_{3}$

1b Monomer

$\begin{array}{ll}-1407.08997 & 121.48\end{array}$

$-2814.20579 \quad 243.96$

$-15.22$

$-1410.13850$

120.33

2b syn-dimer

$-2814.20901 \quad 243.91$

$-17.28$

$-2820.29946 \quad 241.88$

$-12.87$

3b anti-dimer

\section{$\mathbf{R}=\mathbf{O C}_{2} \mathbf{H}_{5}$}

1c Monomer

2c syn-dimer

$\begin{array}{ll}-1485.43478 & 158.08\end{array}$

$-1488.78502 \quad 156.02$

3c anti-dimer

$-2970.89711 \quad 317.10$

$-16.35$

$-2977.59465$

313.35

$-14.13$

$-2970.90000 \quad 317.04$

$-18.23$

$-2977.59683 \quad 312.94$

$-15.91$

Methoxy BTBT

TATB-thiophene model

TATB-phenyl model

\section{Dioxane}

chair

Ethanol

1a:chair dioxane

1a:boat dioxane

1a: dioxane (H-bond) $C_{I}$

1a: dioxane (H-bond) $C_{s}$

1a:(dioxane)2 (H-bond)

1a:(ethanol)2

1b:chair dioxane

1b:boat dioxane

$(\mathrm{BTBT})_{2}:(\mathrm{EtOH})_{4}$

$(\mathrm{BTBT})_{2}$ (dioxane) $)_{4}$

BTBT-OMe:(dioxane)

TATB-thiophene:(dioxane)

TATB-phenyl:(dioxane)
$-1292.90389 \quad 100.16$

$-875.40651 \quad 106.57$

$-554.93628 \quad 127.33$

$\begin{array}{ll}-306.69320 & 78.85\end{array}$

$-306.68151 \quad 78.70$

$-154.51697 \quad 51.53$

$-1485.42273 \quad 158.76$

$-1485.40910$

158.66

$-1485.42159 \quad 158.90$

$-1485.42033 \quad 158.74$

$-1792.12295 \quad 238.01$

$-1487.76381 \quad 182.93$

$\begin{array}{ll}-1713.79587 & 200.83\end{array}$

$\begin{array}{ll}-1713.78314 & 200.59\end{array}$

$-2975.59045 \quad 369.68$

$-1599.60685 \quad 179.66$

$-1182.10920 \quad 185.65$

$-861.63994 \quad 206.54$ $\begin{array}{ll}-1295.61222 & 100.15\end{array}$

$-877.54290 \quad 106.31$

$-556.78996 \quad 127.50$

\begin{tabular}{lrrr} 
E(rel) & -307.68164 & $\mathbf{7 7 . 1 0}$ & \multicolumn{1}{l}{ E(rel) } \\
7.18 & -307.67009 & 76.79 & 6.95 \\
& -155.04883 & 50.22 & \\
E(int) & & & E(int)
\end{tabular}

$\begin{array}{lll}-7.13 & -1488.77849 & 157.62\end{array}$

$-6.60$

$\begin{array}{llll}-5.86(+1.32) & -1488.76743 & 157.35 & -6.88(+0.07)\end{array}$

$\begin{array}{lll}-6.27 & -1488.77861 & 157.68\end{array}$

$-6.62$

$\begin{array}{lll}-5.65 & -1488.77524 & 157.58\end{array}$

$-4.61^{\mathrm{a}}$

$\begin{array}{lll}-11.14 & -1796.46480 & 235.28\end{array}$

$-8.96$

$\begin{array}{lll}-7.37 & -1491.19543 & 181.64\end{array}$

$-6.51$

$\begin{array}{rrrr}-7.47 & -1717.83155 & 197.83 & -6.75 \\ -6.90 & -1717.82045 & 197.78 & -6.79 \\ -35.60 & -2982.44510 & 366.44 & -30.87 \\ & -3592.96308 & 471.98 & -19.59 \\ -5.48 & -1603.30260 & 177.89 & -5.48 \\ -5.72 & -1185.23303 & 184.01 & -4.71^{\mathrm{a}} \\ -6.20 & -864.48132 & 205.53 & -5.16^{\mathrm{a}}\end{array}$

$(\text { BTBT })_{2}+4$ dioxane $\rightarrow 2$ (BTBT:(dioxane $\left.)_{2}\right)$

$-7.74$

$-7.74$

$-0.20$

${ }^{\text {a }}$ Constrained to $C_{s}$ symmetry; one imaginary frequency. 


\section{MP2/6-31G(d) -optimized geometries}

$1 a$

$\begin{array}{rrrr}6 & -1.380233 & -0.049740 & -0.000026 \\ 6 & -0.689237 & -1.257555 & -0.000078 \\ 6 & 0.711426 & -1.212383 & -0.000052 \\ 6 & 1.380233 & 0.049740 & 0.000026 \\ 6 & 0.689237 & 1.257555 & 0.000078 \\ 6 & -0.711426 & 1.212383 & 0.000052 \\ 16 & 3.115006 & -0.157762 & 0.000044 \\ 6 & 2.941935 & -1.886371 & -0.000049 \\ 6 & 1.644039 & -2.303965 & -0.000093 \\ 16 & -3.115006 & 0.157762 & -0.000044 \\ 6 & -2.941935 & 1.886371 & 0.000049 \\ 6 & -1.644039 & 2.303965 & 0.000093 \\ 1 & -1.212344 & -2.212294 & -0.000136 \\ 1 & 1.212344 & 2.212294 & 0.000136 \\ 1 & 3.831543 & -2.505068 & -0.000067 \\ 1 & 1.352254 & -3.349858 & -0.000153 \\ 1 & -3.831543 & 2.505068 & 0.000067 \\ 1 & -1.352254 & 3.349858 & 0.000153\end{array}$

$2 \mathbf{a}$

\begin{tabular}{rrrr}
6 & -2.267290 & -0.735222 & 0.748224 \\
6 & -1.120581 & -0.584750 & 1.523254 \\
6 & 0.032962 & -1.277638 & 1.129629 \\
6 & 0.008746 & -2.081345 & -0.051958 \\
6 & -1.130848 & -2.214049 & -0.838723 \\
6 & -2.283137 & -1.519498 & -0.446667 \\
16 & 1.546782 & -2.862464 & -0.313003 \\
6 & 2.206794 & -2.116997 & 1.108649 \\
6 & 1.320462 & -1.309327 & 1.760871 \\
16 & -3.833244 & -0.029733 & 1.056018 \\
6 & -4.481894 & -0.752259 & -0.381697 \\
6 & -3.574302 & -1.503393 & -1.071136 \\
1 & -1.121836 & 0.020789 & 2.428171 \\
1 & -1.134202 & -2.831627 & -1.736050 \\
1 & 3.238086 & -2.311417 & 1.378213 \\
1 & 1.565337 & -0.764661 & 2.667910 \\
1 & -5.524156 & -0.590024 & -0.632055 \\
1 & -3.811502 & -2.034935 & -1.988492 \\
6 & -0.009048 & 2.081000 & 0.051629 \\
6 & 1.130571 & 2.214808 & 0.838185 \\
6 & 2.282902 & 1.519915 & 0.446881 \\
6 & 2.267698 & 0.735820 & -0.748123 \\
& & \multicolumn{2}{c}{$\mathrm{S} 85$}
\end{tabular}




$\begin{array}{rrrr}6 & 1.120961 & 0.584250 & -1.522929 \\ 6 & -0.032597 & 1.277636 & -1.130208 \\ 16 & 3.833567 & 0.029690 & -1.054732 \\ 6 & 4.481648 & 0.752532 & 0.383101 \\ 6 & 3.573839 & 1.504022 & 1.071854 \\ 16 & -1.547146 & 2.862287 & 0.311889 \\ 6 & -2.206701 & 2.116324 & -1.109678 \\ 6 & -1.320050 & 1.308719 & -1.761575 \\ 1 & 1.133573 & 2.832579 & 1.735374 \\ 1 & 1.122788 & -0.020823 & -2.428158 \\ 1 & 5.523847 & 0.590458 & 0.633819 \\ 1 & 3.810669 & 2.035832 & 1.989150 \\ 1 & -3.237985 & 2.310251 & -1.379621 \\ 1 & -1.564774 & 0.763801 & -2.668513\end{array}$

$2 b$

$\begin{array}{rrrr}6 & 0.027484 & -1.677440 & 0.980843 \\ 6 & 1.315382 & -1.343942 & 1.388363 \\ 6 & 2.260607 & -1.049754 & 0.395717 \\ 6 & 1.892382 & -1.133199 & -0.981452 \\ 6 & 0.605932 & -1.471446 & -1.389359 \\ 6 & -0.340382 & -1.763535 & -0.396950 \\ 16 & 3.245941 & -0.747093 & -2.015817 \\ 6 & 4.277063 & -0.508463 & -0.639980 \\ 6 & 3.642192 & -0.696460 & 0.553145 \\ 16 & -1.315564 & -2.094319 & 2.014859 \\ 6 & -2.339293 & -2.358293 & 0.639413 \\ 6 & -1.711643 & -2.149140 & -0.555001 \\ 1 & 1.585845 & -1.293602 & 2.441698 \\ 1 & 0.341121 & -1.543432 & -2.443391 \\ 1 & 5.316140 & -0.242509 & -0.797039 \\ 1 & 4.133953 & -0.592848 & 1.516294 \\ 1 & -3.370039 & -2.654687 & 0.794400 \\ 1 & -2.200807 & -2.273053 & -1.516448 \\ 6 & -1.892395 & 1.133878 & -0.980581 \\ 6 & -0.605895 & 1.472190 & -1.388276 \\ 6 & 0.340452 & 1.763519 & -0.395675 \\ 6 & -0.027383 & 1.676449 & 0.982062 \\ 6 & -1.315268 & 1.342634 & 1.389364 \\ 6 & -2.260492 & 1.049052 & 0.396535 \\ 16 & 1.315631 & 2.092782 & 2.016350 \\ 6 & 2.339365 & 2.357607 & 0.641057 \\ 6 & 1.711722 & 2.149187 & -0.553486 \\ 16 & -3.246172 & 0.749260 & -2.015211 \\ 6 & & & \end{array}$




$\begin{array}{rrrr}6 & -4.277241 & 0.509501 & -0.639512 \\ 6 & -3.642185 & 0.696065 & 0.553739 \\ 1 & -0.341073 & 1.544819 & -2.442261 \\ 1 & -1.585651 & 1.291338 & 2.442673 \\ 1 & 3.370166 & 2.653727 & 0.796221 \\ 1 & 2.200945 & 2.273495 & -1.514853 \\ 1 & -5.316577 & 0.244717 & -0.796833 \\ 1 & -4.133842 & 0.591507 & 1.516838\end{array}$

$1 b$

$\begin{array}{rrrr}6 & 1.374824 & 0.100882 & 0.091934 \\ 6 & 0.620225 & 1.256523 & 0.281977 \\ 6 & -0.773403 & 1.168675 & 0.147938 \\ 6 & -1.374681 & -0.100907 & -0.092292 \\ 6 & -0.620109 & -1.256553 & -0.282129 \\ 6 & 0.773534 & -1.168721 & -0.148084 \\ 16 & -3.108952 & 0.026374 & -0.211080 \\ 6 & -3.027632 & 1.731419 & 0.121195 \\ 6 & -1.757899 & 2.200968 & 0.295460 \\ 16 & 3.109049 & -0.026535 & 0.211096 \\ 6 & 3.027702 & -1.731585 & -0.121079 \\ 6 & 1.757957 & -2.201051 & -0.295585 \\ 8 & 1.233806 & 2.463891 & 0.553971 \\ 8 & -1.233768 & -2.463963 & -0.553922 \\ 1 & -3.948833 & 2.299725 & 0.180607 \\ 1 & -1.519895 & 3.234248 & 0.525310 \\ 1 & 3.948886 & -2.299918 & -0.180491 \\ 1 & 1.519937 & -3.234313 & -0.525500 \\ 6 & 1.533970 & 3.191452 & -0.651104 \\ 6 & -1.534478 & -3.190907 & 0.651474 \\ 1 & 2.020587 & 4.113379 & -0.331483 \\ 1 & 0.615787 & 3.423502 & -1.200591 \\ 1 & 2.210040 & 2.616465 & -1.291943 \\ 1 & -2.210236 & -2.615175 & 1.291967 \\ 1 & -0.616477 & -3.423314 & 1.201084 \\ 1 & -2.021697 & -4.112618 & 0.332158\end{array}$

2b

\begin{tabular}{rrrr}
6 & -1.989467 & 0.600217 & -1.433268 \\
6 & -1.268691 & -0.588275 & -1.406140 \\
6 & 0.117215 & -0.527261 & -1.604324 \\
6 & 0.773606 & 0.737218 & -1.753329 \\
\multicolumn{3}{c}{$S 87$}
\end{tabular}




\begin{tabular}{|c|c|c|c|}
\hline 6 & 0.041937 & 1.931869 & -1.791966 \\
\hline 6 & -1.342035 & 1.860929 & -1.548952 \\
\hline 16 & 2.474622 & 0.498646 & -2.085708 \\
\hline 6 & 2.311110 & -1.219146 & -1.930425 \\
\hline 6 & 1.036298 & -1.623165 & -1.657779 \\
\hline 16 & -3.709848 & 0.778874 & -1.239036 \\
\hline 6 & -3.565031 & 2.507971 & -1.349092 \\
\hline 6 & -2.281533 & 2.942561 & -1.518495 \\
\hline 8 & -1.916841 & -1.809507 & -1.306965 \\
\hline 8 & 0.529365 & 3.185945 & -2.051619 \\
\hline 1 & 3.195507 & -1.840942 & -2.008027 \\
\hline 1 & 0.748213 & -2.658115 & -1.505051 \\
\hline 1 & -4.461411 & 3.115966 & -1.299669 \\
\hline 1 & -1.999198 & 3.985362 & -1.613471 \\
\hline 6 & -2.263797 & -2.327691 & -2.605353 \\
\hline 6 & 1.823191 & 3.528583 & -1.522267 \\
\hline 1 & -2.770220 & -3.277285 & -2.426205 \\
\hline 1 & -1.363590 & -2.489612 & -3.206794 \\
\hline 1 & -2.936783 & -1.639016 & -3.125765 \\
\hline 1 & 2.618858 & 3.234401 & -2.212936 \\
\hline 1 & 1.974890 & 3.067119 & -0.545285 \\
\hline 1 & 1.816870 & 4.616703 & -1.436286 \\
\hline 6 & -0.773606 & -0.737218 & 1.753329 \\
\hline 6 & -0.041937 & -1.931869 & 1.791966 \\
\hline 6 & 1.342035 & -1.860929 & 1.548952 \\
\hline 6 & 1.989467 & -0.600217 & 1.433268 \\
\hline 6 & 1.268691 & 0.588275 & 1.406140 \\
\hline 6 & -0.117215 & 0.527261 & 1.604324 \\
\hline 16 & 3.709848 & -0.778874 & 1.239036 \\
\hline 6 & 3.565031 & -2.507971 & 1.349092 \\
\hline 6 & 2.281533 & -2.942561 & 1.518495 \\
\hline 16 & -2.474622 & -0.498646 & 2.085708 \\
\hline 6 & -2.311110 & 1.219146 & 1.930425 \\
\hline 6 & -1.036298 & 1.623165 & 1.657779 \\
\hline 8 & -0.529365 & -3.185945 & 2.051619 \\
\hline 8 & 1.916841 & 1.809507 & 1.306965 \\
\hline 1 & 4.461411 & -3.115966 & 1.299669 \\
\hline 1 & 1.999198 & -3.985362 & 1.613471 \\
\hline 1 & -3.195507 & 1.840942 & 2.008027 \\
\hline 1 & -0.748213 & 2.658115 & 1.505051 \\
\hline 6 & -1.823191 & -3.528583 & 1.522267 \\
\hline 6 & 2.263797 & 2.327691 & 2.605353 \\
\hline 1 & -1.816870 & -4.616703 & 1.436286 \\
\hline 1 & -1.974890 & -3.067119 & 0.545285 \\
\hline
\end{tabular}




$\begin{array}{rrrr}1 & -2.618858 & -3.234401 & 2.212936 \\ 1 & 2.936783 & 1.639016 & 3.125765 \\ 1 & 1.363590 & 2.489612 & 3.206794 \\ 1 & 2.770220 & 3.277285 & 2.426205\end{array}$

3b

$\begin{array}{rrrr}6 & -2.419540 & -0.794376 & -0.583075 \\ 6 & -1.182768 & -1.218218 & -1.061397 \\ 6 & -0.320141 & -0.261598 & -1.619139 \\ 6 & -0.688021 & 1.116495 & -1.566535 \\ 6 & -1.936631 & 1.538967 & -1.111175 \\ 6 & -2.797942 & 0.579620 & -0.557582 \\ 16 & 0.512280 & 2.125900 & -2.319729 \\ 6 & 1.507720 & 0.742733 & -2.643954 \\ 6 & 0.970204 & -0.439073 & -2.214745 \\ 16 & -3.654638 & -1.811764 & 0.104111 \\ 6 & -4.681501 & -0.431883 & 0.356661 \\ 6 & -4.124660 & 0.749754 & -0.040832 \\ 8 & -0.877809 & -2.569876 & -1.091805 \\ 8 & -2.296124 & 2.866818 & -1.201198 \\ 1 & 2.474115 & 0.884911 & -3.113980 \\ 1 & 1.461341 & -1.398956 & -2.332218 \\ 1 & -5.670512 & -0.580347 & 0.775340 \\ 1 & -4.634080 & 1.705696 & 0.020877 \\ 6 & -1.278626 & -3.168700 & -2.339525 \\ 6 & -2.149527 & 3.565631 & 0.053045 \\ 1 & -1.015183 & -4.224773 & -2.265688 \\ 1 & -0.747160 & -2.706107 & -3.177476 \\ 1 & -2.358299 & -3.063935 & -2.485314 \\ 1 & -1.126065 & 3.470069 & 0.420767 \\ 1 & -2.846073 & 3.170600 & 0.800054 \\ 1 & -2.390544 & 4.607576 & -0.162402 \\ 6 & 0.361244 & 0.177679 & 1.704442 \\ 6 & 1.139022 & 1.204999 & 1.176250 \\ 6 & 2.365273 & 0.874472 & 0.583610 \\ 6 & 2.745805 & -0.494785 & 0.471380 \\ 6 & 1.982310 & -1.522920 & 1.022943 \\ 6 & 0.734380 & -1.193029 & 1.576295 \\ 6 & 4.314650 & -0.651945 & -0.273061 \\ 6 & 4.415252 & 1.069975 & -0.491236 \\ 6 & 3.333781 & 1.748848 & -0.007516 \\ 6 & -1.178464 & 0.346657 & 2.497238 \\ 6 & -1.288952 & -1.374815 & 2.702104 \\ 6 & & & \mathrm{~S} 89 \\ 6 & -130 & \end{array}$




$\begin{array}{rrrr}6 & -0.226925 & -2.061404 & 2.185518 \\ 8 & 0.766857 & 2.530782 & 1.322784 \\ 8 & 2.420386 & -2.830675 & 1.034756 \\ 1 & 5.286268 & 1.488367 & -0.983162 \\ 1 & 3.216076 & 2.826072 & -0.065488 \\ 1 & -2.154848 & -1.788797 & 3.205360 \\ 1 & -0.127677 & -3.140943 & 2.217217 \\ 6 & 1.266304 & 3.084492 & 2.555091 \\ 6 & 2.246628 & -3.499402 & -0.230382 \\ 1 & 0.920748 & 4.118808 & 2.582789 \\ 1 & 2.360510 & 3.054708 & 2.571862 \\ 1 & 0.869012 & 2.534612 & 3.414148 \\ 1 & 2.909819 & -3.073814 & -0.991580 \\ 1 & 1.206195 & -3.422610 & -0.553027 \\ 1 & 2.522502 & -4.539883 & -0.052803\end{array}$

$1 c$

$\begin{array}{rrrr}6 & -0.892312 & -1.048662 & -0.102500 \\ 6 & -1.375408 & 0.241998 & -0.307113 \\ 6 & -0.482230 & 1.314238 & -0.163033 \\ 6 & 0.892337 & 1.048759 & 0.102446 \\ 6 & 1.375452 & -0.241886 & 0.307160 \\ 6 & 0.482260 & -1.314117 & 0.163005 \\ 16 & 1.814396 & 2.522263 & 0.230225 \\ 6 & 0.397858 & 3.464570 & -0.130909 \\ 6 & -0.729017 & 2.717926 & -0.320995 \\ 16 & -1.814375 & -2.522169 & -0.230118 \\ 6 & -0.397822 & -3.464466 & 0.131013 \\ 6 & 0.729035 & -2.717801 & 0.321096 \\ 8 & -2.706760 & 0.457752 & -0.602855 \\ 8 & 2.706825 & -0.457542 & 0.602786 \\ 1 & 0.486032 & 4.543167 & -0.193962 \\ 1 & -1.698838 & 3.136293 & -0.569527 \\ 1 & -0.485987 & -4.543067 & 0.193997 \\ 1 & 1.698850 & -3.136173 & 0.569649 \\ 6 & -3.501783 & 0.655876 & 0.589781 \\ 6 & 3.501633 & -0.656436 & -0.589883 \\ 6 & -4.934032 & 0.835063 & 0.141700 \\ 1 & -3.131646 & 1.538731 & 1.126116 \\ 1 & -3.391546 & -0.216639 & 1.245449 \\ 1 & 3.391271 & 0.215682 & -1.246043 \\ 1 & 3.131444 & -1.539660 & -1.125541 \\ 6 & 4.933973 & -0.835266 & -0.141887 \\ & & & \mathrm{~S} 90 \\ 6 & & & \end{array}$




$\begin{array}{rrrr}1 & -5.584091 & 0.994864 & 1.006814 \\ 1 & -5.274705 & -0.053235 & -0.394442 \\ 1 & -5.017186 & 1.697115 & -0.523815 \\ 1 & 5.017245 & -1.696833 & 0.524237 \\ 1 & 5.274671 & 0.053439 & 0.393568 \\ 1 & 5.583955 & -0.995653 & -1.006953\end{array}$

2c

$\begin{array}{rrrr}6 & 0.661783 & 2.542516 & -0.264583 \\ 6 & -0.438749 & 1.834138 & -0.739307 \\ 6 & -0.207311 & 0.684715 & -1.511727 \\ 6 & 1.133174 & 0.223699 & -1.680051 \\ 6 & 2.236075 & 0.949406 & -1.230743 \\ 6 & 2.001132 & 2.096990 & -0.458913 \\ 16 & 1.197340 & -1.204392 & -2.671649 \\ 6 & -0.532130 & -1.217126 & -2.807925 \\ 6 & -1.146943 & -0.190439 & -2.146033 \\ 16 & 0.603457 & 4.006754 & 0.676089 \\ 6 & 2.340325 & 4.053997 & 0.749819 \\ 6 & 2.947462 & 3.011259 & 0.110456 \\ 8 & -1.714801 & 2.339340 & -0.548338 \\ 8 & 3.514092 & 0.528579 & -1.529319 \\ 1 & -1.014181 & -2.020776 & -3.352836 \\ 1 & -2.222179 & -0.049854 & -2.124910 \\ 1 & 2.824233 & 4.881261 & 1.256724 \\ 1 & 4.023665 & 2.893659 & 0.037275 \\ 6 & -2.112134 & 3.202325 & -1.642086 \\ 6 & 4.129779 & -0.202191 & -0.437889 \\ 6 & -3.428147 & 3.839899 & -1.258346 \\ 1 & -2.199913 & 2.604926 & -2.558410 \\ 1 & -1.334090 & 3.959387 & -1.797566 \\ 1 & 3.452162 & -0.998406 & -0.119131 \\ 1 & 4.285710 & 0.478874 & 0.408920 \\ 6 & 5.440718 & -0.743436 & -0.960666 \\ 6 & 0.112027 & -0.684938 & 1.601433 \\ 6 & 0.465104 & -1.810016 & 0.860666 \\ 6 & -0.555724 & -2.552574 & 0.251441 \\ 6 & -1.904833 & -2.103118 & 0.348082 \\ 6 & -2.264098 & -0.994657 & 1.113415 \\ 6 & -1.235662 & -0.225575 & 1.682071 \\ 16 & -2.991962 & -3.194730 & -0.468098 \\ 6 & -1.657314 & -4.182774 & -0.983861 \\ 6 & -0.442788 & -3.736161 & -0.547440 \\ & & & S 91 \\ 6 & & & \end{array}$




$\begin{array}{rrrr}16 & 1.198892 & 0.375361 & 2.450708 \\ 6 & -0.130057 & 1.377913 & 2.947397 \\ 6 & -1.344373 & 0.953036 & 2.487027 \\ 8 & 1.777926 & -2.246092 & 0.812703 \\ 8 & -3.583330 & -0.642940 & 1.308144 \\ 1 & -1.853457 & -5.052469 & -1.601028 \\ 1 & 0.501835 & -4.216368 & -0.781993 \\ 1 & 0.069333 & 2.245170 & 3.565910 \\ 1 & -2.282577 & 1.457005 & 2.692783 \\ 6 & 2.069697 & -3.178650 & 1.881088 \\ 6 & -4.153010 & 0.080831 & 0.190060 \\ 6 & 3.530294 & -3.550468 & 1.763949 \\ 1 & 1.420146 & -4.056484 & 1.775130 \\ 1 & 1.851158 & -2.700878 & 2.843971 \\ 1 & -4.232254 & -0.590267 & -0.675415 \\ 1 & -3.486177 & 0.909668 & -0.063989 \\ 6 & -5.517743 & 0.559210 & 0.630857 \\ 1 & -3.763877 & 4.515641 & -2.050675 \\ 1 & -3.312484 & 4.412220 & -0.335231 \\ 1 & -4.196676 & 3.079132 & -1.103514 \\ 1 & 6.083785 & 0.072518 & -1.299181 \\ 1 & 5.260810 & -1.416690 & -1.801866 \\ 1 & 5.961879 & -1.296527 & -0.173177 \\ 1 & 4.159424 & -2.666518 & 1.891967 \\ 1 & 3.732180 & -3.985767 & 0.782397 \\ 1 & 3.796792 & -4.281303 & 2.533237 \\ 1 & -6.011548 & 1.099923 & -0.182556 \\ 1 & -5.424307 & 1.227012 & 1.490340 \\ 1 & -6.143454 & -0.289962 & 0.915345 \\ & & & \end{array}$

$3 c$

$\begin{array}{rrrr}6 & -0.722386 & -2.371019 & 0.379636 \\ 6 & -1.220164 & -1.212773 & 0.966232 \\ 6 & -0.319357 & -0.364923 & 1.624796 \\ 6 & 1.082405 & -0.656598 & 1.623646 \\ 6 & 1.577985 & -1.831775 & 1.044117 \\ 6 & 0.671458 & -2.650994 & 0.346568 \\ 16 & 1.944126 & 0.504903 & 2.606945 \\ 6 & 0.486642 & 1.390770 & 2.915486 \\ 6 & -0.618543 & 0.844319 & 2.329396 \\ 16 & -1.639892 & -3.585907 & -0.463836 \\ 6 & -0.185242 & -4.469304 & -0.819848 \\ 6 & 0.947823 & -3.880771 & -0.334888\end{array}$




\begin{tabular}{|c|c|c|c|}
\hline 8 & -2.582912 & -0.966173 & 1.006466 \\
\hline 8 & 2.870936 & -2.282500 & 1.092729 \\
\hline 1 & 0.540512 & 2.308993 & 3.488927 \\
\hline 1 & -1.613701 & 1.272496 & 2.393525 \\
\hline 1 & -0.256367 & -5.404117 & -1.364551 \\
\hline 1 & 1.945405 & -4.289851 & -0.453039 \\
\hline 6 & -3.195977 & -1.544842 & 2.18355 \\
\hline 6 & 3.938503 & -1.313487 & 0.96669 \\
\hline 6 & -4.674586 & -1.238248 & 2.11337 \\
\hline 1 & -2.733544 & -1.109139 & 3.07790 \\
\hline 1 & -3.009644 & -2.625700 & 2.18862 \\
\hline 1 & 4.229556 & -0.965952 & 1.96492 \\
\hline 1 & 3.591321 & -0.464653 & 0.37433 \\
\hline 6 & 5.090378 & -2.031324 & 0.29685 \\
\hline 6 & -1.083691 & 0.657468 & -1.623522 \\
\hline 6 & -1.577688 & 1.833307 & -1.04405 \\
\hline 6 & -0.669980 & 2.651723 & -0.34714 \\
\hline 6 & 0.723536 & 2.370049 & -0.380 \\
\hline 6 & 1.219722 & 1.211077 & -0.967181 \\
\hline 6 & 0.317707 & 0.364243 & -1.62538 \\
\hline 16 & 1.642718 & 3.584061 & 0.46235 \\
\hline 6 & 0.189237 & 4.469309 & 0.81853 \\
\hline 6 & -0.944672 & 3.881998 & 0.33406 \\
\hline 16 & -1.947309 & -0.502979 & -2.60632 \\
\hline 6 & -0.490882 & -1.390242 & -2.91604 \\
\hline 6 & 0.615241 & -0.845126 & -2.33047 \\
\hline 8 & -2.870321 & 2.285080 & -1.09247 \\
\hline 8 & 2.582136 & 0.962667 & -1.00800 \\
\hline 1 & 0.261666 & 5.404191 & 1.36294 \\
\hline 1 & -1.941732 & 4.292303 & $0.45237 \varepsilon$ \\
\hline 1 & -0.546053 & -2.308231 & -3.489733 \\
\hline 1 & 1.609907 & -1.274330 & -2.39527 \\
\hline 6 & -3.938230 & 1.316993 & -0.96189 \\
\hline 6 & 3.195606 & 1.541757 & -2.18469 \\
\hline 6 & -5.088032 & 2.036697 & -0.290482 \\
\hline 1 & -3.590052 & 0.468964 & -0.36894 \\
\hline 1 & -4.231993 & 0.967753 & -1.95873 \\
\hline 1 & 3.011190 & 2.622946 & -2.188363 \\
\hline 1 & 2.731906 & 1.107932 & -3.07929 \\
\hline 6 & 4.673705 & 1.232453 & -2.11571 \\
\hline 1 & -4.839678 & -0.158168 & 2.10269 \\
\hline 1 & -5.190137 & -1.661218 & 2.98071 \\
\hline 1 & -5.106086 & -1.668757 & 1.20661 \\
\hline 1 & 5.377747 & -2.912175 & 0.87606 \\
\hline
\end{tabular}




$\begin{array}{rrrr}1 & 5.956707 & -1.366918 & 0.219825 \\ 1 & 4.802712 & -2.352991 & -0.707175 \\ 1 & -5.376167 & 2.916801 & -0.870445 \\ 1 & -4.797820 & 2.359824 & 0.712355 \\ 1 & -5.954641 & 1.373017 & -0.210365 \\ 1 & 4.836819 & 0.152068 & -2.105976 \\ 1 & 5.106609 & 1.661465 & -1.208906 \\ 1 & 5.189455 & 1.655183 & -2.983053\end{array}$

\section{Methoxy BDT}

$\begin{array}{rrrr}6 & -3.022578 & 0.122585 & -0.072511 \\ 6 & -2.153492 & -1.012606 & -0.092343 \\ 6 & -0.765598 & -0.804457 & -0.077660 \\ 6 & -0.288049 & 0.496139 & -0.221301 \\ 6 & -1.161933 & 1.626308 & -0.201791 \\ 6 & -2.551791 & 1.431582 & -0.172674 \\ 6 & -0.417395 & 2.851910 & -0.296636 \\ 6 & 0.934119 & 2.643395 & -0.329374 \\ 16 & 1.387027 & 0.964877 & -0.285308 \\ 16 & -4.695471 & -0.382210 & -0.033156 \\ 6 & -4.230841 & -2.053983 & 0.002717 \\ 6 & -2.876507 & -2.249688 & -0.021034 \\ 8 & 0.119606 & -1.866877 & -0.063572 \\ 1 & -3.231703 & 2.282412 & -0.160045 \\ 1 & -0.870897 & 3.839272 & -0.325842 \\ 1 & 1.710330 & 3.397498 & -0.406327 \\ 1 & -5.001361 & -2.816857 & 0.039805 \\ 1 & -2.410081 & -3.230089 & -0.035149 \\ 6 & 0.389086 & -2.325570 & 1.277561 \\ 1 & 0.830097 & -1.520104 & 1.875152 \\ 1 & 1.100027 & -3.146169 & 1.174364 \\ 1 & -0.529858 & -2.680652 & 1.756111\end{array}$

\section{TATB-thiophene model}

$\begin{array}{rrrr}6 & -4.536155 & 0.184447 & 0.044247 \\ 6 & -3.964716 & -1.008796 & 0.497658 \\ 6 & -2.586689 & -1.199484 & 0.424575 \\ 6 & -1.761658 & -0.177268 & -0.065606 \\ 6 & -2.336062 & 1.013196 & -0.537586 \\ 6 & -3.719398 & 1.188948 & -0.478971 \\ 7 & -0.372571 & -0.424612 & -0.119575\end{array}$




$\begin{array}{rrrr}6 & 0.420498 & 0.531504 & 0.240253 \\ 6 & 1.854874 & 0.380283 & 0.167536 \\ 16 & 2.579172 & -1.074643 & -0.419439 \\ 6 & 4.156142 & -0.441431 & -0.174108 \\ 6 & 4.134287 & 0.839539 & 0.338516 \\ 6 & 2.817163 & 1.310580 & 0.534474 \\ 1 & -5.613312 & 0.324669 & 0.087343 \\ 1 & -4.597596 & -1.799521 & 0.893641 \\ 1 & -2.124246 & -2.124549 & 0.759419 \\ 1 & -1.701776 & 1.777652 & -0.981288 \\ 1 & -4.160808 & 2.108989 & -0.855298 \\ 1 & 0.050531 & 1.493187 & 0.626593 \\ 1 & 5.023740 & -1.042343 & -0.418509 \\ 1 & 5.030796 & 1.408631 & 0.561311 \\ 1 & 2.564196 & 2.290754 & 0.928909\end{array}$

TATB-phenyl model

$\begin{array}{rrrr}6 & 4.579760 & 0.248712 & -0.059657 \\ 6 & 4.052854 & -0.955420 & -0.537624 \\ 6 & 2.686471 & -1.210234 & -0.443365 \\ 6 & 1.827112 & -0.240254 & 0.091341 \\ 6 & 2.356924 & 0.961157 & 0.586047 \\ 6 & 3.729914 & 1.200251 & 0.507652 \\ 7 & 0.450479 & -0.550090 & 0.168182 \\ 6 & -0.385605 & 0.370385 & -0.177702 \\ 6 & -1.834556 & 0.172023 & -0.088918 \\ 1 & 5.648559 & 0.438322 & -0.118920 \\ 1 & 4.712134 & -1.705134 & -0.968781 \\ 1 & 2.259719 & -2.145711 & -0.796328 \\ 1 & 1.696866 & 1.684156 & 1.060418 \\ 1 & 4.137341 & 2.128499 & 0.901744 \\ 1 & -0.044895 & 1.343889 & -0.564302 \\ 6 & -2.374375 & -1.032752 & 0.390782 \\ 6 & -3.754598 & -1.194741 & 0.461656 \\ 6 & -4.610363 & -0.162777 & 0.058197 \\ 6 & -4.077839 & 1.036344 & -0.419010 \\ 6 & -2.694773 & 1.203110 & -0.493002 \\ 1 & -1.694440 & -1.822023 & 0.700420 \\ 1 & -4.170113 & -2.128461 & 0.833381 \\ 1 & -5.688192 & -0.294896 & 0.116515 \\ 1 & -4.739155 & 1.840110 & -0.733547 \\ 1 & -2.276725 & 2.137066 & -0.866259\end{array}$




\section{Dioxane, chair}

$\begin{array}{rrrr}8 & -1.372467 & -0.005991 & 0.337622 \\ 6 & -0.732738 & -1.167916 & -0.191167 \\ 6 & 0.739030 & -1.166437 & 0.175322 \\ 8 & 1.372467 & 0.005991 & -0.337622 \\ 6 & 0.732738 & 1.167916 & 0.191167 \\ 6 & -0.739030 & 1.166437 & -0.175322 \\ 1 & -1.252095 & -2.029648 & 0.238209 \\ 1 & -0.838941 & -1.192917 & -1.286372 \\ 1 & 1.263009 & -2.019448 & -0.265694 \\ 1 & 0.845407 & -1.205730 & 1.270090 \\ 1 & 1.252095 & 2.029648 & -0.238209 \\ 1 & 0.838941 & 1.192917 & 1.286372 \\ 1 & -0.845407 & 1.205730 & -1.270090 \\ 1 & -1.263009 & 2.019448 & 0.265694\end{array}$

\section{Dioxane, boat}

$\begin{array}{rrrr}8 & -1.318386 & 0.024497 & -0.398890 \\ 6 & -0.730543 & 1.067027 & 0.365271 \\ 6 & 0.730543 & 1.236007 & -0.061196 \\ 8 & 1.318386 & -0.024497 & -0.398890 \\ 6 & 0.730543 & -1.067027 & 0.365271 \\ 6 & -0.730543 & -1.236007 & -0.061196 \\ 1 & -1.303602 & 1.974231 & 0.157402 \\ 1 & -0.815986 & 0.857421 & 1.442017 \\ 1 & 1.309290 & 1.729610 & 0.735771 \\ 1 & 0.796606 & 1.841318 & -0.968516 \\ 1 & 0.815986 & -0.857421 & 1.442017 \\ 1 & 1.303602 & -1.974231 & 0.157402 \\ 1 & -1.309290 & -1.729610 & 0.735771 \\ 1 & -0.796606 & -1.841318 & -0.968516\end{array}$

\section{Ethanol}

$\begin{array}{rrrr}6 & 1.169468 & -0.399710 & 0.000000 \\ 6 & 0.000000 & 0.560942 & 0.000000 \\ 8 & -1.190654 & -0.229496 & 0.000000 \\ 1 & -1.947809 & 0.378873 & 0.000000 \\ 1 & 0.040469 & 1.209156 & 0.887079 \\ 1 & 0.040469 & 1.209156 & -0.887079 \\ 1 & 2.117836 & 0.145075 & 0.000000 \\ 1 & 1.128730 & -1.036841 & 0.886053 \\ 1 & 1.128730 & -1.036841 & -0.886053\end{array}$




\section{1a:chair dioxane}

\begin{tabular}{|c|c|c|c|}
\hline 6 & 2.021447 & 0.634734 & -0.401479 \\
\hline 6 & 1.671895 & 0.202021 & 0.915630 \\
\hline 6 & 0.429146 & 0.552504 & 1.458678 \\
\hline 6 & -0.426784 & 1.320518 & 0.676396 \\
\hline 6 & -0.083933 & 1.746399 & -0.643531 \\
\hline 6 & 1.163217 & 1.401254 & -1.184561 \\
\hline 6 & -1.142774 & 2.508628 & -1.242824 \\
\hline 6 & -2.222543 & 2.643370 & -0.418695 \\
\hline 16 & -2.022444 & 1.866265 & 1.120744 \\
\hline 16 & 3.608255 & 0.058174 & -0.852101 \\
\hline 6 & 3.791709 & -0.738201 & 0.680621 \\
\hline 6 & 2.716796 & -0.586410 & 1.506673 \\
\hline 1 & 0.137533 & 0.211572 & 2.449615 \\
\hline 1 & 1.438890 & 1.717888 & -2.189227 \\
\hline 1 & -1.096295 & 2.930571 & -2.242554 \\
\hline 1 & -3.143555 & 3.175391 & -0.628003 \\
\hline 1 & 4.706728 & -1.281085 & 0.887465 \\
\hline 1 & 2.664787 & -1.009801 & 2.505659 \\
\hline 8 & -1.661948 & -2.191379 & -1.670476 \\
\hline 6 & -0.419687 & -2.135422 & -0.964381 \\
\hline 6 & -0.614150 & -2.592533 & 0.468199 \\
\hline 8 & -1.578492 & -1.768539 & 1.129010 \\
\hline 6 & -2.815572 & -1.800231 & 0.412981 \\
\hline 6 & -2.610327 & -1.344557 & -1.019204 \\
\hline 1 & 0.271571 & -2.793880 & -1.499827 \\
\hline 1 & -0.023432 & -1.111410 & -0.974695 \\
\hline 1 & 0.314173 & -2.502541 & 1.039678 \\
\hline 1 & -0.948548 & -3.641737 & 0.479429 \\
\hline 1 & -3.497853 & -1.135326 & 0.949955 \\
\hline 1 & -3.225161 & -2.822470 & 0.416394 \\
\hline 1 & -2.260213 & -0.302060 & -1.033098 \\
\hline 1 & -3.538717 & -1.419211 & -1.59436 \\
\hline
\end{tabular}

1a:boat dioxane

$\begin{array}{rrrr}6 & 1.951097 & -0.337222 & 0.574817 \\ 6 & 1.876517 & -0.556070 & -0.836223 \\ 6 & 0.775315 & -1.233528 & -1.378456 \\ 6 & -0.223129 & -1.658163 & -0.505820 \\ 6 & -0.151646 & -1.433036 & 0.904339 \\ 6 & 0.953777 & -0.762942 & 1.447556 \\ 6 & -1.296157 & -1.973482 & 1.582697 \\ 6 & -2.176290 & -2.574230 & 0.729875 \\ 16 & -1.675890 & -2.529602 & -0.931506\end{array}$




$\begin{array}{rrrr}16 & 3.404479 & 0.529829 & 1.000919 \\ 6 & 3.897875 & 0.587471 & -0.662545 \\ 6 & 3.018096 & -0.012687 & -1.515124 \\ 1 & 0.708330 & -1.414599 & -2.450219 \\ 1 & 1.022561 & -0.585023 & 2.519612 \\ 1 & -1.447062 & -1.917736 & 2.656963 \\ 1 & -3.109935 & -3.061297 & 0.987027 \\ 1 & 4.833215 & 1.071183 & -0.919301 \\ 1 & 3.169351 & -0.069313 & -2.589054 \\ 8 & -1.029935 & 2.746753 & 0.856094 \\ 6 & -0.459822 & 2.215358 & -0.334747 \\ 6 & -1.495550 & 2.291640 & -1.458744 \\ 8 & -2.816324 & 2.061398 & -0.956970 \\ 6 & -2.770456 & 1.181179 & 0.158816 \\ 6 & -2.077419 & 1.891752 & 1.324387 \\ 1 & 0.416653 & 2.826963 & -0.567487 \\ 1 & -0.117642 & 1.187001 & -0.174569 \\ 1 & -1.250675 & 1.563642 & -2.249612 \\ 1 & -1.520044 & 3.292847 & -1.897209 \\ 1 & -2.257676 & 0.246387 & -0.102345 \\ 1 & -3.805775 & 0.936040 & 0.411755 \\ 1 & -1.682867 & 1.151266 & 2.038729 \\ 1 & -2.779053 & 2.547567 & 1.847151\end{array}$

\section{1a: dioxane (H-bond) C1}

\begin{tabular}{rrrr}
6 & -2.334522 & -1.005241 & 0.094105 \\
6 & -1.001321 & -1.042513 & -0.416817 \\
6 & -0.308995 & 0.153078 & -0.654092 \\
6 & -0.955091 & 1.346364 & -0.347563 \\
6 & -2.287147 & 1.387207 & 0.166953 \\
6 & -2.981371 & 0.190382 & 0.393754 \\
6 & -2.721860 & 2.735988 & 0.397404 \\
6 & -1.771877 & 3.658556 & 0.070654 \\
16 & -0.301422 & 2.956609 & -0.532582 \\
16 & -2.974323 & -2.619466 & 0.290590 \\
6 & -1.492608 & -3.314123 & -0.296359 \\
6 & -0.548463 & -2.388571 & -0.632045 \\
1 & 0.708046 & 0.120664 & -1.036522 \\
1 & -3.997595 & 0.205417 & 0.784454 \\
1 & -3.700307 & 2.999443 & 0.788361 \\
1 & -1.849174 & 4.736606 & 0.150826 \\
1 & -1.407221 & -4.392686 & -0.362055 \\
1 & 0.440856 & -2.631766 & -1.007958 \\
& & \multicolumn{2}{c}{$\mathrm{S} 98$}
\end{tabular}




$\begin{array}{rrrr}8 & 2.586809 & -1.285415 & -0.494137 \\ 6 & 2.477127 & -1.199777 & 0.933342 \\ 6 & 2.794222 & 0.207473 & 1.399711 \\ 8 & 4.111212 & 0.579249 & 0.987581 \\ 6 & 4.207619 & 0.505760 & -0.433359 \\ 6 & 3.903744 & -0.903039 & -0.905532 \\ 1 & 1.450480 & -1.483969 & 1.177891 \\ 1 & 3.174771 & -1.911184 & 1.399851 \\ 1 & 2.781646 & 0.274626 & 2.491470 \\ 1 & 2.054404 & 0.912006 & 0.990663 \\ 1 & 5.229104 & 0.800408 & -0.691743 \\ 1 & 3.502783 & 1.212333 & -0.899339 \\ 1 & 4.643627 & -1.600501 & -0.485651 \\ 1 & 3.919562 & -0.975625 & -1.996881\end{array}$

\section{1a: dioxane (H-bond) Cs}

$\begin{array}{rrrr}6 & 2.092844 & 2.342729 & -0.000000 \\ 6 & 0.675927 & 2.162528 & -0.000000 \\ 6 & 0.132279 & 0.870776 & -0.000000 \\ 6 & 1.019390 & -0.202089 & -0.000000 \\ 6 & 2.437333 & -0.025146 & -0.000000 \\ 6 & 2.977038 & 1.268456 & -0.000000 \\ 6 & 3.129222 & -1.283004 & -0.000000 \\ 6 & 2.278016 & -2.348231 & -0.000000 \\ 16 & 0.599214 & -1.901433 & -0.000000 \\ 16 & 2.512633 & 4.039407 & -0.000000 \\ 6 & 0.834021 & 4.488492 & -0.000000 \\ 6 & -0.014945 & 3.421484 & -0.000000 \\ 1 & -0.942585 & 0.704843 & 0.000000 \\ 1 & 4.055485 & 1.418580 & -0.000000 \\ 1 & 4.211101 & -1.379445 & -0.000000 \\ 1 & 2.545962 & -3.398658 & -0.000000 \\ 1 & 0.568463 & 5.539244 & -0.000000 \\ 1 & -1.096756 & 3.517334 & 0.000000 \\ 8 & -2.525186 & -0.929240 & 0.000000 \\ 6 & -3.175018 & -1.427257 & 1.174873 \\ 6 & -3.175018 & -2.943244 & 1.166985 \\ 8 & -3.840301 & -3.428038 & 0.000000 \\ 6 & -3.175018 & -2.943244 & -1.166985 \\ 6 & -3.175018 & -1.427257 & -1.174873 \\ 1 & -2.615456 & -1.028525 & 2.025725 \\ 1 & -4.210053 & -1.056073 & 1.213104 \\ 1 & -3.722404 & -3.344546 & 2.024988 \\ & & & S 99 \\ 6 & & & \end{array}$




$\begin{array}{llll}1 & -2.138908 & -3.311466 & 1.194853 \\ 1 & -3.722404 & -3.344546 & -2.024988 \\ 1 & -2.138908 & -3.311466 & -1.194853 \\ 1 & -4.210053 & -1.056073 & -1.213104 \\ 1 & -2.615456 & -1.028525 & -2.025725\end{array}$

\section{1a:(dioxane)2 (H-bond)}

$\begin{array}{rrrr}6 & 0.440515 & -1.308257 & 0.000000 \\ 6 & -0.958618 & -1.025234 & 0.000000 \\ 6 & -1.403273 & 0.304197 & -0.000000 \\ 6 & -0.440515 & 1.308257 & 0.000000 \\ 6 & 0.958618 & 1.025234 & 0.000000 \\ 6 & 1.403273 & -0.304197 & 0.000000 \\ 6 & 1.747994 & 2.225188 & -0.000000 \\ 6 & 0.981183 & 3.352936 & -0.000000 \\ 16 & -0.729533 & 3.032931 & -0.000000 \\ 16 & 0.729533 & -3.032931 & -0.000000 \\ 6 & -0.981183 & -3.352936 & -0.000000 \\ 6 & -1.747994 & -2.225188 & -0.000000 \\ 1 & -2.470264 & 0.510320 & -0.000000 \\ 1 & 2.470264 & -0.510320 & 0.000000 \\ 1 & 2.833992 & 2.221353 & -0.000000 \\ 1 & 1.324038 & 4.381188 & -0.000000 \\ 1 & -1.324038 & -4.381188 & -0.000000 \\ 1 & -2.833992 & -2.221353 & -0.000000 \\ 8 & -4.641200 & -0.385136 & -0.000000 \\ 6 & -5.291326 & 0.114204 & -1.174613 \\ 6 & -5.291326 & 1.630677 & -1.166814 \\ 8 & -5.955344 & 2.115599 & -0.000000 \\ 6 & -5.291326 & 1.630677 & 1.166814 \\ 6 & -5.291326 & 0.114204 & 1.174613 \\ 1 & -4.733334 & -0.285337 & -2.026135 \\ 1 & -6.326562 & -0.255836 & -1.212554 \\ 1 & -5.838423 & 2.032345 & -2.024729 \\ 1 & -4.255934 & 2.004658 & -1.197121 \\ 1 & -5.838423 & 2.032345 & 2.024729 \\ 1 & -4.255934 & 2.004658 & 1.197121 \\ 1 & -6.326562 & -0.255836 & 1.212554 \\ 1 & -4.733334 & -0.285337 & 2.026135 \\ 8 & 4.641200 & 0.385136 & 0.000000 \\ 6 & 5.291326 & -0.114204 & -1.174613 \\ 6 & 5.291326 & -1.630677 & -1.166814 \\ 8 & 5.955344 & -2.115599 & 0.000000 \\ & & & \mathrm{~S} 100 \\ 6 & & & \end{array}$




$\begin{array}{rrrr}6 & 5.291326 & -1.630677 & 1.166814 \\ 6 & 5.291326 & -0.114204 & 1.174613 \\ 1 & 4.733334 & 0.285337 & -2.026135 \\ 1 & 6.326562 & 0.255836 & -1.212554 \\ 1 & 5.838423 & -2.032345 & -2.024729 \\ 1 & 4.255934 & -2.004658 & -1.197121 \\ 1 & 5.838423 & -2.032345 & 2.024729 \\ 1 & 4.255934 & -2.004658 & 1.197121 \\ 1 & 6.326562 & 0.255836 & 1.212554 \\ 1 & 4.733334 & 0.285337 & 2.026135\end{array}$

\section{1a:(ethanol)2}

$\begin{array}{rrrr}6 & -0.001478 & 1.380047 & -0.000000 \\ 6 & -1.234881 & 0.660408 & -0.000000 \\ 6 & -1.234881 & -0.741380 & -0.000000 \\ 6 & 0.001478 & -1.380047 & -0.000000 \\ 6 & 1.234881 & -0.660408 & -0.000000 \\ 6 & 1.234881 & 0.741380 & -0.000000 \\ 6 & 2.365540 & -1.544980 & 0.000000 \\ 6 & 2.005354 & -2.860035 & 0.000000 \\ 16 & 0.284590 & -3.107014 & 0.000000 \\ 16 & -0.284590 & 3.107014 & 0.000000 \\ 6 & -2.005354 & 2.860035 & 0.000000 \\ 6 & -2.365540 & 1.544980 & 0.000000 \\ 1 & -2.177560 & -1.284606 & -0.000000 \\ 1 & 2.177560 & 1.284606 & -0.000000 \\ 1 & 3.394954 & -1.199494 & 0.000000 \\ 1 & 2.662640 & -3.721877 & 0.000000 \\ 1 & -2.662640 & 3.721877 & 0.000000 \\ 1 & -3.394954 & 1.199494 & 0.000000 \\ 6 & -3.510600 & -4.011589 & -0.000000 \\ 6 & -4.807355 & -3.231820 & -0.000000 \\ 8 & -4.465540 & -1.840240 & -0.000000 \\ 1 & -3.708354 & -5.087417 & -0.000000 \\ 1 & -2.922384 & -3.765686 & 0.887137 \\ 1 & -2.922384 & -3.765686 & -0.887137 \\ 1 & -5.404196 & -3.482788 & 0.887717 \\ 1 & -5.404196 & -3.482788 & -0.887717 \\ 1 & -5.293270 & -1.331047 & -0.000000 \\ 6 & 3.510600 & 4.011589 & -0.000000 \\ 6 & 4.807355 & 3.231820 & -0.000000 \\ 8 & 4.465540 & 1.840240 & -0.000000 \\ 1 & 3.708354 & 5.087417 & 0.000000 \\ & & & S 101 \\ & & & \end{array}$




$\begin{array}{rrrr}1 & 2.922384 & 3.765686 & 0.887137 \\ 1 & 2.922384 & 3.765686 & -0.887137 \\ 1 & 5.404196 & 3.482788 & 0.887717 \\ 1 & 5.404196 & 3.482788 & -0.887717 \\ 1 & 5.293270 & 1.331047 & -0.000000\end{array}$

\section{1b:chair dioxane}

$\begin{array}{rrrr}6 & -1.652869 & -0.351201 & 0.359335 \\ 6 & -1.611283 & 0.764238 & -0.527606 \\ 6 & -0.503738 & 1.625250 & -0.493936 \\ 6 & 0.473245 & 1.411956 & 0.475946 \\ 6 & 0.436867 & 0.287357 & 1.350584 \\ 6 & -0.678334 & -0.561464 & 1.331875 \\ 6 & 1.586645 & 0.242951 & 2.203005 \\ 6 & 2.460835 & 1.258722 & 1.938844 \\ 16 & 1.938115 & 2.325818 & 0.675424 \\ 16 & -3.064864 & -1.333983 & 0.085863 \\ 6 & -3.565065 & -0.291241 & -1.212565 \\ 6 & -2.716129 & 0.753318 & -1.441794 \\ 8 & -0.397017 & 2.674135 & -1.388338 \\ 8 & -0.732480 & -1.677429 & 2.147451 \\ 1 & 1.759206 & -0.527681 & 2.947474 \\ 1 & 3.407785 & 1.450488 & 2.430814 \\ 1 & -4.468106 & -0.532457 & -1.761683 \\ 1 & -2.857634 & 1.488001 & -2.227673 \\ 6 & -1.002654 & 3.875842 & -0.878295 \\ 6 & -1.373349 & -1.387700 & 3.403326 \\ 1 & -2.072106 & 3.721738 & -0.700170 \\ 1 & -0.858147 & 4.635471 & -1.647140 \\ 1 & -0.516456 & 4.189671 & 0.050911 \\ 1 & -2.403458 & -1.052903 & 3.243614 \\ 1 & -0.817802 & -0.620273 & 3.952328 \\ 1 & -1.370965 & -2.322817 & 3.964291 \\ 8 & 1.156622 & -2.796860 & -1.966089 \\ 6 & 0.734493 & -1.468780 & -2.286148 \\ 6 & 1.903351 & -0.508335 & -2.179095 \\ 8 & 2.454016 & -0.541396 & -0.860502 \\ 6 & 2.849934 & -1.870957 & -0.521757 \\ 6 & 1.672016 & -2.819659 & -0.633638 \\ 1 & 0.342987 & -1.505396 & -3.307630 \\ 1 & -0.065664 & -1.152100 & -1.603847 \\ 1 & 1.588342 & 0.525416 & -2.352327 \\ 1 & 2.675530 & -0.783022 & -2.914961 \\ & & & \mathrm{~S} 102 \\ 6 & & & \end{array}$




$\begin{array}{rrrr}1 & 3.230777 & -1.821917 & 0.502701 \\ 1 & 3.655599 & -2.207253 & -1.193409 \\ 1 & 0.890409 & -2.530703 & 0.084369 \\ 1 & 1.974776 & -3.853014 & -0.436898\end{array}$

\section{1b:boat dioxane}

$\begin{array}{rrrr}6 & 0.965909 & 1.255747 & 0.395461 \\ 6 & 1.680094 & 0.581873 & -0.638592 \\ 6 & 1.579198 & -0.813922 & -0.748802 \\ 6 & 0.821687 & -1.497910 & 0.199769 \\ 6 & 0.105738 & -0.821166 & 1.231190 \\ 6 & 0.241733 & 0.568090 & 1.365993 \\ 6 & -0.626624 & -1.738676 & 2.055570 \\ 6 & -0.505862 & -3.029017 & 1.624409 \\ 16 & 0.510303 & -3.212850 & 0.225709 \\ 16 & 1.157580 & 2.979807 & 0.289304 \\ 6 & 2.153037 & 2.803120 & -1.122907 \\ 6 & 2.337739 & 1.506926 & -1.513786 \\ 8 & 2.221956 & -1.497637 & -1.762116 \\ 8 & -0.429993 & 1.249660 & 2.361601 \\ 1 & -1.235787 & -1.437467 & 2.901804 \\ 1 & -0.965334 & -3.909389 & 2.059459 \\ 1 & 2.533648 & 3.692524 & -1.612348 \\ 1 & 2.905520 & 1.212139 & -2.390165 \\ 6 & 3.569149 & -1.847940 & -1.396089 \\ 6 & 0.370009 & 1.373234 & 3.552407 \\ 1 & 4.162123 & -0.948561 & -1.200333 \\ 1 & 3.981016 & -2.388166 & -2.248925 \\ 1 & 3.573453 & -2.491379 & -0.510312 \\ 1 & 1.291416 & 1.925873 & 3.342606 \\ 1 & 0.616287 & 0.385995 & 3.957317 \\ 1 & -0.240186 & 1.927858 & 4.265753 \\ 8 & -2.209162 & 1.555003 & -0.600052 \\ 6 & -1.628440 & 0.756351 & -1.624760 \\ 6 & -2.725276 & 0.151121 & -2.492194 \\ 8 & -3.811640 & -0.352463 & -1.700264 \\ 6 & -3.417804 & -0.561683 & -0.349214 \\ 6 & -3.035302 & 0.771837 & 0.279367 \\ 1 & -0.994309 & 1.424048 & -2.215631 \\ 1 & -0.983097 & -0.021083 & -1.200353 \\ 1 & -2.310819 & -0.653657 & -3.119054 \\ 1 & -3.156680 & 0.916188 & -3.144814 \\ 1 & -2.597995 & -1.291066 & -0.278032 \\ & & & \mathrm{~S} 103 \\ 6 & & & \end{array}$




$\begin{array}{rrrr}1 & -4.285367 & -0.987666 & 0.163120 \\ 1 & -2.520836 & 0.622034 & 1.237152 \\ 1 & -3.938371 & 1.366048 & 0.452270\end{array}$

\section{(BDT)2:(EtOH)4}

$\begin{array}{rrrr}6 & 1.090662 & -0.153782 & 2.141393 \\ 6 & -0.090481 & 0.142670 & 2.889736 \\ 6 & -0.612502 & 1.443423 & 2.879624 \\ 6 & 0.035360 & 2.397020 & 2.101286 \\ 6 & 1.207115 & 2.095003 & 1.341037 \\ 6 & 1.727999 & 0.792986 & 1.344885 \\ 6 & 1.696285 & 3.250491 & 0.645448 \\ 6 & 0.941429 & 4.363519 & 0.877276 \\ 16 & -0.402684 & 4.079500 & 1.939868 \\ 16 & 1.559692 & -1.821742 & 2.349630 \\ 6 & 0.224039 & -2.104565 & 3.418177 \\ 6 & -0.559231 & -1.003406 & 3.612632 \\ 1 & -1.509218 & 1.684978 & 3.448593 \\ 1 & 2.616050 & 0.546027 & 0.765845 \\ 1 & 2.568641 & 3.241698 & -0.001765 \\ 1 & 1.100050 & 5.359237 & 0.478813 \\ 1 & 0.086671 & -3.091777 & 3.843278 \\ 1 & -1.441843 & -1.002211 & 4.246062 \\ 6 & -6.090652 & 1.901046 & -0.618476 \\ 6 & -5.864824 & 0.576749 & 0.093937 \\ 8 & -4.476653 & 0.268210 & 0.213161 \\ 1 & -7.157484 & 2.140410 & -0.680699 \\ 1 & -5.687660 & 1.851851 & -1.633931 \\ 1 & -5.582406 & 2.706007 & -0.080976 \\ 1 & -6.397023 & -0.230172 & -0.430688 \\ 1 & -6.253821 & 0.615383 & 1.115502 \\ 1 & -4.132416 & 0.190694 & -0.705310 \\ 6 & 4.208220 & -2.439416 & -0.365206 \\ 6 & 4.965420 & -1.470363 & 0.514790 \\ 8 & 4.741042 & -0.147421 & -0.016724 \\ 1 & 4.393086 & -3.466569 & -0.037708 \\ 1 & 4.528433 & -2.335245 & -1.404612 \\ 1 & 3.134834 & -2.246257 & -0.308055 \\ 1 & 6.040349 & -1.690850 & 0.509358 \\ 1 & 4.604093 & -1.523989 & 1.548624 \\ 1 & 5.139538 & 0.502263 & 0.587986 \\ 6 & -0.965067 & -2.111305 & 0.044404 \\ 6 & 0.168268 & -2.268522 & -0.814702 \\ & & & S 104 \\ 6 & & & \end{array}$




$\begin{array}{rrrr}6 & 0.676403 & -1.163989 & -1.514187 \\ 6 & 0.058650 & 0.068082 & -1.307468 \\ 6 & -1.077141 & 0.221667 & -0.452361 \\ 6 & -1.573559 & -0.878761 & 0.264728 \\ 6 & -1.579655 & 1.565978 & -0.471753 \\ 6 & -0.885378 & 2.366380 & -1.337906 \\ 16 & 0.443575 & 1.566313 & -2.117631 \\ 16 & -1.437099 & -3.639231 & 0.745497 \\ 6 & -0.157324 & -4.460418 & -0.090906 \\ 6 & 0.601392 & -3.635744 & -0.870639 \\ 1 & 1.533268 & -1.252733 & -2.178579 \\ 1 & -2.462275 & -0.770861 & 0.883155 \\ 1 & -2.447913 & 1.884834 & 0.096789 \\ 1 & -1.054183 & 3.420942 & -1.525608 \\ 1 & -0.045783 & -5.531829 & 0.032088 \\ 1 & 1.435392 & -3.982593 & -1.474287 \\ 6 & 4.368906 & 2.299430 & -2.766066 \\ 6 & 4.273621 & 0.882851 & -3.310672 \\ 8 & 3.379903 & 0.075852 & -2.544464 \\ 1 & 5.021052 & 2.920728 & -3.388807 \\ 1 & 4.780480 & 2.286877 & -1.751553 \\ 1 & 3.374698 & 2.750814 & -2.730340 \\ 1 & 5.271679 & 0.422811 & -3.352037 \\ 1 & 3.870976 & 0.889168 & -4.326809 \\ 1 & 3.747527 & 0.038228 & -1.638482 \\ 6 & -4.033970 & -2.149363 & -2.402911 \\ 6 & -3.054364 & -1.106387 & -2.895174 \\ 8 & -3.547273 & 0.181800 & -2.471988 \\ 1 & -3.720955 & -3.148528 & -2.719775 \\ 1 & -5.031715 & -1.951601 & -2.804276 \\ 1 & -4.082435 & -2.128048 & -1.311574 \\ 1 & -2.978263 & -1.123661 & -3.990029 \\ 1 & -2.059505 & -1.286067 & -2.476177 \\ 1 & -2.791508 & 0.797439 & -2.427281 \\ 2 & & -1063\end{array}$

(BDT)2 (dioxane)4

$\begin{array}{rrrr}6 & 1.066733 & 2.156375 & 0.224527 \\ 6 & -0.312743 & 2.426045 & 0.473028 \\ 6 & -1.297983 & 1.837833 & -0.333041 \\ 6 & -0.878339 & 0.967371 & -1.333859 \\ 6 & 0.501113 & 0.705421 & -1.587477 \\ 6 & 1.485175 & 1.266330 & -0.759710 \\ 6 & 0.683470 & -0.196638 & -2.686524 \\ 6 & -0.499537 & -0.572579 & -3.256884\end{array}$




\begin{tabular}{|c|c|c|c|}
\hline 16 & -1.889664 & 0.127614 & -2.485604 \\
\hline 6 & 2.082191 & 3.024446 & 1.350487 \\
\hline 6 & 0.693244 & 3.765520 & 2.088227 \\
\hline 6 & -0.492049 & 3.369900 & 1.538331 \\
\hline 1 & -2.345052 & 2.034149 & -0.122744 \\
\hline 1 & 2.530560 & 1.036223 & -0.949829 \\
\hline 1 & 1.657221 & -0.534910 & -3.029529 \\
\hline 1 & -0.640577 & -1.246518 & -4.093789 \\
\hline 1 & 0.840718 & 4.475432 & 2.894310 \\
\hline 1 & -1.467317 & 3.731479 & 1.852186 \\
\hline 8 & -3.960261 & 3.353829 & 1.025747 \\
\hline 6 & -4.886198 & 2.618281 & 1.835723 \\
\hline 6 & -5.388811 & 1.409219 & 1.075341 \\
\hline 8 & -6.034489 & 1.816815 & -0.134564 \\
\hline 6 & -5.129105 & 2.565830 & -0.944402 \\
\hline 6 & -4.601111 & 3.769171 & -0.185082 \\
\hline 1 & -4.337415 & 2.320829 & 2.733755 \\
\hline 1 & -5.728334 & 3.266953 & 2.120031 \\
\hline 1 & -6.131086 & 0.841871 & 1.642130 \\
\hline 1 & -4.536703 & 0.752134 & 0.852452 \\
\hline 1 & -5.691325 & 2.877989 & -1.830253 \\
\hline 1 & -4.292455 & 1.926864 & -1.266217 \\
\hline 1 & -5.431129 & 4.452748 & 0.049085 \\
\hline 1 & -3.845145 & 4.306548 & -0.765272 \\
\hline 8 & 4.206021 & 0.802257 & -2.431206 \\
\hline 6 & 5.566128 & 0.855851 & -1.995681 \\
\hline 6 & 5.804593 & 2.111419 & -1.178423 \\
\hline 8 & 5.509452 & 3.267473 & -1.958352 \\
\hline 6 & 4.142049 & 3.225094 & -2.374967 \\
\hline 6 & 3.883155 & 1.974054 & -3.192632 \\
\hline 1 & 5.740248 & -0.048090 & -1.402541 \\
\hline 1 & 6.239705 & 0.849759 & -2.866002 \\
\hline 1 & 6.853753 & 2.197538 & -0.878081 \\
\hline 1 & 5.173425 & 2.092218 & -0.275089 \\
\hline 1 & 3.972408 & 4.127138 & -2.970193 \\
\hline 1 & 3.478320 & 3.245599 & -1.498377 \\
\hline 1 & 4.490555 & 1.995946 & -4.109732 \\
\hline 1 & 2.826205 & 1.880988 & -3.457910 \\
\hline 6 & -0.950203 & -1.036879 & 1.311438 \\
\hline 6 & 0.418275 & -0.761763 & 1.608289 \\
\hline 6 & 1.434627 & -1.319308 & 0.818134 \\
\hline 6 & 1.056626 & -2.214181 & -0.178040 \\
\hline 6 & -0.311644 & -2.495690 & -0.469562 \\
\hline 6 & -1.329094 & -1.914879 & 0.30107 \\
\hline
\end{tabular}




$\begin{array}{rrrr}6 & -0.449157 & -3.441420 & -1.539177 \\ 6 & 0.755849 & -3.828979 & -2.050654 \\ 16 & 2.114573 & -3.078110 & -1.267879 \\ 16 & -2.005367 & -0.195368 & 2.421988 \\ 6 & -0.646587 & 0.515470 & 3.238032 \\ 6 & 0.557263 & 0.145260 & 2.709454 \\ 1 & 2.470848 & -1.075539 & 1.038921 \\ 1 & -2.365234 & -2.129346 & 0.055114 \\ 1 & -1.410636 & -3.810003 & -1.886298 \\ 1 & 0.934457 & -4.537639 & -2.851499 \\ 1 & -0.820092 & 1.191925 & 4.066799 \\ 1 & 1.516379 & 0.493601 & 3.082439 \\ 8 & 4.177982 & -0.767685 & 2.458227 \\ 6 & 5.530632 & -0.763253 & 1.995995 \\ 6 & 5.802766 & -2.002427 & 1.164606 \\ 8 & 5.569563 & -3.174785 & 1.941856 \\ 6 & 4.211069 & -3.190664 & 2.387253 \\ 6 & 3.919253 & -1.955865 & 3.218597 \\ 1 & 5.657771 & 0.151094 & 1.407347 \\ 1 & 6.219617 & -0.737648 & 2.853783 \\ 1 & 6.848473 & -2.045706 & 0.845151 \\ 1 & 5.154200 & -2.001699 & 0.273340 \\ 1 & 4.090909 & -4.102352 & 2.979896 \\ 1 & 3.530071 & -3.233585 & 1.524816 \\ 1 & 4.546547 & -1.958526 & 4.122453 \\ 1 & 2.865372 & -1.907605 & 3.507452 \\ 8 & -4.023702 & -3.349757 & -1.038780 \\ 6 & -4.848320 & -2.510655 & -1.857724 \\ 6 & -5.292307 & -1.296277 & -1.069522 \\ 8 & -6.021764 & -1.696423 & 0.093390 \\ 6 & -5.213854 & -2.544394 & 0.909295 \\ 6 & -4.753040 & -3.757997 & 0.123389 \\ 1 & -4.234114 & -2.221753 & -2.715009 \\ 1 & -5.723577 & -3.077948 & -2.208321 \\ 1 & -5.961943 & -0.650839 & -1.643297 \\ 1 & -4.402486 & -0.717117 & -0.781944 \\ 1 & -5.836009 & -2.839849 & 1.759962 \\ 1 & -4.341666 & -1.988312 & 1.286279 \\ 1 & -5.624947 & -4.358665 & -0.176392 \\ 1 & -4.072291 & -4.380050 & 0.711976\end{array}$

\section{BDT-OMe:(dioxane) $C_{s}$}

0.223391 


$\begin{array}{rrrr}6 & 2.318124 & -0.797845 & 0.015562 \\ 6 & 0.986118 & -0.418899 & -0.201606 \\ 6 & 0.669838 & 0.938221 & -0.189211 \\ 6 & 1.668140 & 1.937300 & 0.020013 \\ 6 & 3.004893 & 1.566613 & 0.224013 \\ 6 & 1.094188 & 3.253120 & -0.008703 \\ 6 & -0.252674 & 3.233555 & -0.221965 \\ 16 & -0.915362 & 1.635028 & -0.395855 \\ 16 & 4.881024 & -0.517463 & 0.463295 \\ 6 & 4.212158 & -2.111729 & 0.293619 \\ 6 & 2.867271 & -2.121032 & 0.063931 \\ 8 & 0.013056 & -1.382046 & -0.380443 \\ 1 & 3.772030 & 2.322104 & 0.383185 \\ 1 & 1.666493 & 4.166186 & 0.127226 \\ 1 & -0.917380 & 4.087772 & -0.283177 \\ 1 & 4.867738 & -2.970387 & 0.381626 \\ 1 & 2.276533 & -3.023420 & -0.051314 \\ 6 & -0.258415 & -1.621903 & -1.776854 \\ 1 & -0.574917 & -0.699983 & -2.271520 \\ 1 & -1.075269 & -2.340264 & -1.803281 \\ 1 & 0.633461 & -2.026155 & -2.267445 \\ 8 & -3.112603 & -1.051852 & -0.668235 \\ 6 & -4.444295 & -0.625944 & -0.963531 \\ 6 & -4.922356 & 0.363328 & 0.081966 \\ 8 & -4.888916 & -0.234414 & 1.376710 \\ 6 & -3.553640 & -0.652308 & 1.675017 \\ 6 & -3.067450 & -1.643035 & 0.636625 \\ 1 & -4.411072 & -0.172289 & -1.958760 \\ 1 & -5.121701 & -1.493494 & -0.984506 \\ 1 & -5.960204 & 0.661097 & -0.096424 \\ 1 & -4.281676 & 1.258147 & 0.060171 \\ 1 & -3.588079 & -1.104832 & 2.670499 \\ 1 & -2.881376 & 0.217683 & 1.696275 \\ 1 & -3.703333 & -2.541531 & 0.659068 \\ 1 & -2.024473 & -1.920050 & 0.801470\end{array}$

\section{TATB-thiophene:(dioxane) $C_{s}$}

\begin{tabular}{cccc}
6 & -3.757828 & -2.953367 & -0.000000 \\
6 & -4.295155 & -1.662233 & -0.000000 \\
6 & -3.460385 & -0.546557 & -0.000000 \\
6 & -2.063028 & -0.712394 & -0.000000 \\
6 & -1.529156 & -2.010251 & -0.000000 \\
6 & -2.372189 & -3.121410 & -0.000000 \\
\multicolumn{3}{c}{$S 108$}
\end{tabular}




$\begin{array}{rrrr}7 & -1.103689 & 0.331475 & -0.000000 \\ 6 & -1.466330 & 1.574647 & -0.000000 \\ 6 & -0.489438 & 2.636082 & 0.000000 \\ 16 & 1.208085 & 2.310742 & 0.000000 \\ 6 & 1.572325 & 3.988541 & 0.000000 \\ 6 & 0.437814 & 4.775138 & 0.000000 \\ 6 & -0.743416 & 4.002036 & 0.000000 \\ 1 & -4.417213 & -3.817998 & -0.000000 \\ 1 & -5.373981 & -1.522892 & -0.000000 \\ 1 & -3.910483 & 0.442718 & -0.000000 \\ 1 & -0.449748 & -2.137716 & -0.000000 \\ 1 & -1.940195 & -4.119469 & -0.000000 \\ 1 & -2.513119 & 1.908882 & -0.000000 \\ 1 & 2.605292 & 4.315196 & 0.000000 \\ 1 & 0.463567 & 5.859982 & 0.000000 \\ 1 & -1.749677 & 4.412147 & 0.000000 \\ 8 & 1.735005 & -2.933041 & -0.000000 \\ 6 & 2.384658 & -2.430513 & 1.172166 \\ 6 & 2.384658 & -0.914357 & 1.165462 \\ 8 & 3.064328 & -0.435943 & 0.000000 \\ 6 & 2.384658 & -0.914357 & -1.165462 \\ 6 & 2.384658 & -2.430513 & -1.172166 \\ 1 & 1.827588 & -2.829195 & 2.025159 \\ 1 & 3.420037 & -2.801894 & 1.211165 \\ 1 & 2.927973 & -0.513936 & 2.026991 \\ 1 & 1.352540 & -0.537040 & 1.177861 \\ 1 & 2.927973 & -0.513936 & -2.026991 \\ 1 & 1.352540 & -0.537040 & -1.177861 \\ 1 & 3.420037 & -2.801894 & -1.211165 \\ 1 & 1.827588 & -2.829195 & -2.025159\end{array}$

\section{TATB-phenyl:(dioxane)}

$\begin{array}{lrrr}6 & 3.979074 & 2.661974 & -0.000000 \\ 6 & 2.619301 & 2.975610 & -0.000000 \\ 6 & 1.663663 & 1.959337 & -0.000000 \\ 6 & 2.055579 & 0.611713 & -0.000000 \\ 6 & 3.427857 & 0.300248 & -0.000000 \\ 6 & 4.376186 & 1.321193 & -0.000000 \\ 7 & 0.988448 & -0.326691 & -0.000000 \\ 6 & 1.221993 & -1.597528 & 0.000000 \\ 6 & 0.147250 & -2.592026 & 0.000000 \\ 1 & 4.726293 & 3.451899 & -0.000000 \\ 1 & 2.295285 & 4.013731 & -0.000000\end{array}$




\begin{tabular}{|c|c|c|c|}
\hline 1 & 0.604945 & 2.203907 & -0.000000 \\
\hline 1 & 3.771584 & -0.730508 & -0.000000 \\
\hline 1 & 5.434089 & 1.068095 & -0.000000 \\
\hline$\perp$ & 2.238504 & -2.016912 & 0.000000 \\
\hline 6 & -1.209911 & -2.227394 & 0.000000 \\
\hline 6 & -2.192202 & -3.213672 & 0.000000 \\
\hline 6 & -1.841736 & -4.568691 & 0.000000 \\
\hline 6 & -0.494537 & -4.936053 & 0.000000 \\
\hline 6 & 0.494237 & -3.952607 & 0.000000 \\
\hline 1 & -1.494350 & -1.181150 & 0.000 \\
\hline 1 & -3.239394 & -2.920006 & 0.00000 \\
\hline 1 & -2.615235 & -5.333241 & 0.000000 \\
\hline 1 & -0.214689 & -5.986880 & 0.000000 \\
\hline 1 & 1.545297 & -4.239067 & 0.000000 \\
\hline 8 & -1.536858 & 3.199776 & -0.000000 \\
\hline 6 & -2.194936 & 2.704753 & 1.170246 \\
\hline 6 & -2.194936 & 1.189126 & 1.170 \\
\hline 8 & -2.863464 & 0.700466 & 0.000000 \\
\hline 6 & -2.194936 & 1.189126 & -1.170896 \\
\hline 6 & -2.194936 & 2.704753 & -1.17024 \\
\hline 1 & -1.642962 & 3.105190 & 2.025633 \\
\hline 1 & -3.229631 & 3.078660 & 1.201015 \\
\hline 1 & -2.748904 & 0.793077 & 2.027621 \\
\hline 1 & -1.163979 & 0.810994 & 1.195524 \\
\hline 1 & -2.748904 & 0.793077 & -2.027621 \\
\hline 1 & -1.163979 & 0.810994 & -1.195524 \\
\hline 1 & -3.229631 & 3.078660 & -1.201015 \\
\hline 1 & -1.642962 & 3.105190 & -2.025633 \\
\hline
\end{tabular}




\section{N. REFERENCES}

(1) Bruker Saint, Bruker AXS Inc.: Madison, Wisconsin, USA, 2012.

(2) G. M. Sheldrick, SADABS, University of Göttingen: Göttingen, 1996.

(3) SHELXT - Integrated space-group and crystal-structure determination. G. M. Sheldrick, Acta Crystallogr. Section A 2015, 71, 3-8.

(4) MP2 energy evaluation by direct methods, M. Head-Gordon, J. A. Pople, M. J. Frisch, Chem. Phys. Lett. 1988, 153, 503-506.

(5) A direct MP2 gradient method, M. J. Frisch, M. Head-Gordon, J. A. Pople, Chem. Phys. Lett. 1990, 166, 275-280.

(6) Analytic MP2 frequencies without fifth-order storage. Theory and application to bifurcated hydrogen bonds in the water hexamer, M. Head-Gordon, T. Head-Gordon, Chem. Phys. Lett. 1994, 220, 122-128.

(7) Self-Consistent Molecular-Orbital Methods .12. Further Extensions of Gaussian-Type Basis Sets for Use in Molecular-Orbital Studies of Organic-Molecules, W. J. Hehre, R. Ditchfield, J. A. Pople, J. Chem. Phys. 1972, 56, 2257-2261.

(8) Influence of Polarization Functions on Molecular-Orbital Hydrogenation Energies, P. C. Hariharan, J. A. Pople, Theor. Chim. Acta 1973, 28, 213-222.

(9) Density-functional thermochemistry. III. The role of exact exchange. A. D. Becke, J. Chem. Phys., 1993, 98, 5648-5652.

(10) Efficient diffuse function-augmented basis-sets for anion calculations. 3. The 3-21+G basis set for 1strow elements, Li-F. T. Clark, J. Chandrasekhar, G. W. Spitznagel, P. v. R. Schleyer, J. Comp. Chem. 1983, 4, 294-301.

(11) M. J. Frisch, G. W. Trucks, H. B. Schlegel, G. E. Scuseria, M. A. Robb, J. R. Cheeseman, G. Scalmani, V. Barone, B. Mennucci, M. Petersson, H. Nakatsuji, M. Caricato, X. Li, H. R. Hratchian, A. F. Izmaylov, J. Bloino, G. Zheng, J. L. Sonnenberg, M. Hada, M. Ehara, K. Toyota, R. Fukuda, J. Hasegawa, M. Ishida, T. Nakajima, Y. Honda, O. Kitao, H. Nakai, T. Vreven, J. A. J. Montgomery, J. E. Peralta, F. Ogliaro, M. Bearpark, J. J. Heyd, E. Brothers, K. N. Kudin, V. N. Staroverov, T. A. Keith, R. Kobayashi, J. Normand, K. Raghavachari, A. Rendell, J. C. Burant, S. S. Iyengar, J. Tomasi, M. Cossi, N. Rega, J. M. Millam, M. Klene, J. E. Knox, J. B. Cross, V. Bakken, C. Adamo, J. Jaramillo, R. Gomperts, R. E. Stratmann, O. Yazyev, A. J. Austin, R. Cammi, C. Pomelli, J. W. Ochterski, R. L. Martin, K. Morokuma, V. Zakrzewski, G. G. A. Voth, P. Salvador, J. J. Dannenberg, S. Dapprich, A. D. Daniels, O. Farkas, J. B. Foresman, J. V. Ortiz, J. Cioslowski, D. J. Fox, Gaussian 09, Revision D.01; Gaussian, Inc.: Wallingford CT, 2010.

(12) A consistent and accurate ab initio parameterization of density functional dispersion correction (DFTD) for the 94 elements H-Pu. S. Grimme, J. Antony, S. Ehrlich, H. Krieg, J. Chem. Phys. 2010, 132, 154104.

(13) Properties of atoms in molecules: atomic volumes, R. F. W. Bader, M. T. Carroll, J. R. Cheeseman, C. Chang, J. Am. Chem. Soc., 1987, 109, 7968-7679.

(14) VMD - Visual Molecular Dynamics, W. Humphrey, A. Dalke, K. Shulten, J. Mol. Graphics, 1996, 1, 33-38.

(15) Über polyarylenalkenylene und polyheteroarylenalkenylene, 14. Synthesen und charakterisierung von poly(thieno[2',3':1,2]benzo[4,5-b]thiophen-2,6-diylvinylenarylenvinylen)en, poly(4,8dimethoxythieno[2',3':1,2] benzo[4,5-b]thiophen-2,6-diylvinylenarylenvinylen)en und einigen modellverbindungen. G. Koßmehl, P. Beimling, G. Manecke, Makromolekul. Chem. 1983, 184, 627-650. (16) Synthesis of 2- and 2,7-functionalized pyrene derivatives: an application of selective C-H borylation. A. G. Crawford, Z. Liu, I. A. Mkhalid, M. H. Thibault, N. Schwarz, G. Alcaraz, A. Steffen, J. C. Collings, A. S. Batsanov, J. A. Howard, T. B. Marder, Chem. Eur. J. 2012, 18, 5022-5035.

(17) Molecular docking sites designed for the generation of highly crystalline covalent organic frameworks, L. Ascherl, T. Sick, J. T. Margraf, S. H. Lapidus, M. Calik, C. Hettstedt, K. Karaghiosoff, M. Döblinger, T. Clark, K. W. Chapman, F. Auras and T. Bein, Nature Chemistry, 2016, 8, 310.

(18) Physisorption of gases, with special reference to the evaluation of surface area and pore size distribution (IUPAC Technical Report), M. Thommes, K. Kaneko, A. V. Neimark, J. P. Olivier, F. 
Rodriguez-Reinoso, J. Rouquerol, K. S. W. Sing, Pure Appl. Chem. 2015, 87, 929-1069. 